\title{
Developing Controlling and Performance Evaluation Of Multinational Companies \\ Operating in Egypt
}

\author{
Dissertation \\ Zur Erlangung des wirtschaftswissenschaftlichen Doktorgrades \\ der Wirtschaftswissenschaftlichen Fakultät \\ der Georg-August-Universität zu Göttingen \\ vorgelegt von \\ Hatem Elsharawy \\ aus Elmenoufia, Ägypten
}

Göttingen 2006 
Erstgutachter:

Zweitgutachter:

Tag der mündlichen Prüfung: $\quad$ 11.09.2006 


\section{Dedication To}

My Father

Soul of my Mother

My Wife

My Daughters: Heba, Esraa, and Roaa 
1 Introduction......................................................................... 1

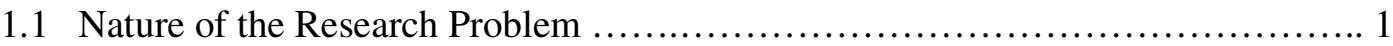

1.2 The Research Assumption................................................. 4

1.3 The Research Objectives ..................................................... 4

1.4 The Research Plan and Structure ............................................ 4

1.5 Innovation Contribution of the Research....................................... 7

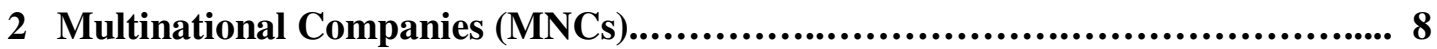

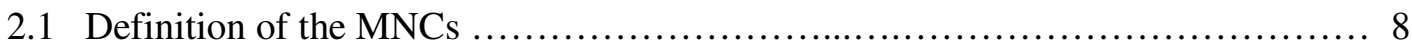

2.2 Characteristics of the MNCs ................................................ 10

2.3 Objectives of the MNCs ............................................... 12

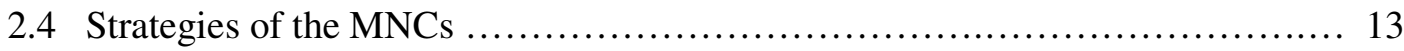

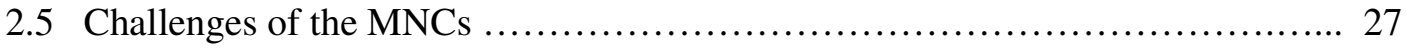

2.6 Criticisms and praise (disadvantage and advantages) of MNCs ............... 30

3 Performance Evaluation of Multinational Companies ............................ 32



3.2 Responsibility Accounting and Performance Evaluation in MNCs ............. 33

3.3 Separating Managerial and Subsidiary Performance ......................... 36

3.4 The measures used for evaluating subsidiaries $\ldots \ldots \ldots \ldots \ldots \ldots \ldots \ldots \ldots \ldots \ldots \ldots \ldots \ldots$

3.5 The past researches and studies on performance evaluation of MNCs ........... 40

3.6 The Main Problems of Performance Evaluation of MNCS ...................... 52

4 Environmental Factors Affecting the Performance of Foreign Subsidiaries...... 54

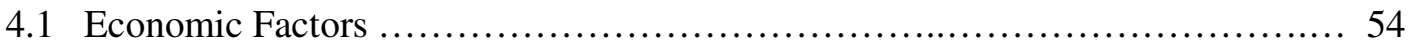

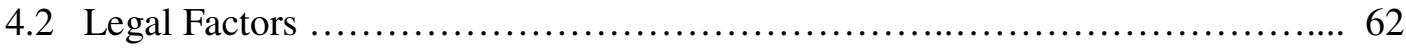

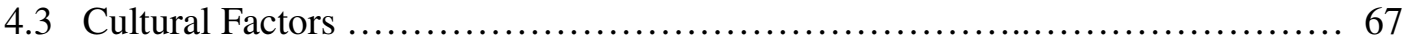

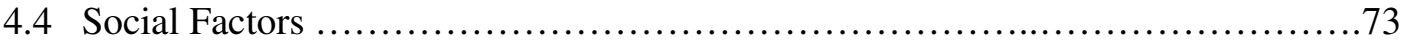

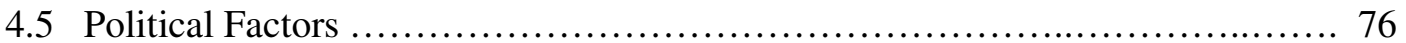

4.6 Other Factors and Variables ................................................ 77 
5. Transfer Pricing and Performance Evaluation of Multinational Companie....... 78

5.1 The nature of transfer pricing problem ..................................... 78

5.2 The Causes and Effects of Transfer Pricing ............................... 71

5.3 Transfer Pricing Practices and Economic Theory ........................... 86

5.4 Transfer Pricing Practices and Accounting Theory $\ldots \ldots \ldots \ldots \ldots \ldots \ldots \ldots \ldots \ldots \ldots$

5.5 Transfer Pricing Practices and Management Theory ........................ 90

5.6 Objectives of Domestic Transfer Pricing System .......................... 91

5.7 Objectives of International Transfer Pricing System ....................... 92

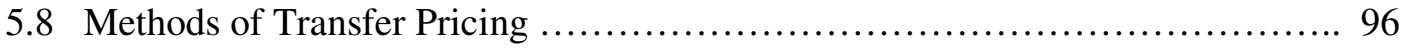

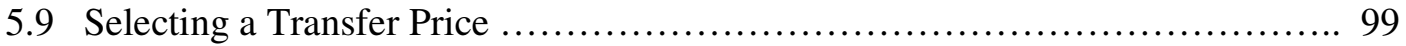

5.10 The International Revenue Code (IRC) and Transfer Pricing .................. 100

5.11 Transfer Pricing and the Arm's length Principle ............................. 101

\section{Inflation and its Effect on the Performance Evaluation of Multinational}

Companies.....................................................................102

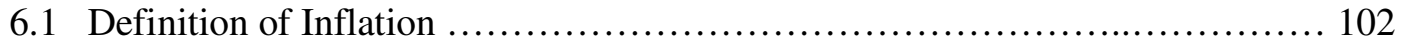

6.2 The Impact of Inflation on the Company f.............................. 103

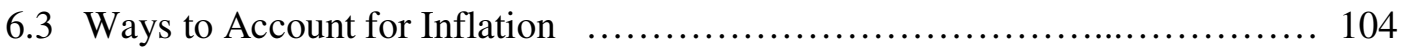

6.4 International Approaches to Account for Inflation......................... 107

6.5 The Relevant Method to account for Inflation to Measure and Evaluate the Real Performance of Subsidiaries in Multinational companies ............... 114

6.6 Restate - Translate or Translate - Restate Approach ...................... 115

7 Foreign currency exchange rates and its effect on the performance measurement and evaluation of the foreign subsidiaries .........................119

7.1 The Problem of Translating the Accounts of the Foreign Subsidiaries ............. 119

7.2 Methods of Translating the Accounts of the Foreign Subsidiaries .............. 121

7.3 International Efforts to Translate the Financial Statements of Foreign

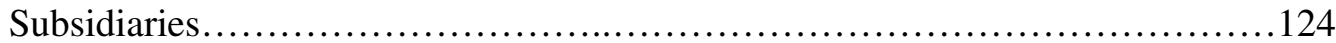

7.4 The Relevant Translation Method for Measuring and Evaluating the Performance of Foreign Subsidiaries. 


\section{Developing the performance evaluation of Multinational Companies}

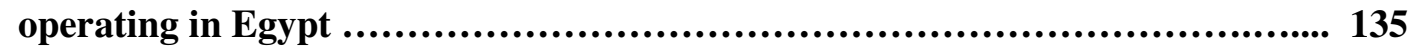

8.1 Measuring the Effect of the Environmental Factors on the Performance of MNCs Operating in Egypt (an Empirical Study) ................................ 136

8.2 Developing the Performance Evaluation of MNCs Operating in Egypt 145

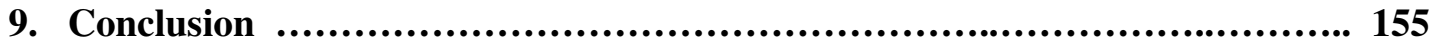

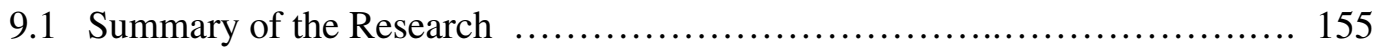

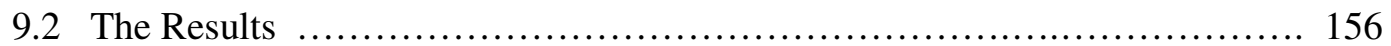

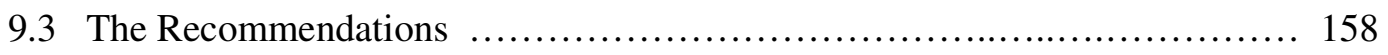

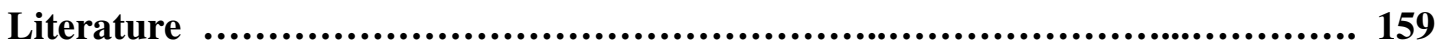

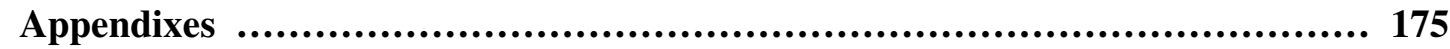




\section{List of Figures}

Figure (1-1): Classification of the Environmental Factors and Variables affecting the Performance of Subsidiary and ................................. 1

Figure (2-1): Organization Structure with being International Division ............. 18

Figure (2-2): Organization Structure by Product Lines ......................... 19

Figure (2-3): Organization Structure by Functions .......................... 19

Figure (2-4): Organization Structure by Geographic Areas ...................... 20

Figure (2-5): The Global Matrix Organization (Mixed Structure) .................. 21

Figure (5-1): Caused and Effects of Transfer Pricing ........................ 82

Figure (5-2): Relationship between Strategy and Transfer Pricing Policy ........... 83

Figure (5-3): Economic Theory's Definition of the Transfer Pricing Problem ....... 88

Figure (5-4): Accounting Theory's Definition of the Transfer Pricing Problem ....... 89

Figure (5-5): Management Theory's Definition of the Transfer Pricing Problem ...... 91

Figure (6-1): Options of Restate and Translation of the Financial Statements of the Foreign Subsidiaries .................................... 117

Figure (7-1): The Exchange Rate of the Egyptian Pound (EGP) against the American Dollar (USD) ............................................ 119

Figure (7-2): The Exchange Rate of the Egyptian Pound (EGP) against the Euro .... 120 


\section{List of Tables}

Table (3-1): Non-financial measures used to evaluate the performance of the subsidiaries and their managers

Table (7-1): The translated balance sheet of a subsidiary under constancy of the exchange rate of the Egyptian Pound against US Dollar (EGP / USD)....

Table (7-2): The translated income statement of a subsidiary under constancy of the exchange rate of the Egyptian Pound against US Dollar (EGP / USD).... 130

Table (7-3): The translated balance sheet of a subsidiary under increase of the exchange rate of the Egyptian Pound against US Dollar (EGP / USD).............. 130

Table (7-4): The translated income statement of a subsidiary under increase of the exchange rate of the Egyptian Pound against US Dollar (EGP / USD).... 131

Table (7-5): The translated balance sheet of a subsidiary under decrease of the exchange rate of the Egyptian Pound against US Dollar (EGP / USD)............ 131

Table (7-6): The translated income statement of a subsidiary under decrease of the exchange rate of the Egyptian Pound against US Dollar (EGP / USD).... 132

Table (7-7): Return on Investment (ROI) of a subsidiary under the three possibilities (Constancy, increase, and decrease)

Table (8-1): The selected sample of the multinational companies operating in Egypt . 139

Table (8-2): The effect of the environmental factors on the performance of the multinational companies operating in Egypt

Table (8-3): Models of Multiple-regression analysis of the relationship between ROI and the effect of the environmental factors 


\section{Abbreviation}

AAA: American Accounting Association

AICPA: American Institute of Chartered Public Accounts

APB: Accounting Principle Board

ASC: Accounting Standards Committee

ASR: Accounting Series Release

CC: $\quad$ Current Cost

CCA: Current Cost Accounting

ED: Exposure Draft

CEO: Chief Executive Officer

EAT: Earnings After Taxes

EPS: Earnings Per Share

EEC: European Economic Committee

EGP: Egyptian Pound

EICA: English Institute of Chartered Accounts

EU: European Union

FAS: Financial Accounting Standards

FASB: Financial Accounting Standards Board

GAFI: General Authority for investment \& Free Zones

FERF: Financial Executives Research Foundation

GNP: Gross National Product

GPP: General Purchasing Power

GPPA: General Purchasing Power Accounting

HC: Historical Cost

H.Q: Headquarters 
IAS: International Accounting Standards

IASC: International Accounting Standards Committee

ICI: Imperial Chemical Industries

IRC: Internal Revenue Code

IRR: Internal Rate of Return

IRS: Internal Revenue Service

MBR: Management By Result

MNC: Multinational Company

MNCs: Multinational Companies

MNE: Multinational Enterprise

MNEs: Multinational Enterprises

OECD: Organisation for Economic Co-operation and Development

QIZ: Qualified Industrial Zones

RC: Replacement Cost

RI: Residual Income

R\&D: Research and Development

ROA: Return on Total Assets

ROI: Return on Investment

SE: Standard Error

SEC: The Securities and Exchange Commission

SPSS: Statistical Package for Social Sciences

SSAP: Statement of Standard Accounting Practice

USD: American United States Dollar 


\section{Introduction}

\subsection{Nature of the research problem}

Multinational company is a business organisation operating in more than one country. Each host country has a different environment from the other countries. According to the concept of the systems approach, multinational company is considered 'open system'; it affects and is affected with the surrounded environment. The environment of host country has some factors and variables which affect the company performance. The environmental factors and variables can be classified into economic, legal, cultural, social, technological and political factors. These environmental factors affect the performance of subsidiary during the operating, and they are out of control of the subsidiary management.

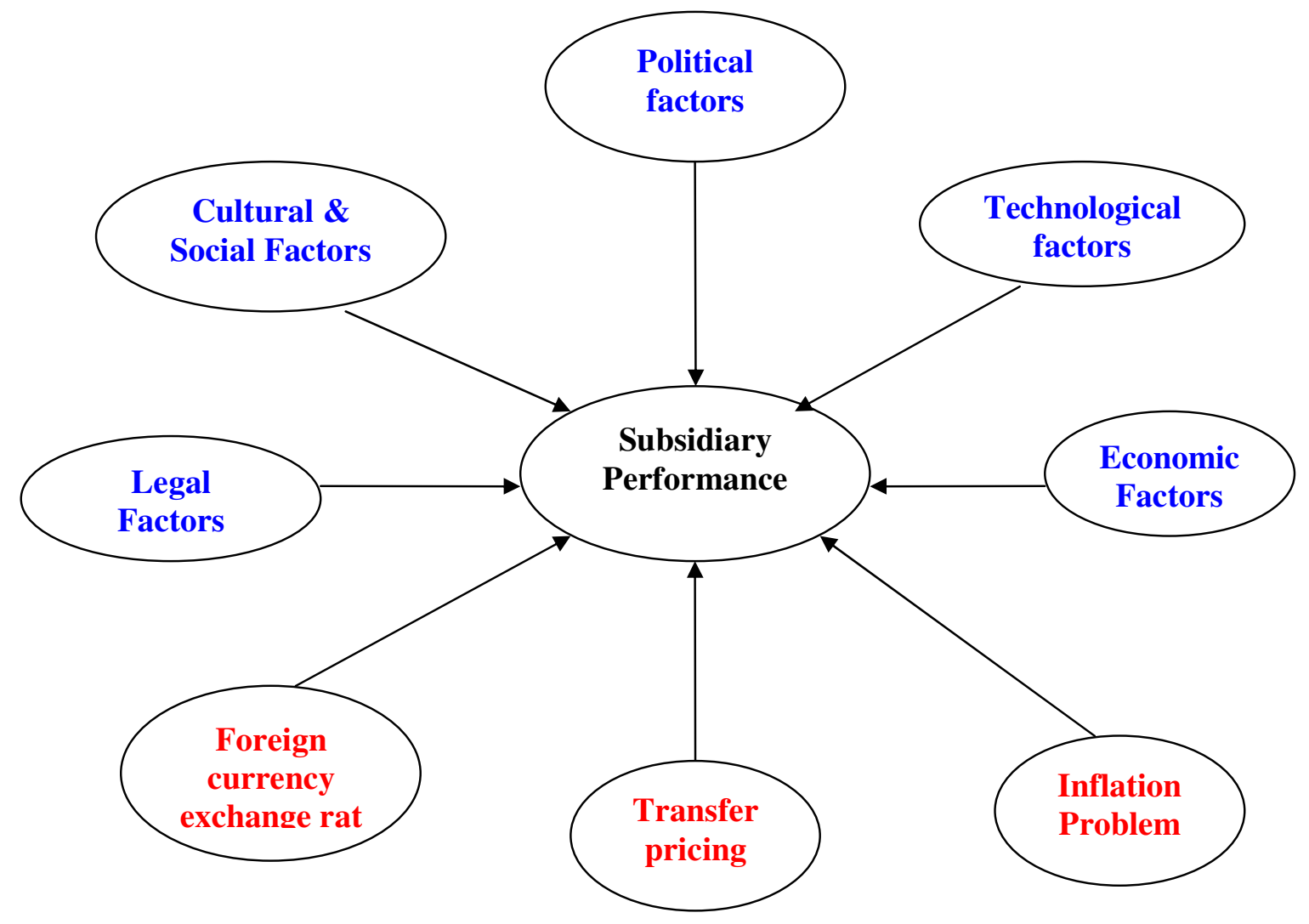

Figure (1-1): The environmental factors and variables affecting Subsidiary performance. 
In addition to the environmental factors (economic, legal, cultural, social, technological and political factors), there are some variables, which affect the performance of subsidiary during measuring and evaluating the performance of subsidiary such as (1) transfer pricing between subsidiaries themselves, and between subsidiaries and Headquarters, (2) change of foreign currency exchange rates, (3) and inflation problem.

From the viewpoint of controlling and performance evaluation, it is very important and necessary to separate between the management performance and the subsidiary performance, in order to measure and evaluate the performance related to the efficiency of subsidiary management and the performance related to the effect of the environmental factors and variables.

Under the effect of the environmental factors on the performance of the foreign subsidiaries and their managers, it is possible to have a good management performance despite poor subsidiary performance, and vice-versa. Thus, the MNC can't measure and evaluate the real performance of the foreign subsidiaries and their managers if it doesn't measure and consider the effect of the environmental factors on the performance of the foreign subsidiaries and their managers. But, how can the MNC measure the effect of the environmental factors on the performance of the foreign subsidiaries and their managers?

Concerning to the transfer pricing (internal pricing) of goods and services, that are transferred (bought or soled) between members of the MNC family, for example, from parent to subsidiaries, between subsidiaries, and from subsidiaries to parent, the MNC often sets the transfer prices to maximize the global after-tax income or otherwise maneuver profits to lower tax rate countries, but this may conflict with the real performance evaluation of foreign subsidiaries and their managers. The issue of transfer pricing in MNC is complicated by the fact that tax and custom authorities of different countries take an active interest in the methods employed. So that, the question which needs to be answered is: "what is the relevant transfer price that MNC use it to evaluate the real performance of the foreign subsidiaries and their managers"?

Concerning to the foreign currencies exchange rate, the accounting records and financial statements of foreign subsidiaries are generally maintained in the subsidiary's local currency. The parent company must be able to translate these foreign currency financial statements to the currency of the parent company. The choice of currency, in which to evaluate the performance, is one of the problems of the performance measurement and 
evaluation of the foreign subsidiaries and their managers. Which is the best method for the $\mathrm{MNC}$ in evaluating the real performance of foreign subsidiaries and their managers, in the local currency results or the results translated into the currency of the parent company? And if the MNC translated the results (accounts) of the foreign subsidiaries into the currency of the parent company, what is the relevant translation method for evaluating the real performance of the foreign subsidiaries and their managers?

And concerning to the inflation in the host countries, doubtless, high inflation rates render accounting numbers fairly useless for performance evaluation. Without adjustments, realistic evaluations of units and management would be very difficult. Thus, a number of companies find it beneficial to adjust their financial statements for inflation and to discuss with their owners and shareholders the related impact on dividend policy and capital requirements. While other companies find it not beneficial to adjust their financial statements for inflation. Therefore, what should the MNC do about the foreign inflation in the host countries in evaluating the real performance of the foreign subsidiaries and their managers?

The research problem can be summarized in the following questions:

(1) How can the MNC measure the effect of the environmental factors (economic, legal, cultural, social, technological and political factors) in the host countries on the performance of the foreign subsidiaries and their managers?

(2) What is the relevant transfer price for evaluating the real performance of the foreign subsidiaries and their managers?

(3) What is the relevant translation method of the financial statements of the foreign subsidiaries from the currency of the host country into the currency of the parent company for evaluating the real performance of the foreign subsidiaries and their managers?

(4) What should the MNC do to adjust the financial statements of the foreign subsidiaries with the effect of inflation in the host countries for evaluating the real performance of the foreign subsidiaries and their managers? 


\subsection{The Research Assumptions}

This research is based on the following assumption: "There is a significant relationship between the performance (represented in ROI) of subsidiary and environmental factors and variables in the host countries, and this relationship can be measured". In other words, the performance of subsidiary is affected by the environmental factors and variables in the host countries.

\subsection{The Research Objectives}

The main objective of this research is to develop the performance measurement and evaluation of multinational companies operating in Egypt, through consideration the effect of the environmental factors and variables in the host countries on the performance of subsidiaries and their managers.

The main objective can be achieved through the following sub-objectives:

- Studying and investigating the environmental factors (economic, legal, social, cultural, and political) affecting the performance of MNCs and their managers operating in Egypt.

- Measuring the effect of the environmental factors and variables on the performance of MNCs operating in Egypt.

- Determining the relevant transfer price which the MNC use for measuring and evaluating the real performance of the foreign subsidiaries and their managers.

- Determining the relevant translation method of the financial statements of the foreign subsidiaries for measuring and evaluating the real performance of the foreign subsidiaries and their managers.

- Determining the relevant method to adjust the financial statements of foreign subsidiaries with effect of inflation in the host countries for measuring and evaluating the real performance of the foreign subsidiaries and their managers.

\subsection{The Research Plan and Structure}

According to the nature of research problem and research objectives, the research plan based on two parts as the following: 
Theoretical part: In this part, the research aims to study and investigate the important literature, which related to and served the theme of the research such as multinational companies, performance evaluation, the environmental factors (economic, legal, social, cultural, and political) affecting the performance of MNCs and their managers, and some problems affecting in measuring and evaluating the performance of the foreign subsidiaries and their managers such as transfer pricing and its effect on the performance evaluation of the foreign subsidiary and its managers, translation of the financial statement of the foreign subsidiaries and its effect on the performance evaluation of the foreign subsidiary and its managers, and the inflation problem and its effect on the performance evaluation of the foreign subsidiary and its managers.

Practical part: This part is an empirical study to investigate the important environmental factors affecting the performance of MNCs operating in Egypt, and also to measure the effect of these environmental factors on the performance of these companies and their managers.

For this purpose, a questionnaire was designed and developed. The questionnaire includes 20 questions to ask and investigate the important environmental factors (economic, legal, social, cultural, technological and political) affecting the performance of MNCs and their managers operating in Egypt. The questionnaire was presented to the managers of MNCs operating in Egypt. The empirical study covered $30 \mathrm{MNCs}$ as a sample of the MNCs operating in Egypt.

The empirical study used the multiple-regression analysis as a statistical method for studying the relationship between the performance (represented in ROI) of the company and the effect of the environmental factors affecting the performance of MNCs in the host countries. The multiple-regression analysis was done by using the software of SPSS (Statistical Package for Social Sciences).

In addition to the introduction chapter and the conclusion chapter, the research includes nine chapters as the following:

The first chapter is an introduction which shows the research problem and how it can be solved, this chapter also shows the research assumption, its objectives, the research plan and structure, and the research contribution. 
In the second chapter analyses multinational companies, its definition, characters, objectives, strategies, and challenges of the multinational companies.

The third chapter deals with the performance evaluation in the companies, in general, and in multinational companies, specially, the concept of responsibility accounting and performance evaluation in the multinational companies, the importance of separating between managerial and subsidiary performance, the measures used for evaluating subsidiaries, the last researches and studies on performance evaluation of multinational companies, and definition of the main problems of the performance evaluation of multinational companies.

The fourth chapter discusses the important environmental factors in the host countries affecting the performance of foreign subsidiaries and their managers.

The fifth chapter discusses the problem of transfer pricing in the multinational companies and its effect on the performance evaluation of the foreign subsidiaries. Also, this chapter discussed the different methods used in transfer pricing in multinational companies and the relevant method of transfer pricing to evaluate the real performance of the foreign subsidiaries and their managers.

The sixth chapter discusses the problem of inflation in the host countries and its effect on the financial statements of the foreign subsidiaries, the different methods to account for inflation, and the relevant method to adjust the accounts of the foreign subsidiaries with the effect of inflation to evaluate the real performance of foreign subsidiaries and their managers.

The seventh chapter discusses the problem of translation of the financial statement of the foreign subsidiaries from the currency of the host country into the currency of the parent company, the different methods of translation and its effect on the net income, and the relevant translation method to translate the accounts of the foreign subsidiaries for evaluating the real performance of the foreign subsidiaries and their managers.

The eighth chapter presents to the empirical study that aims to investigate and determine the important environmental factors (economic, legal, social, cultural, technological and political factors) affecting the performance of multinational companies operating in Egypt, to measure the effect of the environmental factors on the performance of the multinational 
companies operating in Egypt, the statistical analysis method is used in this study, and the proposed model for developing the controlling and performance evaluation of multinational companies operating in Egypt.

The ninth chapter presents the conclusion of the results and recommendations of the research.

\subsection{The Innovation Contribution of the Research}

The main contribution of this research represents an attempt to develop the performance evaluation of the foreign subsidiaries and their managers, through measuring and considering the effect of the environmental factors (economic, legal, social, cultural, and political factors) on the performance of multinational companies operating in Egypt at measuring and evaluating the performance of the foreign subsidiaries and their managers, and suggesting a model for evaluating the performance. This model helps to separate between the performance related to the efficiency of company management and the performance related to the environmental factors in the host country.

Also, this research tries to introduce a contribution concerning the problem of transfer pricing and its effect on the performance evaluation of the subsidiaries, and to discuss the different methods of transfer pricing and the relevant method for measuring and evaluating the real performance of the foreign subsidiaries and their managers. In addition, this research tries to determine the relevant method to adjust the accounts of foreign subsidiaries with the effect of inflation in the host countries for evaluating the real performance of the foreign subsidiaries and their managers. Also, this research tries to determine the relevant translation method of the financial statements of the foreign subsidiaries in the currency of the host country into the currency of the parent company for evaluating the real performance of the foreign subsidiaries and their managers. 


\section{Multinational companies (MNCs)}

\subsection{Definition of the Multinational Companies (MNCs)}

There is no univocal definition of MNC generated by scientific methods; therefore, there is no widespread agreement in the literature as a precise definition of the multinational term. There are many trends to define MNC.

The first trend defines MNC based upon the number of host countries. According to this trend, Miller says that: "the simplest definition of MNC is that considers the MNC as a business organization operating in more than one country." "1 Dunning also defines MNC as "an enterprise which owns or controls producing facilities (i.e. factories, mines, oil refineries, distribution outlets, offices, etc.) in more than one country." "2 Hogget \& Stopford as well think that MNC can be defined as: "an undertaking which owns or controls productive or service facilities in more than one country, thus excluding mere exporters, even those with established sales subsidiaries abroad, as it does more licensers of technology." ${ }^{3}$ Organization for Economic Co-operation and Development (OECD) describes MNC as: "usually comprise companies or entities whose ownership is private, state or mixed, established in different countries and so linked that one or more of them may be able to exercise a significant influence over the activities of others and, in particular, to share knowledge and resources with others ."4 D. K. Fieldhouse describes MNC as: "a business enterprise which owns and controls income-generating assets in more than one country.",

The second trend defines MNC based upon the amount of foreign investments. Through this trend, MacDonald \& Parker say that: "an enterprise can be considered as a MNC if it has at least $20 \%$ of its assets overseas." $" 6$ But the report of Business International decides that "an enterprise becomes MNC when it has at least $35 \%$ of its total sales and profit from foreign investments."7

\footnotetext{
${ }^{1}$ Elwood L. Miller 1979 , P.3.

2 John H. Dunning, 1971, P.16.

${ }^{3}$ Hoogvelt, A., Puxty ,A. G. \&Stopford, J. M. , 1987, P.157 :as cited in Marius Ronge , 2001, P10 .

${ }^{4}$ OECD, Paris, 1988 , P27.

${ }^{5}$ D. K. Fieldhoouse. 1986, P.9.

${ }^{6}$ Victor Z. Priel , vol.14 No.(4-5)1974, P.47.

${ }^{7}$ Ibid. P.47.
} 
The third trend the two previous trends, it defines the MNC based upon the number of host countries and the amount of foreign investments. For example, Hood says that: "a corporation to be an MNC it must have $25 \%$ or more "foreign content", either in assets, employment or income sourcing in a minimum number of countries, usually five or six ". 8

The fourth trend presents a definition of the MNC through an international view of management. So, the study which was done in Harvard Business School by Professor Raymond Vernon defines the MNC as: "a parent or dominant enterprise controlling the operations of a network of foreign corporations and furnishing them with common objectives, strategies and resources."

After reviewing the previous definitions of $\mathrm{MNC}$, it seems that there is no agreement on one definition or concept of MNC. In addition to this, there are more than one term used, for example, there is a term "Multinational Company" and another "International Company". But through all previous definitions I can define the MNC as: "a main company (a parent company) manages a group of branches or subsidiaries in different countries to achieve certain objectives, by working together through a world managerial strategy under the constraints and laws in the home and host countries."

According to this definition of the MNC we can conclude the following facts about the MNC:

- There is a parent company in the home country where the H.Q. is.

- There are branches or subsidiaries in different countries (host countries).

- The branches or subsidiaries operate not only to achieve special objectives for themselves, but also for general objectives of the MNC as a whole, according to a certain international strategy.

- The parent company works under the laws of the home country, while the foreign branches or subsidiaries work under the applied laws in the host countries.

\footnotetext{
${ }^{8}$ Hood, N. \& Young S., 1979, P.2 .

${ }^{9}$ Elwood L. Miller, Op Cit, P.3 .
} 


\subsection{Characteristics of Multinational Companies (MNCs)}

Although the underlying forces creating MNCs are varied and complex, all MNCs have several common dimensions and distinguishing features as the following:

Geographical spread: MNCs have wide spread networks of affiliates in different countries in the world. For example, Ford Company has affiliates in more than 30 countries, Shell Company in more than 40 countries, and Coca Cola Company in more than 150 countries. This geographical spread of MNCs places them in a considerable flexible position, because of the wide rang of the multi-options in some decision areas, such as sourcing, pricing, financing, cash flow etc. The best MNC is able to take the advantage of changes in the economic environment internationally. The existence of networks of foreign affiliates within MNC gives the possibility of integrated production and marketing on a global basis. So, this may give rise to extensive intra-firm trade, such as various stages in the production process which are located in different countries or affiliates which specialize in a particular part of the total product line. The intra-transfers of MNC constitute a very significant part of the total volume of international trade ${ }^{10}$.

The efficiency: The magnitude of the available resources of MNCs enables it to distribute these resources wherever they want in different countries in the world. MNC can transport investments, money, people, machines, materials, goods, special technical knowledge and cleverness, and other services. All these are managed from a global and national perspective. This attitude of globalization in management thinking means that all affiliates are managed and controlled by the headquarters of the MNCs, but with a certain degree of the decentralization in some decision making areas. From this vantage point, the MNC is capable of tapping and manipulating its resources on a worldwide basis, using them in the locations considered to offer the best opportunities and/or the lowest risks. In other words, the MNC can generally obtain financing and produce its products at the lowest possible total costs, and also select the most promising available markets in which to sell. ${ }^{11}$

The power: the power attribute of the MNC is a result of its size, geographical spread, scope of operations, and efficiency. Today it is normal that the MNC records annual sales greater than GNP in some countries where it operates. Consequently, the MNC, as a giant among local firms, in general, has the power (at least in the economic sense) to dominate

\footnotetext{
${ }^{10}$ Hood, N. \& Young S., Op. Cit.,P.24.

${ }^{11}$ Elwood L. Miller, Op. Cit., P.18 .
} 
and control the local markets. Because the MNC lacks the protection of the international law, it relies upon itself to compete and win. For this, the MNC transcends the national boundaries and controls to have the potential to influence the world affairs and course of events in the host countries in very significant ways. ${ }^{12}$

The stability: The stability factor of the MNC is also clearly a function of its size and power. The relatively huge resources of the MNC may enable it to absorb losses from unexpected operating constraints, from being an unprofitable investment, or from other externalities, without threatening its success and continued existence as a whole group. Also, the relatively power of the MNC enables it to sustain losses in the short run, until it achieves an efficient economy. An affiliate of the MNC can also absorb losses resulting from undercutting competitors especially in a new market area ${ }^{13}$. We can say that, this later facet of the MNC stability interests the host countries.

The flexibility: According to its size and scope, the $\mathrm{MNC}$ is certainly the most flexible of the economic enterprises. The excellent communication systems enable the widely decentralized operations to serve the local needs, and also permit the centralized direction to assure the goal congruence. Thus, the headquarters can manipulate the mobile resources of the MNC on a global basis, based upon the best overall interests for MNC. It can produce, assemble, and market in the locations offering the best opportunity. This kind of flexibility often enables the MNC to offset or escape from restrictive regulations or controls in certain sections of the world ${ }^{14}$. Transfer prices, credit terms, loans, and other points are examples of devices available to the MNC.

Dynamic: The MNC is certainly dynamic. It must grow in order to survive, particularly where advanced technologies are involved. The MNC is often described as a key innovator, which creates markets as well as the products related to them. The MNC can convert the conflicting forces and apparent problems into opportunities, by means of its integrated planning techniques. It assimilates, adapts and reconciles the external threats into beneficial strategies ${ }^{15}$. The MNC, as an innovator, not only adapts to change but also anticipates or initiates change. The MNCs often operate in monopolistic market structures,

\footnotetext{
${ }^{12}$ Ibid, P.18 .

${ }^{13}$ Ibid, P.18 .

${ }^{14}$ Ibid, P.20 .

${ }^{15}$ Ibid, P20.
} 
and it is clear that the speed of commercial introduction of new products and processes is more rapid in oligopoly, which gives them more dynamic. ${ }^{16}$

Monopolistic: The MNCs are usually monopolistic, and consequently they are the byproducts of developed countries. These monopolies attempt to spend more on their technology and access to the capital and other resources markets, in order to acquire the vital growth of their existence. Equally to all other conditions, The MNC will choose the environment in which the continued growth will be ensured by its ability to regulate the competition through the controlled release of its technology. The monopolistic firm requires an environment of relatively free enterprise in order to spend money on the technological and other competitive advantages. It is logical that the MNC would elect to establish its affiliates in countries having little or no technology and therefore little or no competition $^{17}$.

\subsection{Objectives of the Multinational Companies (MNCs)}

There are many opinions about the nature of the main objective of the MNCs, but there is no doubt that their main objective of the MNCs is profit maximization (Earnings after taxes (EAT)) of the parent company and of the group as a whole. Also, some people say although various objectives are possible, they assume that the goal of the firm is to maximize the wealth of the firm's present owners. ${ }^{18}$ The profit maximization is not only the objective of the MNCs, but there are also other objectives the MNCs try to achieve, such as obtaining a big share of the world markets, overcoming the customs protection imposed by the host country, minimization of the total costs by using the less cost labor and materials, in order to benefit from the available tax advantages in the host countries, and to maximize the returns and revenues from the total transactions and sales, to have a giant economic power, in order to achieve a high rates of economic growth, so that they can invest in profitable areas which have no or less technology and also no or less risks.

I think that the main and most important objective of the MNCs is profit maximization, and the other objectives represent sub-objectives, and all of them finally aim to achieve the main objective which is maximization of the profits of the MNC as a whole unit.

\footnotetext{
${ }^{16}$ Hood, N. \& Young S., Op. Cit.,P.115.

${ }^{17}$ Elwood L. Miller, Op. Cit., P.19.

${ }^{18}$ James C. Van Horne and John M. Wachowicz, JR., 2005, P.3
} 


\subsection{Strategies of the Multinational Company (MNC)}

Strategies of the MNC are the general policies, which the company uses for achieving their purposes in the long term. As we mentioned previously, both the main objective and the other sub-objectives of the MNC aim to maximize the profits. Thus, when the MNC determines its policies it considers that all these policies aim to maximize the profits of the MNC as a whole and especially of the parent company in the long term. The policies of the MNC may have negative effects on the profits of some subsidiaries in the host countries, but in the same time they have positive effects on the profits of some other subsidiaries or the parent company. The subsidiaries are operating not only for themselves but also in order to achieve the objectives of the MNC as a whole (profit maximization), because the objectives of each subsidiary are determined by the headquarters general policies of the MNC.

We can say that the policies of investment and ownership, planning, financing, organizing, marketing, and controlling aim to maximize the income from the transactions and sales, as high possible as, to minimize the cost of products, as low possible as, and consequently to maximize the profits of the MNC as a whole. These policies represent the strategies of the MNC, which will be discussed in the following.

\subsubsection{Strategy of foreign investment}

When the MNC enters a new market by foreign direct investment, it faces two strategic issues concerning the organizational form: (1) the mode of foreign entry has to be determined. The MNC can choose between a Greenfield investment and the acquisition of an existing company, (2) the level of control over the local subsidiary has to be determined. Therefore, the MNC can choose between a wholly owned subsidiary and a joint venture agreement with a local partner in a subsidiary in a foreign country.

\subsubsection{Strategy of foreign entry (Greenfield Investment versus Acquisition)}

When the MNC enter a new market by foreign direct investment, it must determine the mode of foreign investment entry. The MNC can choose between a Greenfield investment and the acquisition of an exiting company (takeover). ${ }^{19}$

\footnotetext{
${ }^{19}$ Thomas Müller, 2002, PP 19-20.
} 
The proponents of Greenfield entry support their opinion with the following arguments ${ }^{20}$. At firstly, the Greenfield investment can be a cheaper way to enter, because the scale of involvement can be precisely controlled and the facility can be exactly expended in line with achieved market penetration. This argument is likely to be particularly strong for small firms which face difficulty in raising the capital necessary for a takeover (buy). Secondly, building a new plant means that there is no risk of inheriting problems. Thirdly, the most modern techniques of production and management can be installed. Fourthly, it is likely that most governments would welcome for Greenfield investments which, are seen as an increase of activity, employment and competition. Advantage is, this may entail financial assistance and negatively, there is less risk of anti-trust action. Fifthly, the choice of location is open to the entrant and a least cost site including possible regional grants can be chosen. Finally, Greenfield entry can be the second best solution where no suitable takeover victims can be found.

On the other hand, there are arguments in favor of an entry by takeover ${ }^{21}$ (acquisition). Firstly, takeovers permit rapid market entry and allow a quicker return on capital and learning procedures. In cases of strong competition, the pre-emption of a rival firm's move may dictate a takeover entry. Secondly, cultural, legal, and management problems, particularly in the difficult start up period, can be avoided by assimilating a going concern. Thirdly the major advantage of the takeover is often the purchase of crucial assets, such as asset skills, products with different circumstances, management brand names, technology, and distribution networks. Lastly, the takeovers do not disturb the competitive framework in the host country and avoid the competitive retaliation.

But there are several potential drawbacks of an entry by takeover. Firstly, the entrant is faced with the problem of evaluating the worth of the acquired assets. This involves a costly and difficult assessment of the synergy between these new assets and the firm's existing operations. Secondly, there may be difficult problems of integrating a previously independent unit into a larger entity. And thirdly, the search for the ideal victim often involves much cost.

Finally, almost MNCs make the decision of the foreign investment entry based upon the estimations of the investment climate in the host country. The estimations of the

\footnotetext{
${ }^{20}$ Peter J. Buckley, 1987, P.44

${ }^{21}$ Ibid, P.44-45 .
} 
investment climate include many factors; the most important factors are the political and financial stability, inflation rates, governmental constraints concerning with the transfer of money and profit to the home country, controls on imports and exports, and the tax laws employed in the host countries. The MNCs determine a measure to estimate the investment climate, so that the MNCs determine the most important factors in decision making of the investment in the host country, each factor has a suitable weight estimated with some of points, this weight reflect the materiality of these factors. In the end, by collecting these estimations the MNC can classify the investment climate into suitable climate or unsuitable climate for investment.

\subsubsection{Strategy of ownership: (a wholly owned subsidiary or a joint venture)}

When the MNC enter a new market by foreign direct investment, it must determine the level of control over the local subsidiary. Therefore, the MNC can choose between a wholly owned subsidiary and a joint venture agreement with a local partner. Both types of ownership structures defer considerably in their level of control, resource commitment, and risk. $^{22}$

If the MNC chooses a wholly owned subsidiary (100\% ownership), it is preferable to buy an exiting firm. The arguments for $100 \%$ equity ownership of an exiting foreign subsidiary rely on the following facts. Firstly, the MNC inherits an exiting marketing position. Secondly, the MNC avoids a probably big competitor. Thirdly, the acquired firm usually has important advantages in the management and profits opportunities. Fourthly, with $100 \%$ ownership the MNC has full control, by the parent company over the subsidiaries, and there is no conflict over potentially contentious issues of company policy such as dividend payments, exports and imports, the distribution of new investment, and internal transfer prices. Fifthly, in case that the parent company can supply all the necessary input for its subsidiary, $100 \%$ ownership is preferable, because the costs of these inputs need not to be borne. Sixthly, when the MNC has $100 \%$ ownership of a foreign subsidiary, there is no leaking of some technical and competitive information to outsiders who may not fully share the goals of the parent company. Finally, some types of strategy are incompatible with the joint ownership ${ }^{23}$.

\footnotetext{
${ }^{22}$ Thomas Müller, Op. Cit., P 19

${ }^{23}$ Peter J. Buckley, Op. Cit., P.45
} 
On the other hand, the joint ownership between the MNC and a local firm or government of the host country has some advantages. Firstly, the joint ownership permits rapid entry to foreign markets, and facilitates the products marketing, and consequently allows a quicker return on capital. Secondly, the joint ownership allows to the MNC to be near to the material markets. Last, the MNC can overcome some governmental constraints in the host country by the joint ownership. But the joint ownership restricts the full control of the parent company on the subsidiaries, where the local partner restricts the flexibility of the MNC headquarters in determining the objectives and policies, and in planning, even in a small degree.

In a questionnaire by the USA Trade Ministry, the managers of MNCs decided that they do not want to have conflicts with the local partners about the important managerial issues, such as the programs of marketing, money and profits transfer, re-investment, exports, transfer prices, and the management selection. And they also decided that, some of these issues may cause a dangerous conflict with the local partners. They agreed also that the joint ownership restricts their full flexibility and freedom in management of subsidiaries.

Of course, the success of the decision of entry by a joint owner depends on the choice of partner. And the MNCs may face some difficulty to appraise the prospective partner in the future, but the success of the decision to enter by a joint owner depends on this appraise. ${ }^{24}$

\subsubsection{Strategy of organization}

If the organization is generally a complex issue in the local enterprises, without doubt, it becomes more complex especially in the MNCs, because the MNCs have more complex lines of authorities and responsibilities, which link the top management and all managers of departments and areas of all subsidiaries in the host countries.

The organization structure shows the authority lines, which determine the range of decision making, the authority of executing and management, and all control operations. Also, the authority lines must define the amount of the authority, which the top management has, and the amount which delegates to the managers of subsidiaries. This determination of the authority lines is reflected on the performance of managers.

\footnotetext{
${ }^{24}$ Ibid, P.45 .
} 
Organizationally, the MNCs must respond to the global challenges in the way, which allows the maximum control of policy by the top decision makers with maximum flexibility of response to changing circumstances. This means that the authority lines create an efficient communications network within the $\mathrm{MNC}^{25}$. The efficiency of the authority and responsibility lines within the MNC needs a big amount of efficiency in the communications within the MNC. Efficient communication is necessary to inform the subsidiaries managers in all host countries with the main objectives and policies, for which they are responsible to achieve in the short and long run. The MNC must overcome the communication problems related to length, nationality, culture, and language.

When the MNC designs the organization structure it must save a level of decentralization of the authority to the local managers of subsidiaries in order to enable them to do their tasks under the surrounded environmental circumstances. But the top management of the MNC tries to hold the authority to do uniformity of the policies related to the financial decisions and the other important decisions, which affect the strategy of the MNC as a whole.

There are five common forms of organization used by MNCs: (1) an organization structure with international division or international department, (2) grouping by the functions within the MNC, (3) grouping by the products, (4) grouping by geographical area, and (5) the global matrix organization (mixed basis). ${ }^{26}$

\subsubsection{Organization structure with being an international division}

According to this approach, the MNC can create a division of the foreign operations within the organization structure. This division of international operations is considered as a world path of international activities in the MNC. All non-domestic (foreign) activities in the MNC are grouped together and managed by the division of international operations, and reporting about these activities is directly between the executive Chief of the MNC and the executive Chief of the international division. The executive chief of the division of the international operations must have a high level of experience and efficiency which is necessary to coordinate the operations in different situations. This organization structure allows some of the decentralization through the authority delegation to subsidiaries

\footnotetext{
${ }^{25}$ Ibid, P.47.

${ }^{26}$ G. G. Mueller, H. Gernon, and G. Meek, 1994, P.125.
} 
managers in the host countries, thus, the MNC can deal with foreign subsidiaries as profit or investment centers under the authority and responsibility.

Although this organization structure is useful for the MNC in giving power to the international way, it does not allow the MNC to benefit fully from the cooperation between local and foreign operations, but with some coordination between them, the MNC can achieve this benefit. Also, under this organization structure can be found some personal problems in the MNC, expatriate executives are more expensive than employed ones at home and pose problems in promotions, pensions, emoluments and reintegration at home. The employment of local executive managers may be difficult and risky but may be forced on the company by the host governments, which demand to have a fixed proportion of executive managers. The cultural differences among executive managers often require careful handling by top management through training programs in order to match these personal needs ${ }^{27}$.

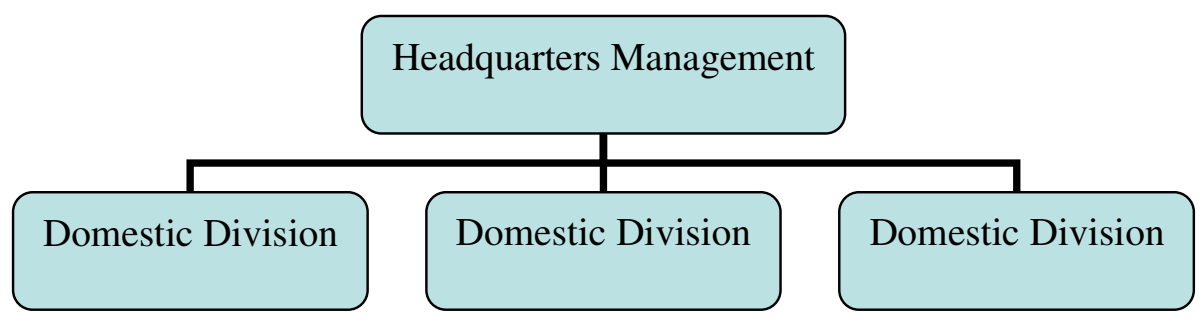

Figure (2-1): Organization Structure with an International Division

\subsubsection{Organization structure based upon product line}

The MNC can also design its organization structure based upon the products lines. The organization by product line results in integration of domestic and foreign operations and evaluation of product lines based on worldwide results ${ }^{28}$. This organization is suitable for the companies which have a big diversity in their products ${ }^{29}$, and also have widespread operations in the international field. According to this organization, each product division is responsible for all activities of the product in the entire world; consequently, the

\footnotetext{
${ }^{27}$ Peter J. Buckley, Op. Cit., P.48.

${ }^{28}$ G. G. Mueller, H. Gernon, and G. Meek, Op. Cit., P125.

${ }^{29}$ Victor Z. Priel, Op. Cit.,P53.
} 
performance of each division is evaluated based upon the profits achieved from its activity in production and marketing of the product.

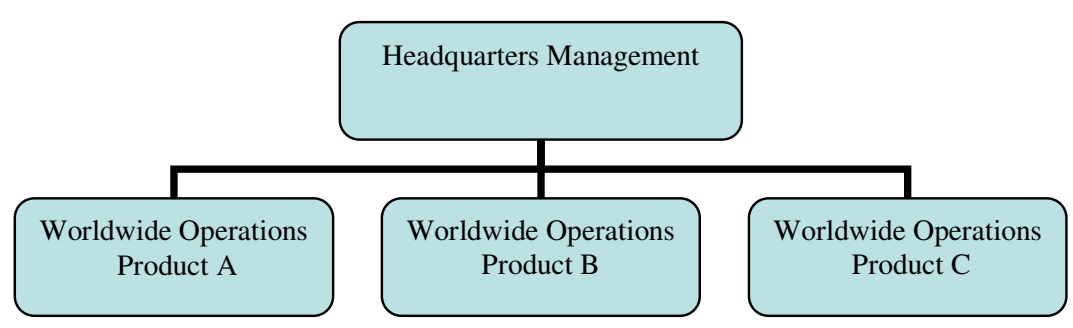

Figure (2-2): Organization Structure by Product line

\subsubsection{Organization structure by functions}

The MNC can design its organization structure based upon the main functions in the company, where it determines a division to each main function in the company (e.g. production, marketing, financing ....etc.), and the managers of these divisions have widespread responsibilities. ${ }^{30}$

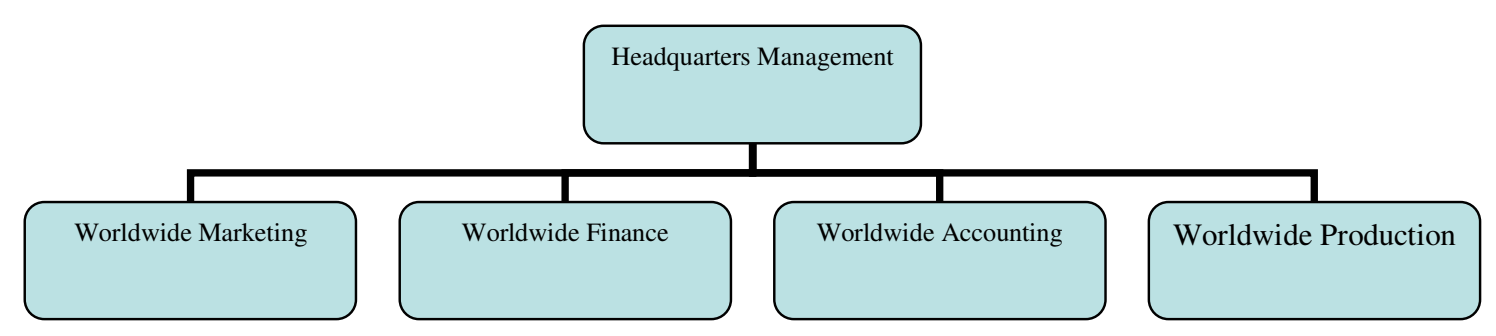

Figure (2-3): Organization Structure by functions

\subsubsection{Organization structure by geographic areas}

The MNC can design its organization structure based upon geographical areas, by dividing the world into geographical divisions (e.g. North America, Latin America, Europe, Asia, Africa, etc.). This organization is suitable when the MNC merchants consumer goods ${ }^{31}$. Every division has an executive manager responsible for producing and marketing all products and services in the geographical division following him. The executive manager of a geographical division presents his reports directly to the executive chief of the MNC,

\footnotetext{
${ }^{30}$ Peter J. Buckley, Op. Cit., P48.

${ }^{31}$ Victor Z. Priel, Op. Cit., P53.
} 
and he can take the advice and support from the staff, which is responsible for the international tasks.

This organization structure helps the manager of the geographical division to concentrate his interests an a group of companies, that have the near nature of the environmental circumstances, thus, he will have more ability to manage these companies. Also, this organization structure allows a decentralization level of the subsidiaries, which are, at the same time, under control and coordination by the parent company.

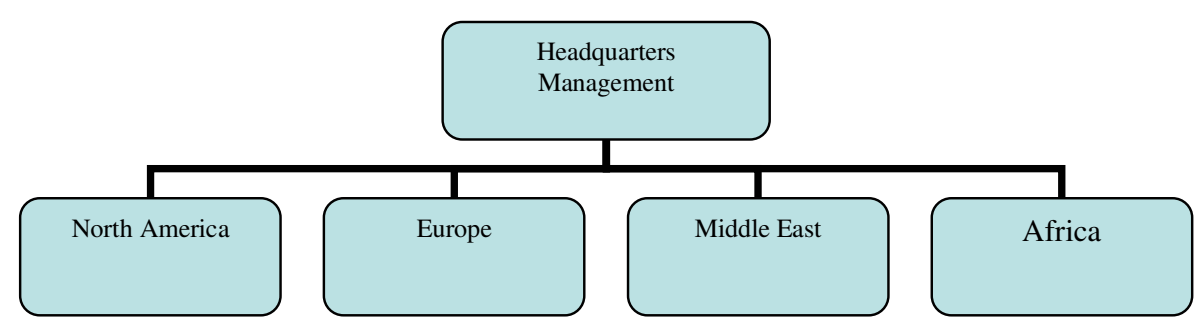

Figure (2-4): Organization Structure by Geographic area

\subsubsection{The global matrix Organization (a mixed structure)}

The global matrix organization blends two or more of the forms mentioned before (e.g., the general manager of a French subsidiary will report to the vice president for worldwide product lines and to the vice president in Europe). Union Carbide's international operations are organized as area companies (geographic), by reporting to the highest management levels in the company (functions). The area companies are viewed as separate, profitresponsible entities, not as extensions of domestic divisions. Dow Chemical Company uses the matrix organization to avoid the problems inherent in either integrating or separating foreign operations. $^{32}$

\footnotetext{
${ }^{32}$ G. G. Mueller, H. Gernon, and G. Meek, Op. Cit., P27.
} 


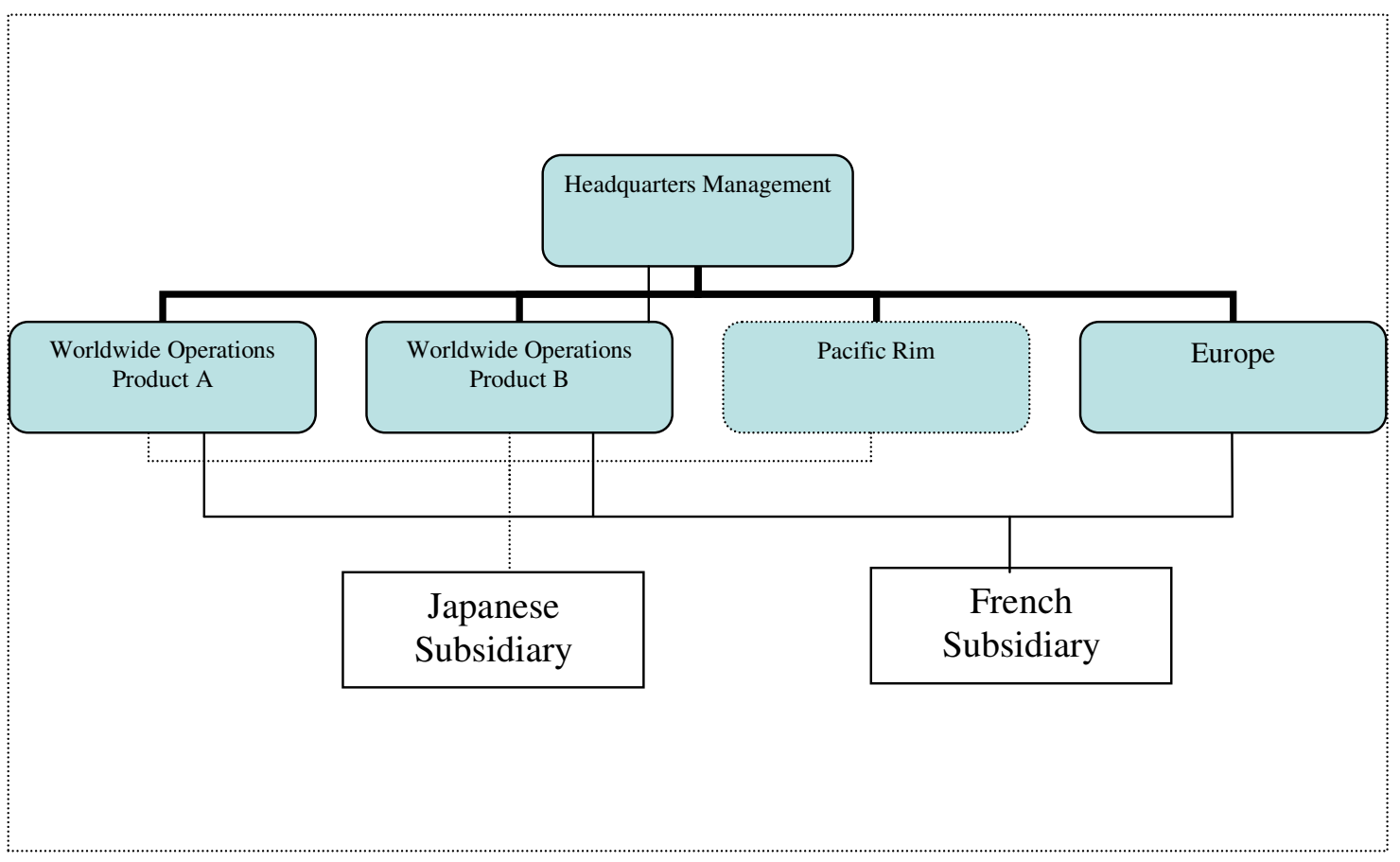

Figure (2-5): The Global Matrix Organization (Mixed Structure)

Most MNCs organize their activities using a mixed structure, blending certain elements of two or more forms. Structures are dynamic in nature, but their flexibility is limited by the constraint of a company's cultural heritage

\subsubsection{Strategy of financing}

The financing strategy is an important one of the general strategies of the $\mathrm{MNC}$, because the financing decisions have an influence on the profits in subsidiaries and in the MNC as a whole. The MNC has alternative sources of funds to finance their foreign operations in the host countries. The subsidiaries of the MNC may obtain the funds from the following sources: ${ }^{33}$

1. The parent company: In this case, the finance of subsidiary may come from the parent company itself either in form of equity or loans. Also the subsidiary may obtain funds from other sources in the home country. The MNC allows this policy when the ratio of expected loss, resulting from the currency depreciation in the host country, is less than the ratio of local loans charges.

\footnotetext{
${ }^{33}$ Hood N. \& Young S., Op. Cit., P38.
} 
2. Internal finance: Here, the finance of subsidiary may come from its undistributed (reserved) profits and depreciation provisions. Once the subsidiary becomes established and begins earn profits, it may be financed from this source. A certain proportion of profits are likely transferred to the parent company, and any undistributed (reserved) profits are available for capitalizing to support the financial position in the subsidiary. Also, the depreciation provisions are considered as a source of internal finance. This source is discriminative, because it reduces the income tax in the home country and the divides tax in the host country. But, it is considered as a short term policy that the subsidiary can not reserve its profits for a long time.

3. The host country: The subsidiaries can find a wide range of other finance sources within the host country. They may be able to raise equity capital, to borrow from banks and other financial institutions, and to sell securities. The MNC allows a subsidiary to use this source when the charge of the local loans is less than the ratio of the expected loss resulting from the currency depreciation in the host country, and when the MNC wants to avoid the oscillation of the currency price in the host country, and when there is a central control of the MNC on the subsidiaries, HQ prevents subsidiaries to use their cash liquidity and profits, and to reduce them as low possible as. The MNC allows also the subsidiary to borrow funds from another sister subsidiary in other host country. ${ }^{34}$

But there are some constraints on the flexibility of a subsidiary in order to use the previous sources of finance, which are that the capital markets in the third world countries are often undeveloped, and even in some European countries the full rang of financial institutions and markets are not available. Perhaps more important constraints on the subsidiary are the regulations of host countries, which may limit the raising of capital locally or restrict the dividend remittances, and regulations of the home country concerning the permitted outflow of the capital from the parent company. However, the subsidiary has a much wider range of finance sources than the equivalent local firm, and this factor has been considered as a significant advantage to the foreign subsidiary. ${ }^{35}$

\subsubsection{Strategy of planning}

If the planning plays an important role in all enterprises generally, it plays specially a more important role in the MNC, because of its great size, geographical diversity, huge

\footnotetext{
${ }^{34}$ Ibid, P38.

${ }^{35}$ Ibid , P39.
} 
activities, and interfered and complicated operations. Thus, the MNC is interested in planning as a tool to facilitate making decisions that achieve maximization of the efficiency in operating its resources, and a consequent maximization of the profits. The plan of management should incorporate well defined targets, which can be measured. The multiple targets, which are comprehensible to decision makers, should include a time scale for their achievement and an action program in order to tackle the key problems and take advantage of opportunities. These provisions prevent the plan to be vague and give clear guidance to managers ${ }^{36}$.

The process of strategic planning in most MNCs is continuous and it consists of several steps. In reality, many of these steps are performed at the same time. Each step serves as a distinctive diagnostically analytical purpose. The main steps of the planning process are as follow: ${ }^{37}$

1. Formulation of strategic objectives: The formulation of strategic objectives must be regarded as the key issue in the whole process of the strategic planning, and this is confirmed by all top managers. It is very important to include all top managers in the process of strategic planning, to ensure efficient executing of these strategies. The process of strategic planning that depends on the prevailing structure value in the given organization is generally agreed about. Since the process of strategic planning is directly related to subjective assessments of the future and the attitude toward risk taking, very little could be found about the working of such these processes.

2. Environmental analysis: Analyzing the business environment serves some purposes: ${ }^{38}$ At firstly, determination of the statue quo (the present position), secondly, diagnosis of the exiting trends and their implications for their operations, thirdly, forecasting future trends, fourthly, determining particular opportunities and treats.

The environment analysis must cover all environment fields including the economic, political, social, cultural, regulatory, and technological environment.

3. Market and product analysis: It is very important that MNCs do analysis of the market and products, because the market analysis phase demonstrates the best approaches used in microanalysis, and requires a strict product orientation.

\footnotetext{
${ }^{36}$ Peter J. Buckley, Op. Cit., P.48

${ }^{37}$ H.P. Holzer \& H.M. Schoenfeld, 1987, P. 225

${ }^{38}$ Ibid, P.226
} 
4. Competitor analysis: The competitor analysis considers all aspects of the competition, and attempts to determine the strengths and weaknesses of all major competitors. This calls for a diagnosis of all business functions and even an assessment of the strategy pursued by these firms. Therefore, this analysis usually includes data concerning the historical development, the financial performance and structure, the importance of particular products in competitor's portfolios, $\mathrm{R} \& \mathrm{D}$ policies, manufacturing plants, labor problems, cost structure, marketing approach, sales force, market development activities, expected product line changes, as well as management abilities, reward systems, and so on.

5. Analysis of subsidiary's strength and weaknesses: To analyze the subsidiary, the MNC considers all factors previously mentioned for competitor analysis. The MNCs develop a plan for analyzing the subsidiaries, and they can apply this plan later to competitors. This system actually represents a comprehensive management audit of all functions and available recourses. The system should include a specific emphasis on the ability to respond to future challenges, in addition to the dependence on other subsidiaries of the $\mathrm{MNC}$ in order to fulfill a particular strategic mission. ${ }^{39}$

6. Formulation of the key strategies, individual plans, and budgets: To see the basic strategies of the MNC and a definition of the long- and short-term mission of subsidiaries, the collected information in the previous steps is usually shown in reports, schedules and graphic summaries.

Finally, all companies claim to have a long-term strategy development procedure. The plans in most MNCs are determined by the HQ, with the participation of all top managers and the managers of subsidiaries, thus, the allocation rules and determination of the objectives of each subsidiary must be regarded to achieve the general objectives of the MNC and to serve its world strategy. But in the case of full centralization, the subsidiaries are denied to participate in the strategic decision making.

\subsubsection{Strategy of controlling}

The control function in the MNCs is affected by the policies and orientations of the MNC management towards their foreign operations and subsidiaries. There are many classifications based upon the orientation of the MNC management towards the foreign

\footnotetext{
${ }^{39}$ Ibid, P232.
} 
operations and subsidiaries. Howard Permute proposed that the MNCs are classified into three classes or groups, in the frame of reference or attitude of the parent company:

(1) Home-country oriented (ethnocentric).

(2) Host-country oriented (polycentric).

(3) World-oriented (geocentric). $:^{40}$

The MNC that is home-country oriented (ethnocentric) is virtually dominated by the parent company. The standards, norms, methods, and attitudes of the parent company are employed throughout the system, including the foreign subsidiaries and branches as much as possible. Each subsidiary and / or branch is perceived as a small replica of the parent company. Also the overseas operating units are treated as extensions of the parent company rather than as foreign operations. All subsidiaries and branches are tightly controlled by the parent company, but with considering very little independence operation if necessary or needed.

In the case of home-country oriented, the MNCs accounting systems and reports would be specified by the parent company, except in those countries where laws and regulations dictate the official records to conform to criteria prescribed by the host country ${ }^{41}$. In the last case, two sets of records are usually be maintained (the official set to satisfy the host country and the set prescribed and used by the parent company).

It should be apparent that a home-country orientation is a highly centralized concept of international operations that treats the subsidiaries in all host countries as they are located in the home country. Thus, this approach is suitable to the MNC when it has a highly centralized system at the parent company, especially in the establishment and the early years of the foreign subsidiaries and branches. According to this approach, the control and decision making require saving necessary information, which help to assimilate the variables that affect these decisions, the efficiency of the executing control also requires a good system for data flow and processing, and a reporting system through communication channels determined by the HQ. But this strategy is only beneficial in a very short-term. The problems of time, distance, size, lost opportunity and social responsibility would eventually require a change of attitude.

\footnotetext{
${ }^{40}$ G. G. Mueller, H. Gernon, and G. Meek, Op. Cit., P. 127

${ }^{41}$ Elwood L. Miller, Op. Cit., P13
} 
Host-country orientation (polycentric): This approach assumed that the local circumstances, conditions and environmental variables and factors in the host countries are different from those in the home country, and the MNC must consider them in the performance evaluation of the foreign subsidiaries and branches. According to this approach, few business methods or attitudes can be universally employed with success. Most parent companies usually find that their subsidiaries and branches must adapt in many ways the local circumstances, conditions, markets and the environmental variables and factors in the host countries. Additionally, the problems of the size, distance, communications, geographical spread and the compliance with the local law firstly require that the MNC loosen the extent of structure and control, and consequently providing a degree of independence to its subsidiaries and branches.

This approach is conformable to decentralization, where the HQ management of the MNC tends to delegate the management of subsidiaries and branches in a high level of freedom in decision making according to its interests and the environmental circumstances in the host countries. Thus, the HQ of the MNC adopts a flexible concept of control including the standards and measures relevant to the environmental circumstances and variables that affect the performance of foreign subsidiaries and branches management

The accounting systems would also follow the host-country orientation. So that the accounting systems in the foreign subsidiaries and branches would be designed to serve some purposes: compliance with the laws and regulations of the host countries, management orientation, in order to provide the information needed by local managers to compete and adopt to changes in the local environments, and financial orientation, to enable the parent company to monitor and respond to those variables critical to the wellbeing of the MNC, as well as to facilitate preparation of the consolidated financial statements. ${ }^{42}$ This approach requires multi-reports system including many subsystems, but depending on one information system to provide the information needed by both the subsidiary management and the HQ.

The world or global orientation (geocentric): The goal of this approach is to focus on worldwide objectives and to consider foreign subsidiaries as a part of a whole. To accomplish this goal, corporate managers try to establish standards for evaluation and control that are both universal and local. This approach represents the full development of the MNC, where the management of the MNC adopts an international viewpoint at its

\footnotetext{
${ }^{42}$ Ibid, P14.
} 
decision making. Here, the foreign subsidiaries and branches in the host countries are considered as parts of the MNC, and they contribute in achieving global objectives as the local subsidiaries and branches in the home country. Thus, the standards of control and performance evaluation must be global and flexible, where the MNC can apply these standards in each subsidiary according to its environmental circumstances (e.g. each subsidiary can obtain the production requirements from the local market where it operates with less cost by, and also sell the product by some subsidiaries, which the tax law in its host country allows tax reduction on the international income of the MNC).

The organizational structure of the MNC must facilitate the global coordination of decisions, while at the same time being able to respond to the demands of the host governments and the local consumer. Operating with geocentric attitude is an ideal model not achieved by many MNCs. ${ }^{43}$

But some trade-offs would be involved, of course, since no country can attest the best accounting framework. ${ }^{44}$ The real constraints would be likely related to political, legal, and tax matters; and these will require more subjective analysis, and a wide recognition and appreciation of the interdependence of the world economy, regardless of ideologies.

\subsection{Challenges of Multinational Companies (MNCs)}

The previous attributes of the MNCs may seem to portray the MNC as a huge, powerful, stable, dynamic, flexible, technological monopoly, with a monolithic structure subject to few real controls and, therefore, faced with few challenges. But it is not true altogether. In fact, the MNCs are faced with the following challenges in practice:

The governments of the home and host countries: They represent the first challenge of the MNCs. In the game of international business the host governments hold four effective things. These four things are: the power to legislate, to tax, to expropriate, and to use “immoral suasion", to coin a phrase ${ }^{45}$.

The legislation: The legislative power of the host country is the key factor, because it can restrict or motivate the MNCs. In the beginning, the host government can determine the

\footnotetext{
${ }^{43}$ G. G. Mueller, H. Gernon, and G. Meek, Op. Cit., P.129

${ }^{44}$ Elwood L. Miller, Op. Cit., P.15

${ }^{45}$ Ibid, P.23
} 
factors to be permitted to enter the country, and particular economic areas. Also, the host government can use various forms of legislation to control the operation, foreign-exchange holdings, dividend remittances, interest rates, and other fees charged by the parent or subsidiaries. In short, the host government can essentially determine the rules under, which the game is played. Of course, the rules can be drawn in order to totally exclude the foreign participation, but action like this would also exclude the opportunity for the economic benefits that the foreign firm might provide.

Taxation: While speaking about tax we should know that there is a conflict between the MNC and the host government. The MNC wants and tries to reduce the tax charge to the minimum, and to maximize the net income after tax, because maximization of the net income after tax is considered as a strategic object of the MNC. For achieving this object, the MNC does all its best to reduce (or avoid) the tax charge to the minimum, by using some methods such as transfer pricing between subsidiaries, or/and between the subsidiaries and the $\mathrm{HQ}^{46}$. Also the MNC tries to reduce the tax charge by benefiting from some laws concerning the reduction of the double taxation.

On the other hand, the host government wants to collect the maximum of tax as much as possible. Various forms of taxation represent the most direct and visible sharing by the host government of the economic activity created by the foreign firms. The ability to tax is also an effective factor that can restrict or motivate the economic activity and, like legislation, can be used to change the game rules, whenever the host government wants. This is particularly true in the sectors, in which different tax rates or schemes are applied to the domestic and foreign firms.

The expropriation: The host government has the ability to expropriate or take over any foreign firm operating in its land. The expropriation is an "ace card" in the hand of the host government; it can use it whenever it is needed. Whether conducted with or without eventual compensation, the act of expropriation puts an end to the game. ${ }^{47}$

The immoral suasion: Also the immoral suasion is a challenge for the MNC. It is a feature to which none of the players in the game will admit, and much like the proverbial "little man who wasn't there", most of the participants wish it would disapear. Pressures or

\footnotetext{
${ }^{46}$ Hood, N. \& Young S., Op. Cit., P.210

${ }^{47}$ Elwood L. Miller, Op. Cit., P.24.
} 
coercion applied to cause certain actions to be taken or avoided, can be effective in the short run, but they leave scars that are subsequently remembered when the circumstances change $e^{48}$.

Each MNC contemplating establishment of a foreign subsidiary is aware of the foregoing four factors (the legislation, taxation, the expropriation, the immoral suasion), which give the host government the ultimate ability to control the game or bring it to an abrupt halt. Thus, host governments represent the formidable adversaries; because they are the source of most problems confronting the MNC. But the MNCs attempt to asses the probability of such actions in conjunction with other economic and environmental variables involved, to determine the degree of risk associated with the venture. Also, the political roles of the host governments are as significant as the economic and technical complexities affecting the risks of the foreign ventures.

Although there are charges for the host governments by the MNCs, there are also some charges for the MNC by the host governments, such as: being above any government, abrogating the sovereignty of the local government, evading tax, competing unfairly, fostering technological dependence, lacking social responsibility, disrupting the foreign exchange markets, destroying stability of the labor markets, and exploiting the local resources and capital.

The competition: The second challenge facing the $\mathrm{MNC}$ is the competition from another company having similar strengths and options. Competition, whether local or international, is certainly not a new phenomenon for most businesses. The MNCs are depicted as having an edge on the local competitors, and this is generally true. The MNC is also accused of undercutting the local competition where it exists, knowing that the temporary losses can be sustained until the time the local competition is disposed. The MNCs often try to have this potential for dominance in most local market areas. The MNCs also use unfair transfer prices in order to support the charged local prices.

The competition, whatever it is, is met by the MNC primarily in the developed countries and, often originates from one or more of the fellow MNCs. In those arenas there are few holds barred, and the more efficient firms will prevail. The real competition for the MNC

${ }^{48}$ Ibid, P.24. 
is not often encountered in developing countries. The MNC will be authorized to enter the economic area of the developing countries that simply is not tractable with the local capital and technology.

Also, the firms in the host country may resort to entry-forestalling practices, reducing prices or taking political action to protect domestic industry from foreign investors ${ }^{49}$. In these situations, the competition is not direct but indirect, concerning primarily the importation of certain resources and secondarily the allocation of the exported products. It is not unusual for the perceived best interests of the MNC and the host country to be divergent in some of these instances. The most appropriate solution is afforded by joint discussions and resolution of all expected problems prior to inception of the investment by the MNC, with joint consideration of unexpected problems as they arise. Price controls by the host governments have not proved to be practicable, since the MNC has access to the world markets and has the ability to use transfer pricing as an advantage. ${ }^{50}$

\subsection{Criticisms and praise (disadvantages and advantages) of MNCs}

\subsubsection{Criticisms (disadvantages) of Multinational Companies (MNCs) ${ }^{51}$}

1. They are selfish, short-term greedy and tend to exploit national resources.

2. They create tensions in the host countries in the political, social and economic aspects.

3. They foster excessive nationalism and anti-company feelings.

4. They exercise arbitrary control over their operations in the host countries to the exclusion of local factors.

5. They constitute crippling competition to the local enterprise.

6. They possess strong economic power and thereby exert unfair pressures and gain unfair advantages.

7. They tend to achieve economic domination over smaller economies.

8. They sometimes practice unethical business methods, such as pricing speculations, excessive royalties, loss accounting.

9. They tend to aggravate the host country's currency situation.

10. They have adverse effects on the motivation of their own staff, by the impersonal stratification of controls, thus stifle initiative and encourage risk avoidance.

\footnotetext{
${ }^{49}$ Peter J. Buckley, Op. Cit., P.34 .

${ }^{50}$ Elwood L. Miller, Op. Cit., P.28-29.

${ }^{51}$ Victor Z. Priel, Op. Cit.,P57.
} 
11. They export capital and thereby jobs to the foreign countries.

12. They build up profits abroad at the expense of the home country.

13. They are insensitive to the local social and cultural values.

\subsubsection{Praise (advantages) of Multinational Companies (MNCs) ${ }^{52}$}

1. They ensure optimum utilization of resources both in their domestic and foreign companies.

2. They represent risk-taking enterprise for advancement, development and the provision of services.

3. They provide capital investments where urgently needed.

4. They assist the development of emerging nations and distant regions, by generating investment-multiplier effects and invisible trade.

5. They are leaders in innovation, business methods and financial practices.

6. They prove the validity of international cooperation and regional schemes.

7. They provide advanced training of staffs and opportunity for employment and career development.

8. They allow a wide participation on their investments, thereby contributing support democracy.

9. They assist in the balance of payments between developed and developing regions.

10. They lead to international mobility and trade.

11. They launch nations on a path of the self-sufficiency.

12. They provide a framework of interlocking operations and financial strategies.

\footnotetext{
${ }^{52}$ Ibid, P57.
} 


\section{Performance Evaluation of Multinational Companies (MNCs)}

\subsection{Definition of the Performance Evaluation}

The control system in any organization must include performance evaluation techniques which include gathering, summarizing, and analyzing information to determine whether goals are being achieved, and to prescribe the actions required to further those goals. We can define the performance evaluation as: "the periodic review of operations to ensure that the objectives of the enterprise are being accomplished" ${ }^{\text {"53 }}$. A corporation's performance evaluation system is considered as an important part of its financial control system. The MNC must have accounting information to evaluate domestic and foreign operations.

If the performance evaluation is a critical issue in the companies in general, it is a more critical one in the MNCs, because the development of the MNCs requires an accounting system that records and reports the results of worldwide operations of all subsidiaries in different countries, and every country may have a different economic, legal, political, technological, social and cultural environment different from the other countries. It means that, the foreign subsidiaries deal with different environmental factors and variables that affect the performance of subsidiaries and their managers. Thus, the MNCs must consider these different environmental factors and variables when they evaluate the performance of subsidiaries and their managers. Headquarters of MNCs must have information to evaluate the performance of subsidiaries all over the world.

The proper measurement of the performance of an individual, a division, a subsidiary, or even a company as a whole is not simple. The main reason for this is that different bases of measurement result in different measures of performance; that is how you choose to keep score affects the final score. In addition to this, many events affecting performance are not controllable by the subsidiary. ${ }^{54}$

The proper performance evaluation of MNCs requires to distinguish between the performance of the subsidiary and the performance of its management. Also, the proper performance evaluation of MNCs requires choosing a relevant transfer price for internal transfers between subsidiaries or subsidiaries and headquarters.

\footnotetext{
${ }^{53}$ G. G. Mueller, H. Gernon, G. Meek, Op. Cit., P.150

${ }^{54}$ Jeffrey S. Arpan \& Lee H. Radebaugh, $2^{\text {nd }}$ Ed., 1985, P248-249
} 
The performance evaluation systems should permit the parent's management: (1) to evaluate the economic performance of its international operations, this is frequently referred to as an evaluation of the unit's economic performance; (2) to evaluate the unit's management performance; (3) to monitor progress toward corporate objectives including strategic goals; (4) to assist the efficient allocation of resources. ${ }^{55}$

\subsection{Responsibility Accounting and Performance Evaluation in MNCs}

The concepts of responsibility accounting are devised to place performance evaluation into manageable contexts. Responsibility accounting merely defines spheres of reference (responsibility centers) that had control over costs and / or revenues and to which inputs (resources) and outputs (products, services, or revenues) could be traced. These responsibility centers varied in complexity of control, structure, and purpose. The responsibility centers can be classified as following:

3.2.1 Cost Centers: Insofar as controls and objectives are concerned, the cost centers are the simplest spheres of the responsibility centers. Control is exercised over incurred costs. Objectives normally call for the maximization of outputs, in quantity and quality, within the constraints on inputs specified by time and effort, standard cost, flexible budget, and similar systems. Structures vary from a single person, operation, or machine to the function of an entire plant. In practice, control and evaluation are enhanced by breaking down structures into smallest components exercising control over costs.

Responsibility reports should focus attention on costs that are controllable at the levels being addressed. Costs that are not controllable should be either separated or excluded. For example, any cost that has to be allocated arbitrarily among responsibility centers is considered to be non-controllable. All costs, of course, are controllable at some level in organization; the objective is to report each cost as controllable by the level exercising the authority to incur the cost.

Performance evaluations of cost centers are primarily financial and focus upon variances from predetermined standards. The better systems are based upon reasonably attainable standards, tailored to suit the responsibility centers, and revised as conditions change. Other quantitative, non-financial measures are often employed as well: number of reject products, machine breakdowns, employee turnovers, and alike. Qualitative assessments

\footnotetext{
${ }^{55}$ H. P. Holzer \& H. M. Schoenfeld, , Op. Cit.,P.9
} 
may be made by product engineers by using surrogate measures (such as using the numbers of grievances to judge employee attitudes), or all too often, by relegating assessments to consumers where products are concerned.

3.2.2 Revenue Centers: By definition, revenue centers can affect output levels (revenues) in relation to the inputs (resources represented in expense budgets), but no direct control is exercised over the costs of the products or services to be soled. Motivation and control are sought by means of budgeted revenues and expenses. The twin objectives are two maximize revenues while spending within authorized levels. Sales offices are typical revenue centers, often with further segmentation into product lines, territories, salesmen, and so on.

Performance evaluation usually begins with financial comparisons of actual and budgeted levels of revenues and expenses, after variable portion of the latter have been adjusted to reflect actual activity levels. Since the costs and qualities of the sold items are not controllable, appropriate adjustments should be made for any favourable or unfavourable effects caused by changes in these factors that are not recognized by budget revisions. Non-financial measures are also employed, although not necessarily in a systematic fashion (market shares, changes in sales mix, repeat sales, numbers of customers, quotas, calls made by salesmen, complaints, and others). The non-financial measures become increasingly important as inflation, which affects revenues expressed in monetary units.

3.2.3 Profit centers: The profit centers are units or divisions that have control over both costs and revenues. ${ }^{56}$ But this simple definition of the profit centers requires some crucial conditions relating to independence which are: (1) the unit must be free to produce or purchase the trade goods and services it requires where and when it wants. Decisions concerning investments (such as capital acquisitions and expenditures over specified amounts) are reserved for, or must be approved by, higher headquarters. (2) The unit must be allowed to market its outputs solely to external customers anywhere or within defined territories or regions. Selling prices and other marketing decisions must be controllable by the unit so that it may respond to the conditions in the outside marketplace.

\footnotetext{
${ }^{56}$ Miller, Elwood L, Op. Cit., P181.
} 
In fact, true profit centers are independent miniature businesses financed by a parent company. The interdependencies that exist among units of most complex organizations preclude the existence of many true profit centers.

Performance evaluations relate outputs (revenues) with inputs (costs and expenses) by focusing on profits (revenues minus identifiable expenses). Profit is an absolute measure that, standing alone, can be assessed subjectively acceptable representation or a poor one. Profit becomes a more meaningful measure when relative comparisons are also possible with budget with results of prior periods and with the profit of other divisions of the firm.

The measurement methods must measure the performances of bona fide profit centers and their managers. Problems result when divisions operating with significant interdependencies are converted into artificial profit centers, usually by the imposition of transfer prices containing pseudo profits. Such practices do not measure the performance profit of independent units operating in free markets, or the abilities of their managers to act in the best long-run interests of the total enterprise. Instead, margins created by the use of transfer prices and other cost allocations that are considered to be equitable and are imposed by top managements are equally measured. Also, profit can vary, favourable or unfavourably, because of a host of events is not attributable to segment manager's acting in the best interests of the enterprise as a whole.

Regardless of the inherent inequities cited, two characteristics of the profit (its simplicity and its power to motivate) have made it a favourite measure of the performances of operations and their managers. Unfortunately, the fictions, upon which most profit center evaluations are based, have not been taken seriously. If they would be considered, many domestic segments would no longer be cast in ridiculous roles as profit centers. The mythical need to concoct transfer prices in order to generate pseudo profits and equitable treatment among units would also have been eliminated. Attention must have been directed to isolating real measures of performance and appropriate standards, upon which evaluations could be based.

3.2.4 Investment Centers: Theoretically, investment centers are extensions of profit centers whose control is presumed over revenues, expenses, and the levels of assets employed in generating profits. All the requisites of profit centers apply, (freedom to purchase, produce and market) the control over capital acquisitions and expenditures. 
Few divisions of complex organizations are bona fide investment centers. Most enterprises reserve decisions on or approvals of major capital acquisitions and expenditures (over a specified amount) for the central headquarters. Many divisions are strategic as well as financial segments of the larger enterprise. They perform work and supply services for other divisions. They are often required to use common support services furnished by the headquarters. Levels of inventories and receivables usually are affected by their strategic roles (service for other units) and often are influenced (if not effectively controlled) by the headquarters. Where such conditions are given, consideration of the divisions as independent investment centers is absurd. If the domestic investment center is a fiction, perhaps it would not be surprising that the prevailing method of performance evaluation would also be a fiction.

\subsection{Separating Managerial and Subsidiary Performance}

It is also difficult but important to separate managerial performance from subsidiary performance. It is possible to have good management performance despite poor subsidiary performance, and vice-versa, again largely due to non-controllable. In other words, a manager may have done a superb job facing real adversities largely beyond his or her control, and although the subsidiary's performance did not measure up to the expectations, it would have fared even worse without the manager's Herculean efforts. Similarly, a subsidiary's good performance may have been due to considerable luck or occurred despite poor managerial performance. Thus, in order to properly reward and keep good managers and not inadvertently reward poor managers, the evaluation system must be able to separate subsidiary and managerial performance. ${ }^{57}$

Choosing the right system is therefore no easy task. Nonetheless, a system must be designed and implemented. Many of the larger U.S. MNCs have developed multiple measurement systems and computer models to assist in the separation of controllable and uncontrollable impacts. These models, for example, can estimate what the translated financial results of a foreign subsidiary would have been, if the foreign currency had not moved to this direction or magnitude that actually did. Earlier budgets can be recast using the actual exchange rates that were in effect as the year progressed, and than these recast budgets can be compared with actual results. Or actual results can be recast in terms of the

${ }^{57}$ Jeffrey. S. Arpan \& Lee H. Radebaugh, Op. Cit., P.251 
exchange rates that had been predicted earlier when the budget was prepared and then compared with the original budget.

To sum it up, if plans and budgets were properly prepared including expected ranges to allow major contingencies, comparisons of performance to the original plan and related budgets present viable and equitable methods to evaluate the performance. To some degree, it can also permit performance comparisons among units or managers, or both. For example, a subsidiary that achieved $95 \%$ of its planned activities and goals by utilizing $10 \%$ less funds than it had been allocated can be compared favourably to one that achieved only $90 \%$ of its goals and went $5 \%$ over budget (of course, all other factors are equal).

\subsection{The measures used for evaluating subsidiaries}

The MNCs use both financial and non-financial measures in performance evaluation of domestic and foreign subsidiaries as the following:

3.4.1 The financial measures: The MNCs use various measures to evaluate the results of their operations at home and abroad. In the last 25 years, U.S.-based MNCs have consistently reported using three measures more frequently than any others: (1) profit, (2) budgeted profit compared to actual profit, and (3) return on investment (ROI). Although the rankings of these measures change over the time, the three most used frequently measures have remained the same. ${ }^{58}$

The U.K.-based MNCs use the following measures: (1) budget versus actual profit, (2) return on investment, (3) budget versus actual return on investment, (4) cash-flow potential from subsidiary, and (5) profit. But the three most frequently used measures are (1) 1) budget versus actual profit, (2) return on investment, (3) budget versus actual return on investment. We notice that profit, which is the most frequently used measure by U.S. MNCs, falls to fifth place when we look at the operating environment of the U.K. Both return on investment and budgeted to actual return on investment are important for U.K. managers.

Return on investment (ROI): Return on investment is the most common measure to evaluate the performance of the domestic and foreign subsidiaries as investment centers. Return on investment (or rate on return) is a method that relates profit with the resources

\footnotetext{
${ }^{58}$ G. G. Mueller, H. Gernon, and G. Meek, Op. Cit., Pp150-151.
} 
employed in their generation, that means with the relationship of profit to invested capital. Return on investment indicates how efficiently capital has been employed by the company during a period of time, usually one year.

Development of the concept of the return on investment is attributed to the DuPunt Company and for many years was known as the "DuPunt formula". Virtually all major decentralized domestic corporations use some version of return on investment as a primary measure of the performances of divisions and their managers.

There are two general forms of the return on investment have been employed for evaluating the investment centers. The first form employed to evaluate the division is:

$\mathrm{ROI}=$ division return (segment margin) / investment in division.

The second form employed to evaluate the division manager is:

ROI = division controllable return (manager's contribution)/controllable investment.

The measure of return on investment (ROI) has the following advantages: (1) it encompasses all the important factors in a single measure, (2) it is simple to compute from conventional financial statements, (3) it measures the overall efficiency, since it relates results (operating income) with inputs (resources used), (4) it is a common denominator that can be used for comparative evaluations, both internally (with plans, other divisions, prior periods, and trends) and externally (with similar ratios for the industry, other firms, and other opportunities); and (5) it is a logical motivator of managers, since, if they know they will be evaluated by ROI, they will act to maximize the ROI of their units. ${ }^{59}$

Budgets as a success Indicator: For some time, budgeting has been accepted as a management tool for controlling operations and forecasting future operations of domestic companies. One purpose of the budget is to clearly set out the objectives of the entity. A budget generally provides a forecast and a means of comparing the actual results of operation to the budget. This comparison produces variances that can be analyzed to evaluate performance and improve the efficiency of future operations.

When a budget is used for a foreign subsidiary, the budget should be developed by that subsidiary. The experience of the local manager is extremely important, with that it provides a very deep knowledge of the specific business situation. A budget developed on

\footnotetext{
${ }^{59}$ Miller, Elwood L, Op. Cit., P185.
} 
this level will help control the operations and make achievement of goals possible. This budget can be used by the local manager on a daily basis.

Budgeting gives local managers the opportunity to set their own performance standards. In international operations, the top management is not familiar with what the standards should be. Headquarters must rely to a greater extent on good local or regional budgets, which help facilitate the strategic planning process.

Preparation of the budget at the local level is not always an easy task. Local managers have different degrees of budgeting expertise. Local customs and norms may affect the budgeting process and are likely to affect the degree of its acceptance and usefulness. Implementation of a system is also difficult due to a lack of the familiarity with the technique on the part of local employees of foreign subsidiaries. Budgeting may be a more critical performance evaluation tool for international operations than for domestic ones.

Headquarters uses each foreign subsidiary's budget to develop a worldwide and company wide forecast. Headquarters analyses are based upon a wide spectrum of knowledge, including knowledge of possible environmental, objective, and strategic changes at the international level. At this headquarters level, profit and return on investment provide the information, which is necessary to assess worldwide profitability and its success or failure. Budgeted information is used more frequently to assess the individual subsidiaries performances rather than the overall performance of the MNC.

The subsidiaries' budgets are approved at parent-company level and often require the endorsement of the president and/or the broad of directors. Presumably, headquarters uses the budget to consider the circumstances peculiar to each subsidiary. However, as noted above, executives repeatedly return to the ROI statistic. They may use the budget for supplementary information on subsidiary performance; but, they still select ROI as a key success indicator.

3.4.2 The non-financial measures: In addition to the financial measures, the MNCs also use non-financial measures to evaluate the performance of subsidiaries. The table (3-1) lists several non-financial criteria that U.S.-based MNCs use in their performance evaluation system. These criteria are considered important; despite the difficulty one might have in trying to measure them. For example, it is difficult to place a numerical value on "cooperation with parent company." 


\begin{tabular}{|l|c|c|}
\hline \multicolumn{1}{|c|}{ Non-financial Measures } & \multicolumn{2}{c|}{ Average Importance } \\
\cline { 2 - 3 } & Subsidiary & Manager \\
\hline Increasing market share & 1.8 & 1.5 \\
Relationship with host country government & 2.1 & 1.8 \\
Quality control & 2.2 & 1.9 \\
Productivity improvement & 2.2 & 2.1 \\
Cooperation with parent company & 2.4 & 2.0 \\
Environment compliance & 2.4 & 2.3 \\
Employee development & 2.4 & 2.0 \\
Employee safety & 2.4 & 2.2 \\
Labour turnover & 2.7 & 2.5 \\
Community service & 2.9 & 2.8 \\
Research and development in foreign subsidiary & 3.1 & 3.2 \\
\hline * 1 = Very important 2 Important $3=$ Less important & $4=$ Not important
\end{tabular}

Table (3-1): Non-financial Measures Used to Evaluate Performance of Subsidiaries and their Managers ${ }^{60}$

As we see in the table (3-1), market share is considered as the most important non-financial measure. Other important items are productivity improvement, relationships with host governments, quality control, employee development, and safety. Community service, research and development are considered as less important.

\subsection{The past researches and studies on performance evaluation of MNCs}

1960s the international operations have become more important, and the MNCs have begun to recognize the importance of performance evaluation systems. On the other hand, the scholars and researchers are very interested in the issue of the performance evaluation of international subsidiaries. The review of the literature is intended to present a historical introduction to the issue of the performance evaluation of international subsidiaries, and to know the good and weak aspects of this literature in order to benefit from the good aspects and to overcome the weaknesses as much possible as in this research. In the following I will present and discuss the most important researches and studies in the literature on the performance evaluation of the MNCs.

${ }^{60}$ G. G. Mueller, H. Gernon, and G. Meek, Op. Cit., Pp.153. 
35.1 Hawkins (1965): In the paper published in 1965 Hawkins reported that most U.S. companies with overseas subsidiaries use the same system for the control of foreign operations that is used for the control of domestic operations. The primary reason given was that the system is less expensive, that the information can be readily consolidated, and that the domestic executives are more comfortable with a system they are already familiar with. But Hawkins also reported that these exported systems are seldom as effective internationally as they are at home, because (1) the objectives of the foreign subsidiaries are often not identical to the goals of domestic operations, (2) there are organizational and environmental differences and different economic factors, and (3) the foreign operations are usually not as independent as domestic profit centers. ${ }^{61}$

3.5.2 David Zenoff (1967): In 1967 David Zenoff reported the results of interviews with the financial executives of thirty prominent U.S. - based MNCs. He claimed that at that time, many foreign operations were considered as "step children" as tools for tax minimization and as "cash cows". Only a few companies viewed their overseas subsidiaries as bone fide business operations and had developed a long-term international outlook. At that time, the U.S. MNCs were primarily concerned with the safety of their overseas investment and the related cash flows. Long-term profitability apparently was a secondary issue, and little attention was paid to problems of its measurement

3.5.3 Mauriel (1969): The Mauriel survey (1969) was one of the earliest surveys dealing with the performance measurement and control systems of international operations. He reported the results of interviews with fifteen large MNCs. Some of the important findings were that the domestic financial control systems of the MNC were used without modification in the foreign operations. The concepts of the profits center were applied, and return on investment (ROI), as well as residual income (RI), was growing in popularity as a measure of performance, but frequent profit on sales was considered as a more important measure. The companies felt that it was too early to be periodically examining ROI because their foreign operations were fighting to establish a foothold in new markets. ${ }^{62}$

3.5.4 McInnes (1971): In his survey in 1971 McInnes analyzed the financial reporting and evaluation systems of thirty U.S. MNCs. It was found that only minor differences existed among the reporting systems used by the domestic and foreign units. It can be considered

\footnotetext{
${ }^{61}$ David E. Hawkins, (February 1965), PP.25-32.

62 John J. Mauriel, (may 1969), PP.35-39.
} 
as significant, that approximately $50 \%$ of the firms required reports in both dollars and local currencies. The most frequently used evaluation measures were ROI followed by budget comparisons and historical comparisons. ${ }^{63}$

\subsubsection{Edward C. Bursk \& Others study (1971): The Financial Executives Research} Foundation (FERF) study in 1971 covered thirty-four MNCs. An interesting finding was that the primary emphasis had shifted to a comparison of actual versus budgeted profits. ROI followed by a comparison of actual and budgeted sales ranked next in popularity. The study strongly recommended that methods should be developed to permit separate evaluation of the performance of managers from those of their activities. ${ }^{64}$

3.5.6 AAA (1973): The report of the American Accounting Association Committee on International Accounting represents the most comprehensive theoretical analysis of financial control and reporting problems of the MNC. The committee attempted to identify the differences in modes of operations between domestic and multinational companies and describes in detail financial control, reporting, and other accounting problems peculiar to international operations in this context, they also analyzed performance problems. The most important results of the committee's comprehensive analysis are : (1) the approach of profit center is usually not appropriate because overseas units lack independence, because they have not sufficient control over profit influencing factors, and (2) profits are too much influenced by transfer prices which are also presumed outside the control of the subsidiary manager.

The committee suggests the use of a budget-based approach, which should include a careful distinction between controllable and non-controllable variances and thus allow a distinctive evaluation of managers and units. They also suggest the use of additional nonfinancial quantitative measures (for example, employee hours of executive training) and management and performance audits. For transfer pricing, they suggested a system of two or more transfer prices, each serving a different purpose. ${ }^{65}$

3.5.7 Robbins and Stobaugh (1973): In a survey in 1973, Robbins and Stobaugh interviewed representatives of thirty-nine enterprises to identify their evaluation practices

\footnotetext{
${ }^{63}$ J. M. McInnes, Journal of International Business Studies, Fall 1971, PP.11-21.

${ }^{64}$ Edward C. Bursk, et al.,1971. P.25.

${ }^{65}$ A. A. A., 1973, PP.120-167.
} 
of international operations. They found out that $95 \%$ of firms evaluate foreign units in exactly the same way as they do with domestic units and that no distinction is made between the evaluation of the managers and the unit. The principal used measure was ROI. Budgets were utilized for supplementary information purposes only. The survey indicated that $44 \%$ MNCs measured in foreign currencies, $44 \%$ in U.S. dollars, and $12 \%$ used both of the foreign currencies and U.S. dollars. Robbins and Stobaugh recommended that ROI is replaced by a budget-actual-comparison with objectives developed individually for each subsidiary. They also pleaded for the use of so-called secondary criteria, individual elements of budgets, related to the strategic objectives. ${ }^{66}$

3.5.8 Persen and Lessig's (1979): Persen and Lessig's Financial Executives Research Foundation study in 1979 covered four hundred U.S. MNCs. From the 400 questioned, 125 responded. The questionnaires were followed by interviews of executives with twenty companies. The study objective was the evaluation of systems used for wholly owned, overseas subsidiaries over a certain time. In other words, the executives were queried about the evaluation techniques they employed at that time, five years before and five years after. The major result was the lack of uniformity in approaches. The systems varied because the environmental differences were considered, changes in these factors were noted, and judgment was used to supplement objective quantitative measures. Although the operating budget comparisons seemed to be the most prevalent at the beginning of the period covered by the research, ROI becomes an important measure in the last five years. Also the study indicated to other interesting results about the international operations, that return on sales was rated higher than for domestic operations. Inflation-adjusted ROI had gained increasing acceptance by the end of the period.

For the companies with high percentage of international sales, the most common transfer pricing base was cost plus mark up. The other financial measures used were contributions to earnings per share, corporate cash flow, and discount cash flows or internal rate of return (IRR). $58 \%$ used both local currency and parent currency in measuring performance criteria. Some non-accounting measures were market share, quality control (important especially in cost centers), and labour turnover. These measures were primarily used for the evaluation of the individual managers. ${ }^{67}$

\footnotetext{
${ }^{66}$ Sidney M. Robbins and Robert B. Stobaugh, 1973, PP.80-88.s

${ }^{67}$ William Persen and Van Lessig, 1979, PP.60-72.
} 
3.5.9 Morsicato (1980): Morsicato studied seventy MNCs in the chemical industry to determine how these companies evaluate the internal performance of their foreign managers. The most commonly used measures were in U.S. dollars, the used measures included profit, ROI, budgeted versus actual profits, budgeted versus actual sales, cash flow potential, budgeted versus actual ROI and RI. Whenever foreign currency was used to measure performance, the list was headed by budgeted versus actual profits.

The study indicated that the MNCs still used more U.S. dollar information for international evaluation purposes, although the most executives believed that the foreign currency statements provide better information for the evaluation of the subsidiaries and managers. In the majority of cases, the study results indicated that the same basic techniques were used for the evaluation of the foreign units and the evaluation of their managers. ${ }^{6}$

3.5.10 The Czechowicz study (1982): The study covered eighty-eight MNCs; twenty-four of them were European based companies. They were first surveyed by questionnaires; responses to questionnaires were then supplemented by personal and telephone interviews, and three roundtable discussions (which included participants of U.S. based companies).

One of the more important results was that both European and U.S. companies established foreign operations for strategic reasons. Both of the companies viewed the foreign operations as a part of an integrated system, although the European -based MNCs seemed to allow their foreign operations a greater degree of autonomy in terms of organization than U.S. companies. The difference in the style seemed to be reflected in the way which the performance is measured by it.

The study indicated that the employed Performance criteria were both financial and nonfinancial criteria. The financial criteria tended to dominate and most popular were budget comparisons, followed by ROI. For the non-financial criteria, market share and relation with the host governments were the most important aspects. Both U.S. and European MNCs considered budgets and historical performance of foreign useful standards to compare the performance of the foreign units and managers. European MNCs tended to attach more importance to the performance of local competitors as a benchmark than the U.S. MNCs. Few companies made a clear distinction between the evaluation of the

\footnotetext{
${ }^{68}$ Helen Gernon Morsicato, 1981, PP.123-183.
} 
manager and the unit. Approximately the same measurements were used, although additional judgmental factors seem to be considered when evaluating the managers.

Although the criteria seemed similar, the employed measures (budget and ROI) varied. The U.S.-based companies used both pre-tax and after-tax data in the evaluation ROI and return on total assets (ROA). The European companies tended to emphasize pre-tax numbers.

The U.S. companies were separated in the question, whether to include headquarters' expenses and foreign exchange adjustments in the reports of the foreign subsidiaries. The European companies tended to exclude them. The opinions differed about the issue, whether inter-company services should be allocated to foreign operations, and which are the methods to be used. The European companies tended to allocate less frequently than the U.S. MNCs.

The U.S. companies tended to employ a parent currency perspective when evaluating both the foreign unit and its manager. The transaction gains and losses were generally included in the evaluation for both units and managers. The unit managers were held accountable for those gains and losses since they had the authority to hedge this form of risk. The U.S.based MNCs sometimes assigned the translation gains or losses to units and managers while the European-based MNCs did not.

For the inflation adjustments, in the case of the U.S.-based MNCs, the formal incorporation of the inflation adjustments was limited to the budgetary process. The assets were not re-stated. The non-U.S. MNCs had a far more comprehensive approach. It seemed that there is a European consensus that the inflation-adjusted numbers provide more useful measures of the performance than the unadjusted cost figures.

For the transfer prices, the U.S. MNCs tended to use cost-based transfer prices, and these were usually set by the headquarters. The non-U.S. companies generally employed market value to set transfer prices, and this was subject to negotiations by subsidiary managers. In general, the same transfer price was used for the internal performance evaluation and tax purposes.

Most MNCs - both the U.S. and European - did not incorporate risk into their performance evaluation system. The significant minority usually added a subjective risk premium to the performance standards for the foreign operations. 
The most MNCs expressed satisfaction with their evaluation systems of domestic and foreign operations. Only a small minority thought that their system led the overseas managers to suboptimal behaviour, with $14 \%$ of the U.S. MNCs and $21 \%$ of the non-U.S. MNCs believing that there was room for improvement in their systems. $20 \%$ of the U.S. MNCs and $33 \%$ of the European MNCs expected that their existing performance evaluation systems would be modified in the future. The most cited reason for this was the foreign inflation.

Concluding, the study recommended that the systems should be evaluated and, if necessary, modified to ensure short-term goals and that related incentives conform to strategic goals. ${ }^{69}$

3.5.11 Donaldson and Pai (1984): Donaldson and Pai describe the Burroughs system. Burroughs has subsidiaries in countries with chronic inflation (Brazil, Mexico, and Argentina), in countries with currencies that have strongly devalued with respect to the dollar, and in countries such as Germany and Japan with stable currencies. This is in addition to other differences in the cultural, political, and economic environment. Donaldson and Pai list nine important characteristics of the performance evaluation. Some of the more important characteristics are as the following:

1. It should define "the performance", for example, orders and sales, timely delivery, quality, and so on.

2. The criteria used should be measurable and not abstract factors, for example, if the customer satisfaction is an important criterion, order and lease cancellation may be used as surrogate measurable.

3. It should clearly define accountability, for example, responsibility for cancellation cannot be assigned unless the cause is determined (sales person of manufacturer?).

4. It should show positive as well as negative performance; emphasis should be on motivational rather than punitive aspects.

5. It should be aggressive yet fair and flexible (we can readily understand this given because of the rapidly changing conditions in the international environment).

6. It should help management to anticipate problems in time in order to take corrective actions. The system should monitor performance against corporate targets.

\footnotetext{
${ }^{69}$ I. J. Czechowicz, F.D.S.Choi and V.Bavishi, 1982, PP.11-25.
} 
Burroughs uses both financial and non-financial criteria, the examples of the later are orders, productivity, employee turnover, profit, cash flow, contribution margins, ROA, receivable days, inventory levels, and manpower.

But I think that the criteria of profit, cash flow, contribution margins, and ROA are not non-financial criteria, but they are financial criteria.

Burroughs uses a U.S.-dollar perspective for all financial criteria. It wants to motivate subsidiaries to maximize U.S.-dollar results. The transaction gains and losses are excluded from subsidiary evaluation. The corporate services such as research and development $(\mathrm{R} \&$ D) management and royalties are allocated, but only on the basic of budgeted numbers. Depending on conditions, before-and after-tax profits are used (for ROI). ${ }^{70}$

3.5.12 Monsanto Company (1984) ${ }^{\mathbf{7 1}}$ : The Monsanto Company, like most MNCs, attempts to apply the same criteria to evaluate domestic and ex-U.S. operation wherever they are practicable and realistic. The measures applied to ex-U.S. activities tend to be as varied as their mission statements. The earnings and related financial measures of efficiency (sales, assets management, product costs, return on capital, cash flow, and so on) are applied to subsidiaries and other free-standing operations. For more dependent activities, less comprehensive financial measures, from operating incomes to simply gross margins, are used. For support units, operating costs tend to be the only practicable financial measures. All of these are monitored monthly and evaluated annually. The non-financial measures consist of approved operating budgets, standard costs, MBR (Management By Result) programs, local economic and market data (if available. The criteria for evaluations of exU.S. managers parallel those used in the United States wherever they are.

For the currencies used to measure criteria, the financial performances of all free-standing units, domestic and ex-U.S. of Mansanto company are made in U.S. dollars, because the investors contribute U.S. dollars and expect returns in U.S. dollars, in form of dividends and stock appreciation affected by consolidated financial results. The managers of ex-U.S. operations have a shared responsibility for exchange rate fluctuations. Forecast rates (and projected local prices) are used in approved budgets. Actual rates (and actual local prices) are used in tracking and evaluating financial performances. This approach involves the

\footnotetext{
${ }^{70}$ Howard M. Donaldson and amar K. Pai, 1984, PP1-22.

${ }^{71}$ H. P. Holzer \& H. M. Schoenfeld, , Op. Cit., PP 46-48.
} 
local managers in exchange-rate fluctuations and encourages them to adjust selling prices in line with changes in exchange rates, as well as, local inflation wherever possible.

Treatments of exchange-rate fluctuations differ. The total variances are ascribed to activities. For manager evaluations, primary emphasis is placed on the management responses through changes in local market prices. In the past, Monsanto was not overly concerned with exchange rate exposures or fluctuations. Monsanto was operating with more than 100 currencies, and it considered itself hedged internally. After the implementation of SFAS-8 of the FASB in 1976 the resulting "paper or accounting gains and losses" had significant adverse effects on reported earnings per share. In 1982, Monsanto adopted SFAS-52 of the FASB for financial reporting purposes. This and other changes in financial reporting requirements have minimal impact on activity evaluations, however, and are not used to evaluate the managers.

For the transfer prices and inter-area sales, in the main, Monsanto Company used the market prices for intra-corporate transfers regardless of location. Where unavailable or otherwise impractical, transfer prices are negotiated by the units involved. In certain cases where transfer prices must be managed for whatever reason ex-post adjustments are made to the activity and manager evaluations concerned.

For the charges of Mansanto Company, wherever practicable, the charges of corporate, company, divisional, and area of Monsanto are made directly to the using organization. Residual charges are assigned to units by means of an elaborate allocation system. As might be expected, both types of charges produce complaints from the field units regarding the absolute amounts of the charges, their determination, and their non-controllability by field managers.

For the income taxes, Monsanto Company used the foreign income taxes in the evaluations of activities and their managers. The provisions for U.S. income taxes on the foreign earnings are not that much considered; because the Monsanto company normally intends to use ex-U.S. earnings to finance ex-U.S. growth as opposed to repatriations in the near term.

3.5.13 GoldStar Electronics Company: K. Won Kang (executive vice president, GoldStar Co. Inc.) and Soong H. Park (assistant professor of accountancy at the University of Illinois) describe and examine the planning and evaluation system, with an emphasis on the 
mission and evaluation of the overseas subsidiaries of GoldStar Electronics Company as the following.

The core of the evaluation system is the profit center concept used in organization of the company. While all the divisions are evaluated based on a unique set of multiple criteria, some of the considerations given to selection of the evaluation criteria used for the profit centers are the following:

1. Due to the different impact of environmental factors and market conditions, unit-to-unit comparison is between the planed and the actual as well as between profit centers.

2. To discourage the short-term maximizing behaviour, short-and long-term objectives will be evaluated simultaneously.

3. To recognise the uniqueness of each profit center, a unique set of evaluation criteria will be selected for each profit center.

4. To assure balanced growth, balanced satisfaction of all selected criteria will also be evaluated.

5. In addition to the evaluation based on the planed versus actual within each profit center, each centre's contribution to the company's revenue and profit will be evaluated.

Each profit center selects six performance measurement indexes, in consultation with the planning and evaluation office and classifies them into key, primary, and general indexes to reflect the priorities of each profit center. For example, the evaluation indexes of a profit center such as television, electric appliances, audio equipments, and electric motors are: net income and production quantity as key indexes, product development and product quality as primary indexes, and product cost and investment as general indexes.

In addition to the structured measurement indexes, each profit center reports the contributions made to other profit center units in the areas of administration, technology, facilities and machineries, and man power. The company decided to leave a certain amount of flexibility in the evaluation of profit centers and the responsible executive, in order to encourage the future-oriented outlook and the awareness of the changing environment.

For the evaluation of the overseas subsidiaries, there has not been developed formal performance measurement system, but GSEI (a subsidiary as a marketing unit in U.S.) for evaluating the managing director of export sales, it sets four major objectives concerning with prompt delivery, after sales service, product development, and productive 
management. Given these objectives, the Export Sales Division has chosen the following indexes as the performance measures: sales growth, new market development, and profitability. Also GSAI (a subsidiary as a manufacturing division in U.S.) is evaluated based on the same criteria used for other manufacturing facilities. Since the U.S. government imposed several barriers, which made the import sales of Koreanmanufactured colour television sets more difficult, the GSEI became more dependent on GSAI as the primary supplier, and the current key index for GSAI shows its ability to produce sufficient quantities of sets in time. ${ }^{72}$

3.5.14 Abdullah \& Keller (1985): This study covered 64 MNCs to determine the financial measures used in performance evaluation of the foreign subsidiaries and their managers, and also to determine whether the systems of performance evaluation were designed to reflect the environmental differences in the different host countries.

The study reported that the selected MNCs use many criteria for performance evaluation. The study results indicated that $86 \%$ of the companies used budget compared to actual profit, $78 \%$ of the companies used the absolute profit, $74 \%$ of the companies used the return on investment (ROI), and 66\% of the companies used the budget compared to actual ROI.

For the performance evaluation of the managers of the subsidiaries the study indicated that $87 \%$ of the companies used the budget compared to actual profit, $67 \%$ of the companies used ROI , 66\% of the companies used absolute profit, and $64 \%$ of the companies used budget compared to actual ROI. The study also indicated that $82 \%$ of the companies used the same technical methods and tools to evaluate both the performance of the subsidiaries and the performance of their managers, although the performance evaluation of the managers of subsidiaries requires to concentrate only on the factors and variables that are under control of them.

The question whether the systems of performance evaluation in the selected companies were designed to reflect the environmental differences which may have different effects in the host countries, the results of the study reported that $14 \%$ of the companies answered that their systems does not reflect any influence of the environmental factors. While $23 \%$ of the companies answered that their systems reflect a very small influence of the

\footnotetext{
${ }^{72} \mathrm{Ibid}$, PP. 51-70.
} 
environmental factors, $36 \%$ of the companies reported that their systems reflect a small influence of the environmental factors, and $25 \%$ of the companies answered that their systems of performance evaluation reflect a big influence of the environmental factors. The study also indicated that there is no company in the sample that has designed a system of performance evaluation to reflect the complete influence of the environmental factors on the performance of subsidiaries and their managers. ${ }^{73}$

\subsubsection{Appleyard \& Others (1990): This study was conducted by eleven English} companies; these companies were selected because $50 \%$ of its sales are abroad. The study prepared a questionnaire to inquire the currency used in measuring the values of the budgets and accounts of subsidiaries and branches, about the exchange rate used in the translation of the budgets and accounts of the subsidiaries and branches to the home currency, and about the used criteria in the performance evaluation in the selected companies.

For the used currency in measuring the values of the budgets and accounts of the subsidiaries and branches, the study results reported that all eleven companies use the currency of the host countries, and $18 \%$ of these company see that it is necessary to prepare, at the same time, other budgets and accounts of the subsidiaries and branches with the currency of the home country.

For the used exchange rate in translation of the budgets and accounts of the subsidiaries and branches, the study results reported that $36 \%$ of the selected companies translate the budgets and accounts by using the exchange rate at the beginning of the period, $45 \%$ of the selected companies use an expected exchange rate to translate the budgets in the beginning of the period, and $19 \%$ of the companies translate the budgets regularity by using the actual exchange rate in translation of the transactions.

For the used criteria for the performance evaluation in the selected companies, the study results reported that the all selected companies use the method of planned compared to actual values, in addition to ROI. ${ }^{74}$

\footnotetext{
${ }^{73}$ W. M. Abdallah and Donald E. Keller, 1985, Pp.26-30.

${ }^{74}$ Appleyard, A.R., et al., 1990, PP 44-45.
} 


\subsection{The Main Problems of Performance Evaluation of MNCS}

From the previous studies and literature we conclude that MNCs and their subsidiaries operate in different international environments, and the performance of the foreign subsidiaries is affected by some variables and factors such as: environmental factors (economic, legal, political, technological, cultural and social), transfer pricing, foreign currencies, and inflation. If the MNC want to evaluate the real performance of the foreign subsidiaries and their managers it must consider these factors and variables at performance valuation process of foreign subsidiaries and their managers. But the MNC faces some problems and difficulties when it deals with these issues in the performance evaluation of foreign subsidiaries and their managers as the following:

3.6.1 Transfer Pricing: The transfer pricing (internal pricing) of goods and services that are transferred (bought or soled) between members of MNC family, for example, from parent to subsidiaries, between subsidiaries, and from subsidiaries to parent. The MNC often sets the transfer prices to maximize the global after-tax income or otherwise maneuver profits to lower tax rate countries, but this may conflict with the real performance evaluation of foreign subsidiaries and their managers. The issue of transfer pricing in $\mathrm{MNC}$ is complicated by the fact that tax and custom authorities of different countries take an active interest in the methods employed. So that the question which needs to be answered is: "what is the relevant transfer price that MNC use it to evaluate the real performance of the foreign subsidiaries and their managers"? I try to answer this question in the next chapters in this research study.

3.6.2 Foreign Currencies: The accounting records and financial statements of the foreign subsidiaries are generally maintained in the subsidiary's local currency. The parent company must be able to translate these foreign currency financial statements to the currency of the parent company. The choice of currency, in which to evaluate the performance, is one of the problems of performance measurement and evaluation of foreign subsidiaries and their managers. What is the best method for the MNC in evaluating the real performance of the foreign subsidiaries and their managers in the local currency results or the results translated into the currency of the parent company? And if the MNC translated the results (accounts) of foreign subsidiaries into the currency of the parent company, what is the relevant translation method for evaluating the real performance of foreign subsidiaries and their managers? And should exchange gains and 
losses be reflected in the performance evaluation of the foreign subsidiaries and their managers? All these questions I try to answer all these questions next in this research study.

3.6.3 Inflation: Doubtless, high inflation rates render accounting numbers fairly useless for performance evaluation. Without adjustments, realistic evaluations of units and management would be very difficult. Thus, a number of companies find it beneficial to adjust their financial statements for inflation and to discuss with their owners and shareholders the related impact on dividend policy and capital requirements. While other companies find it not beneficial to adjust their financial statements for inflation. Therefore, what should be done about foreign inflation in evaluating the real performance of the foreign subsidiaries and their managers? I try to answer this question next in this research study.

3.6.4 The effect of the environmental factors: The foreign subsidiaries operate in different international environments. Each environment may have economic, legal, political, cultural and social factors different from those in other environments. Because of these environmental factors it is possible to have a good management performance despite poor subsidiary performance, and vice-versa. Thus, if the MNC want to evaluate the real performance of foreign subsidiaries and their managers, it must eliminate the effect of these environmental factors from the performance of the foreign subsidiaries and their managers. But, how can the MNC measure and eliminate the effect of the environmental factors form the performance of foreign subsidiaries and their managers? I try to answer all these questions in the following chapters. 


\section{The Environmental Factors Affecting Performance of Subsidiaries}

The MNC is an organization operating in more than one country. Every host country has a legal, political, economic, social, cultural, and technological environment, which may be different from that in other countries. The environmental factors play an important and effective role in affecting the international economic activity, and particularly on the performance of the MNCs. Thus, it is necessary to study the environmental factors affecting the performance of the MNCs, and also consider them at the performance evaluation of the foreign subsidiaries.

\subsection{The Economic Factors and Variables}

In the great majority of cases, economic factors are the most influential subset that the international manager has to consider in his analysis of the remote environment. In every nation and region in the world, the constant interplay of the factors of production - land, labor, and capital - impacts on the activity of the firms, both domestic and multinational. These basic factors of production are put together in different ways in different countries to effect the production, distribution and consumption of those goods and services which satisfy human wants and needs.

Critical as they are in the domestic context, economic parameters are even more significant in dealing with international markets, because the MNC manager is trying to evaluate many and varied national and regional economies. These are likely to exhibit a number of different themes including the following:

- Differing rates of economic growth.

- Improving or deteriorating balances of payment.

- Various fiscal policies, with governments increasing or decreasing the levels of spending and taxation.

- A wide spectrum of monetary policies, where monetary stability and the increase or decrease in money supply are strategic elements in any government's armory.

- Whether price levels are showing inflationary or deflationary trends, and therefore whether price and wage controls may be enforced or relaxed.

- The stage a country is at in the never-stationary business cycle boom, depressions, recession, recovery, and back to prosperity again. 
Thus it could be argued that these factors are even more important in international markets than they are at home; in taking its business activities overseas, the MNC faces the problem of assessing and understanding many economies whose characteristics are likely to prove highly divergent.

In pursuing his economic analysis of international markets, the MNC manager has to remember that while the decisions and actions of his own firm are most unlikely to have an appreciable impact on the remote environment, the overall effect of all multinational activity is likely to be significant. There are many of economic indicators which the individual MNC is likely to scrutinize carefully before entering a market; in turn; even the largest of international markets is likely to show marked change in these indicators as a result of substantial inward investment activity by MNCs these economic indicators include the gross national product (GNP), GNP per capita, the rate of private (as opposed to public/governmental) investment, the level of personal consumption (especially that made out of discretionary income), variations in unit labour costs, and the distribution of incomes as measured by total disposable income per household or disposable income per capita $^{75}$.

There are many environmental economic factors and variables that affect the economic activity and the performance of subsidiaries of MNCs such as the general economic framework, the monetary and fiscal policies, capital markets, availability of production elements, the competition, inflation, and relationships with other countries

\subsubsection{The General Economic Framework}

One of the most significant economic factors and variables is the general economic framework of the host countries. It has an important and effective influence on the economic activity and the performance of the subsidiaries and their managers. The general economic framework is considered as a result of the economic system and orientation of the governments in the countries.

The economic systems may differ from one country to another. There are three types of economic systems. The first type is the Communist economic system (planned economy), that are applied in the Communist countries. In Communist countries that have a Communist economic system, the state owns all production facilities, makes most of

\footnotetext{
${ }^{75}$ Taggart, James H. \& McDermott, Michael C., 1993, P. 36
} 
economic and business decisions, and controls virtually all operations through a central planning and control system. These countries have a highly standardized and uniform accounting system to facilitate the government's planning and control function, and there are a few users of accounting information other than the government. ${ }^{76}$

The second type of the economic systems is the market-capitalist economy (free market economy). In the countries that have market-capitalist economies, there are predominantly private ownerships. With greater individual freedom in economic activity and decision making, a correspondingly greater diversity in accounting practices is permitted and practiced.

The last type of the economic systems is the market socialist economy (mixed economy), which is between the communist economy and the capitalist economy. In the market socialist economies, there are some countries, which have a considerable ,but not total, government ownership, and some other countries with predominantly private ownership but with some central planning and regulation by the government.

\subsubsection{The Monetary and Fiscal Policies}

The type of monetary and fiscal policies that are employed by the government is an economic factor that has a significant influence on the economic activity and business. For example, when the government reduces the interest rate of loans, the finance cost and fixed cost will be reduced, and sequentially, the profit will be increased and the company will be able to go on and compete. Many countries, in order to stimulate economic activity, have developed investment tax credit systems. Other countries permit the accumulation of sizable reserves or permit income smoothing to provide pools of funds as a cushion during adverse time or for expansion. Through income smoothing, companies can report lower than actual income in the good years and higher than actual income in the bad years by using inventory write downs or movement of funds in and out of reserves. The tax price, custom, and the governmental involvement, in order to determine the prices of products and services, are also important fiscal tools of the government to orient the economic activity.

The International Monetary Fund (IMF) and the World Bank (the Bank of Reconstruction and Development) were created by the Britton Woods Agreement (signed in 1945, was

\footnotetext{
${ }^{76}$ Jeffery S. Arpan \& Lee H. Radebaugh, Op. Cit., Pp.20-21.
} 
intended to provide the basis for a new world economic order, with a liberal yet stable system of trade evolving. The World Bank is purely a lending institution and its main concern is for the economic development of the Third World, although it is now becoming involved in the economic restructuring of Eastern Europe. The IMF was set up to monitor the economic policies of its member countries, to extend them credit when in temporary difficulties with balance of payments, and to allow changes in the rates of exchange when a permanent imbalance is seen to have developed.

\subsubsection{Capital Markets}

The source of funds for investment and working capital is an important economic factor. The MNCs need many funds to finance and operate their activities. The MNCs get these funds from the capital markets in the countries where they operate. In the international level, there are many differences in the capital markets between the countries, especially between the developed countries and developing countries. These differences may be in the types of available capital in every market if the source of funds may be equities, loans from banks, financial intermediaries, or / and wealthy individuals ${ }^{77}$. And the resource of funds may be short-run or / and long-run. The insurance companies also play an important role in the capital markets. Efficiency of the capital market may be different from country to country. In fact, these differences in the capital markets between the countries have an important influence on the economic activity, and consequentially on the performance of subsidiaries and their managers in the host countries.

As soon as a domestic firm begins to internationalize its activities, it encounters foreign financial markets. Its first encounter is likely to be with the global foreign exchange market which has two main purposes: the first is currency conversion, which is necessary if the firm is to sell its goods and/ or services overseas; the second involves the reduction of foreign exchange risk, which MNCs can limit by holding a number of foreign currencies which they use for transactions. However, MNCs also face transaction exposure whenever there is a significant time gap between an international transaction and the payment. If the foreign currency involved weakens against the MNC's domestic currency during the interval, then the firm's cash flow is reduced ${ }^{78}$.

\footnotetext{
77 Ibid, P.21

${ }^{78}$ Taggart, James H. \& McDermott, Michael C., Op. Cit. Pp. 37-38
} 
When considering individual foreign countries, MNCs will obviously be influenced by different financial markets which affect MNC's activities and its profits. A MNC can also achieve a formidable competitive advantage by borrowing funds in countries with low interest rates and investing these funds in other parts of its global network, including the home country.

\subsubsection{Production Elements}

The production elements such as raw materials, labour, and other services are considered as important economic factors that have a big influence on the economic activity. And I think that it is a main factor in the investment decisions of the MNCs. Some countries are rich with raw materials, or / and labour (especially the clever labour) than other countries. Since the prices of raw material and labour are different between the countries, the cost of product or service is different between countries, and consequentially, the performance results also differ. Thus, if we want to evaluate the real performance of subsidiaries in the host countries, we must take these factors to account in the performance evaluation of subsidiaries in the host countries.

In every nation and region in the world, the constant interplay of the factors of production - land, labor, and capital - impacts on the activity of the firms, both domestic and multinational. These basic factors of production are put together in different ways in different countries to effect the production, distribution and consumption of those goods and services which satisfy human wants and needs.

The future global economic growth would be severely restricted by an increasing shortage of row materials. In contrast, took the view that water shortages would become critical by the end of the century and that deforestation would continue unabated; that energy resources would be adequate, though unevenly distributed; and that other mineral resources would be sufficient for foreseeable needs.

By far the largest proportion of investment is undertaken by the developed economies because their high historic GNPs have allowed high levels of savings, and therefore high levels of investment. As capital is one of the key factors of production, it is easy to see the vicious circle within which Low Developed Countries (LDCs) find themselves. To some extent, the same argument applies to MNCs: they make high profit and also have preferential access to international capital markets. 
Most LDCs have a substantial external debt problem, and this also militates against capital information. While the forecast here again is a tale of the rich getting richer and the poor poorer, MNCs also have an important stake in the debt problem. If the situation is not improved and substantial defaults occur, the resultant collapse of the International Monetary Fund would be as disastrous for MNCs as for LDCs. ${ }^{79}$

\subsubsection{The Competition}

The competition that dominate in the environment of the host countries is considered one of the most important factors affecting on the performance of MNCs, whether it is from local companies or other similar MNCs. The degree of the competition depends on the number and strength of the local and foreign competitor companies in the host countries ${ }^{80}$. In some host countries, the competition may be indirect, for example, the government may involve in order to reducing the prices or taking a political action to protect the domestic industry from foreign investors. ${ }^{81}$ Also, the arrangements and agreements for sharing markets may limit the competition, so that a company may have advantages more than other companies. All of these different situations and conditions in competition in the host countries influence the performance of subsidiaries. Thus, we must consider this factor at performance evaluation of the subsidiaries in the host countries.

The competition in an industry is rooted in its underlying economic structure and goes well beyond the behaviour of current competitors. The state of competition in an industry depends on five basic competitive forces which are (1) Treat of new entrants, (2) Rivalry among existing firms, (3) Treats of substitute products or services, (4) Bargaining power of buyers, and (5) Bargaining power of suppliers. The collective strength of these forces determines the ultimate profit potential in the industry, where profit potential is measured in terms of long run return on invested capital. Not all industries have the same potential. They differ fundamentally in their ultimate profit potential as the collective strength of the forces differs. The forces range from intense in industries like tires, paper, and steel -here no firm earns spectacular returns - to relatively mild in industries like oil-field equipment and services, cosmetics, and toiletries - where high returns are quite common.

\footnotetext{
${ }^{79}$ Taggart, James H. \& McDermott, Michael C., Op. Cit. Pp. 220-221

${ }^{80}$ Thomas Muller, Op. Cit., P.20.

${ }^{81}$ Peter J. Buckley, Op. Cit., P.34.
} 
The goal of competitive strategy of a business unit in an industry is to find a position in the industry where the company can best defined itself against these competitive forces or can influence them in its favour. Since the collective strength of the forces may well be painfully apparent to all competitors, the key for developing strategy is to delve below the surface and analyze the sources of each. Knowledge of these underlying sources of competitive pressure highlights the critical strengths and weaknesses of the company, animates its positioning in its industry, clarifies the areas where strategic changes my yield the greatest payoff, and highlights the areas where industry trends promise to hold the greatest significance as either opportunities or treats. Understanding these sources will also prove to be useful in considering areas fore diversification.

Rivalry among existing competitors takes the familiar form of jockeying for position using tactics like price competition, advertising battles, product introductions, and increased customer service or warranties. Rivalry occurs because one or more competitors either feels the pressure or sees the opportunity to improve position. In most industries, competitive moves by one firm have noticeable effects on its competitors and thus may incite retaliation or efforts to center the move; that is, firms are mutually dependent. This pattern of action and reaction may or may not leave the initiating firm and the industry as a whole better off. If moves and countermoves escalate, then all firms in the industry may suffer and be worse off than before.

Some forms of competition, notably price competition, are highly unstable and quite likely to leave the entire industry worse off from the standpoint of profitability. Price cuts are quickly and easily matched by rivals, and once matched they lower revenues for all firms unless industry price elasticity of demand is high enough. Advertising battles, on the other hand, may well expand demand or enhance the level of product differentiation in the industry for the benefit of all firms. Rivalry in some industries is characterized by such phrases as "warlike", "bitter", or "cutthroat", whereas in other industries it is termed "polite" or "gentlemanly".

Intense rivalry is the result of a number of interacting structural factors. These factors are: (1) Numerous or equally balanced competitors, (2) Slow industry growth, (3) High fixed or storage costs, (4) Lack of differentiation or switching costs, (5) Capacity augmented in large increments, (6) Diverse competitors, (7) High strategic stakes, and High exit barriers. These factors that determine the intensity of competitive rivalry can and do change. A very 
common example is the change in industry growth brought about by industry maturity. As an industry matures its growth rate declines, resulting in intensified rivalry, declining profits, and often a shake-out.

A company must live with many of the factors that determine the intensity of industry rivalry - because they are built in to industry economics - it may have some latitude in improving matters through strategic shifts, or the firm can try to raise product differentiation through new kinds of services, marketing innovations, or product changes. Focusing selling efforts on the fastest growing segments of the industry or on market areas with the lowest fixed costs can reduce the impact of industry rivalry. Also, if it is feasible a company can try to ovoid confronting competitors with high exit barriers and can thus sidestep involvement in bitter price cutting, or it can lower its own exit barriers ${ }^{82}$.

\subsubsection{Inflation}

Inflation is an economic characteristic that has an important influence on the economic activity and the accounting practices in individual countries. Although inflation appears to be a worldwide phenomenon, its severity varies from single-digit to triple-digit and even quadruple-digit annual levels often referred to as hyperinflation. Particularly in hyperinflationary countries, the cumulative effect of inflation over a number of years can render all accounting information as meaningless unless it is appropriately adjusted.

Inflation affects both balance sheet and income statement. It results in some strange operating decisions by both managers, who understand inflation and who do not. In the balance sheet the financial assets, such as cash, lose value during inflation because their purchasing power diminishes. Conversely, holding financial liabilities such as trade payables is wise because the business would be paying its obligations with cheaper cash in the future. ${ }^{83}$

The inflation effects on the balance sheet and income statement could lead the firm into unreal profits that result from matching old costs with new revenues, which also could lead to demands from shareholders for more dividends. Although the firm is watching its cash dwindle, as well as the profits rise, the tax liability of the firm also rises and causes a further out flow of cash.

\footnotetext{
${ }^{82}$ Porter, Michael E., 1980, Pp.17-22

${ }^{83}$ Jeffery S. Arpan \& Lee H. Redbug, Op. Cit., P.48.
} 
Finally, the inflated financial statements do not express about the real operating and financial position of the firm, and the analysts and investors cannot make wise decisions without understanding the impact of inflation. Although, if some governments decide to slow down inflation by raising interest rates, reducing the money supply, or imposing wages and prices controls, the liquidity crisis becomes more sever and the operating and financial problems are compounded. Thus, for all these inflation effects, if we want to evaluate the real performance of the subsidiaries and their managers in the host countries, we must eliminate the inflation effects from the financial statements.

\subsubsection{Ties and Relationships with Other Countries}

The ties and relationships with other countries, especially the economic relationships, are also considered as an economic factor deserving to be mentioned because of its influence on the economic activity and its development of the member countries. The formal regional economic groups or unions, such as the European Union (EU), are one form of ties and relations between countries. These groups and unions move toward full integration of the economic and political systems in the union countries. These groups and unions may give advantages to the some member countries more than others, and consequentially, the performance of the MNCs operating in the member countries will be more affected than those operating in other countries.

Also, the product cartels, such as the Organization of Petroleum Exporting Countries (OPEC), represent a type of inter-country economic relationship that can affect the economic activity. These cartels attempt to standardize the world export prices, and in some cases to ensure equitable returns to its members by advising uniform costing and pricing systems among their members in addition to specific production or export quotas.

\subsection{Legal Factors}

The legal environment has also an influence on the economic activity and its development. The MNC operates according to many different legal systems, where the headquarters operates according to the laws applied in the home country, while the subsidiaries operate according to the laws applied in the host countries. The laws and legal system may be different from one country to another. Thus, the management of subsidiaries operate according to laws that may be different from the laws in the home country. The most 
important laws are such as tax law, custom law, importation and exportation law, investment law (especially the foreign investment), companies law, employment law, intellectual property law, competition law, finance market law, consumer protection law, and more. In fact, the performance of subsidiaries and their managers is affected by these laws.

The MNCs do not work within single, unified international legal environment; on the contrary, an MNC faces a different legal context in every country within which it operates. These codes are usually put in place by governments in an attempt to control the amount, rate and impact of both outward and inward investment. There are a very large number of factors as follows: ${ }^{84}$

- Industrial intellectual property rights: this includes all aspects of trade names, trade secrets, copyrights and patents. As business has become progressively internationalized, so MNCs and their home governments have brought pressure to beer - particularly, but not solely, on developing countries - to bring regulations into line with those of the industrialized countries. In industries like pharmaceuticals, MNCs often refuse to set up manufacturing or R\&D facilities in countries with insufficient safeguards in this sphere.

Trade obstacles: this includes tariffs and quotes which are usually clearly laid down by regulations, and other less well-defined factors. A good example here is product labelling where the requirements are not only legal, but also culture-bound; for instance, foreign companies trading in France must produce all labels, warranties, instructions, etc. in French. Also in the pharmaceutical industry, safety and efficacy regulations show a bewildering variety from one country to another, with no individual country's standards being acceptable in another.

- Product liability: this has been a boom area for the legal profession in many industrialized countries in the last years, through this is hardly surprising when the long list of product manufacturing problems is considered.

- Monopoly and restrictive trade practices: this type of legislation is common throughout the developed world. US regulations are regarded as tightest, followed by Germany. However, unlike other areas of legislation, there is a move towards uniformity here, with the EC taking the lead in the approach to the single European Market.

\footnotetext{
${ }^{84}$ Taggart, James H. \& McDermott, Michael C., Op. Cit. Pp. 40-41
} 
- Home-country legislation: this includes all legislation passed in a particular country to regulate the activities of MNCs passed in the country while operating overseas. The best-known example is the US Foreign Corrupt Practices Act which was passed following a number of highly publicized bribery cases in the 1970s involving American multinationals. It forbids US firms giving bribes or any other questionable payments anywhere in the world as these are regarded as "ethically repugnant" and bad for the international reputation of American business.

\subsubsection{Tax Law}

Tax law is considered the most important law affecting the MNCs, because the MNCs submit the tax law in the host countries, and has a high tax rate. Also, the MNCs may not sometimes gain the advantages of the local laws. Some countries decide as a special tax for foreign companies. The profit of the MNCs may submit to tax in more than one country, because of the double taxation which could lead to the MNCs pay more tax in both, the host country and the home country.

The spread of the MNC's activities poses particularly difficult problems for all tax authorities in which it is not easy to determine the allocation of taxable profits in highly integrated groups. Whenever goods and services cross national boundaries within a multinational group, the MNC uses transfer price in order to determine the division of the tax base between the countries, in which the MNC is operating, and which is a difficult $\operatorname{task}^{85}$. We can say that the MNC uses such a procedure to avoid an international double taxation and to assist tax authorities in counteracting tax evasion and avoidance.

These differences in taxation among countries have an important effect on the performance of the MNCs and their managers, and we must consider this influence on performance evaluation of subsidiaries.

\subsubsection{Custom Law}

The custom law is considered as one of the most effective factors on the performance of the MNCs, especially, the custom on the importation of raw material, machines and equipments. The custom rate differs from country to country. There is a high rate in some

\footnotetext{
${ }^{85}$ OECD, 1993, P.1.
} 
countries, while it is fewer in other countries, and in some countries there is no custom. The high custom rate increases the cost of product, and consequentially less profit. On the contrary, less custom causes less cost of product, and consequentially more profit. The differences in the custom laws among countries affect the performance and results of subsidiaries and their managers in the host countries. Thus, if we want to measure and evaluate the real performance of subsidiaries and their managers, we must consider the effect of custom on performance evaluation of subsidiaries and their managers in the host countries.

\subsubsection{Importation and Exportation Law}

The laws and procedures that control and organize the transactions of importation and exportation have a big influence on the economic activities; especially on the MNC's activity. These laws and procedures differ from country to country. Some countries determine constraints and terms for importation transactions such as preventing or restricting importation of some kinds in order to protect the national industries. Also the procedures of importation may be more complex and take more time and effort in some countries, more than others. The documentary credit for importation, its opening procedures and charges, the customs tariff on importation, transportation means and handling charges affect the cost of importation, and these factors are different among the countries.

Also the prices of transportation, handling, and insurance are not the same in every countries according to the degree of political and security stability; of course, the prices of insurance are more expensive in the countries that have no political and security stability; and it causes more cost of exportation, and consequentially a weak competitive position of the company.

\subsubsection{Monetary Law and the Procedures of Transfer Money}

The laws, rules, policies, and procedures, which organize the dealing with monetary, especially foreign monetary, have an influence on the economic activity. More companies need a lot of foreign currency for importation transactions and other transactions. Some countries set difficult terms and procedures for dealing with foreign currencies. For example, they determine a certain level of the amount of the foreign currency that one wants to buy and the government may involve for determining the exchange rate of the 
foreign currencies. Some countries also set some constraints of money transfer outside and inside the country and such a procedure restrict the ability of a company to use its money as it wants.

These differences in the laws and rules which organize the dealing in the monetary and money transfer affect the performance of the MNCs. And if we want to measure and evaluate the real performance of the MNCs and their managers, we must consider this influence at performance evaluation of these companies.

\subsubsection{Investment Law}

The investment law, especially concerning foreign investment, is one of the important factors that have influence the performance of the MNCs. The laws and procedures which organize the investment and economic activities may be different in various countries. In some countries, the investment laws may include more procedures, which need much time to complete them, and which are very expensive. Also in other countries, the investment laws may give the investors some motivations and advantages, for example tax exemption and subventions, more than other countries. In some countries, there is no specialist court for commercial disputes and in addition to this, a long time of prosecution.

As long as the investment laws and procedures affect the performance of MNCs, and they are differences between countries, we must consider this effect on performance evaluation of MNCs.

\subsubsection{Labour Laws}

The laws of labour and employment are one of the important legal factors, which affect the performance of MNCs. The laws of labour and employment are different between countries. Some countries obligate the MNCs to employ a certain number of national workers and staff; who may be not qualified, and this may affect the performance of MNCs. In other countries, they determine some difficult procedures and terms to import foreign workers and experts, and this may prevent the MNCs to use them and benefit from their experiences which they need. But, if this is achieved, it takes a long time, high costs, and complex procedures.

The struggle for some regulation of MNCs conduct, as it relates to labour relations that has been waged by the international organisations of trade unions, has indeed been an uphill 
battle. While it cannot be said that labour's forces have gained their fruits of victory, some progress has been made from the viewpoint of the trade union. ${ }^{86}$

Furthermore, the role of labour unions may vary between countries according to the power of union. The relation with the labour unions and the dynamics of labour disputes go beyond the traditional questions of negotiations. The negotiations are not only about better working conditions, working hours, and wages, but also about the increasing need for improved housing, health, transportation, and educational facilities.

In the end, the performance of MNCs will be affected by the differences in laws of labour and employment between countries. If we want to measure and evaluate the real performance of subsidiaries and their managers, we must take into account the effect of the laws of labour and employment on the performance and on the process of performance measurement and evaluation of subsidiaries and their managers.

\subsection{Cultural Factors}

There are various cultural factors in the environment of every country. These factors affect the economic activity and business. The most important cultural factors are educational characteristics, attitudes towards business, conservatism, and secrecy.

Culture can be regarded as the sum total of attitudes, beliefs and lifestyles. Thus the international manager must be aware of attitudes towards material culture, work and achievement, time, change, decision-making, and risk. Since this description includes a vast number of intangible factors, it should come as no surprise that the cultural environment of international business gives MNC managers so many problems. As host countries have come resent the "cultural imperialism" of so many MNCs, so these companies have come to realize, particularly in the last years, the critical importance of this area. Culture is all-pervasive, and represents a dilemma for both operating and strategic management. It is a truism of strategic management that any strategy which runs counter to the corporate culture is certain to fail. The same is true of an international strategy which runs counter to a national or regional culture, but the results of failure will become apparent even more quickly. The broad prescription for MNC managers is to avoid insensitivity toward, or ignorance of, the aspects of local culture which will have most influence on commercial success in any particular country. This require a high level of

\footnotetext{
${ }^{86}$ Burton Bendiner, 1987, P.120
} 
cultural awareness and sufficient degree of cultural empathy; at the operational level, it is also demands a significant level of cultural training for expatriate managers before a new posting.

Finance and accounting is the functional area least involved; cultural considerations are most important in marketing, with human resource management coming a close second. The language is crucial, and arouses great sensitivity in many countries. While there is a trend toward the acceptance of English as the universal business language, MNC managers should be aware that such a presumption causes great offence in. for example, French. Non-verbal communication also holds its pitfalls, with different elements having different intrinsic meanings; this includes the use of eye contact, touching, personal appearance, relative position between people having a discussion, bodily postures, distance apart, and non-verbal aspects of speech like accents and tones. ${ }^{87}$

\subsubsection{The Educational Characteristics}

The educational characteristics of a country have a significant effect on business and accounting practices. These educational characteristics encompass the literacy level, educational orientation, view of scientific method, and educational match.

\subsubsection{The Literacy Level}

The managerial and accounting systems, especially the developed systems, have relatively little use or significance in a society that is predominantly illiterate, thus, the use of company time, money, and effort will be not judicious and rational. The planning and control systems would be difficult to use effectively because of the limited ability of employees to prepare and understand budgets and reports. At the same time, the need for budgeting and control tends to be greater in developing countries, which have the highest level of literacy. Hence, the management of the MNCs can face many problems in the developing countries that affect the performance.

As the educational level of the population improves, most of these managerial and accounting problems decrease, and more extensive and sophisticated managerial and accounting systems and reports become feasible. In countries with a high degree of

\footnotetext{
${ }^{87}$ Taggart, James H. \& McDermott, Michael C., Op. Cit. Pp. 41-42
} 
illiteracy, business must rely to a greater extent on visual or audio methods for advertisement rather than printed messages. ${ }^{88}$

\subsubsection{The Educational Orientation}

The orientation of the educational system also plays an important role in determining the managerial and accounting practices. The extent of economics, business administration, accounting, computer sciences and information systems, which are part of the educational system, will influence the number of people who have some training and understanding of planning and budgeting, organizing, leading, negotiation, controlling, financial analysis, and decision making. And more specifically related to economics, does business administration and accounting, exist in the curriculum? And if so, what do they entail? And are there degrees in economics, business administration, computer sciences, information systems and accounting? And for what type of work does the degree qualify someone?

More subtly, the teaching and acceptance of the scientific method (the basic law of causality) influences people's acceptance of and adherence to the process of strategic planning, negotiation, and controlling. Stated in another way, if people in the organization are fatalistic (if they believe that whatever happens will happen, regardless of their activities or efforts) they will not perceive any need for planning, budgeting, and control. ${ }^{89}$

\subsubsection{View of scientific method}

The extent of an analytical point of view by decision makers is a pervasive element determining the use of some activities such as marketing research. Analysis is both a function and a state of mind. As a function it is the thoughtful prelude to action, the process in which problems and ideas are organized, and developed in the research for effective patterns of action. As a state of mind, it requires the ability to observe and accept reality together with disciplined and orderly logic in thinking. These tow bases are the essence of scientific management.

In the developed countries, scientific method has become a necessary aid to decision making because it has been shown to lead to profitable decisions. Although systematic analysis may seem for some a quite normal approach for problem solving, it is counter to the instincts of most people throughout the world.

\footnotetext{
88 Jeffrey S. Arpan \& Lee H. Radebaugh, Op. Cit., P.13

${ }^{89}$ Ibid., Pp.16-17
} 
One factor impeding the rise of systematic analysis is the pattern of thought, attributable largely, to the educational systems of societies. In those areas which were not touched by the Renaissance and the scientific revolution, the practice of questioning and examining has not become established as fundamental to life and thus to educational systems.

Countries which have traditionally been influenced strongly by the protestant Calvinist philosophy tend to have the most favourable attitudes toward scientific method. Countries with strong Catholic traditions considerably have had more difficulty in accepting scientific method in their cultures as an operating force. Societies which are Moslem, Buddhist, and Hindu have also been much more reluctant to view scientific method as being compatible with their religions and cultures. Thus, if a country has a strong traditional religious and cultural bias toward non-scientific behaviour, it will be difficult to introduce modern managerial methods, which are based on the same type of predictive and rational view of the world as are the more purely technical devices. ${ }^{90}$

\subsubsection{The Educational Match}

The educational match means the appropriateness of the educational system's output for the country's economic and social needs. The educational match influences the development of economic, managerial, and accounting systems. Investors, managers, accountants, and information users grow in number and sophistication, so that they need greater and developed economic, managerial, accounting, social and information systems. In other words, as the country industrializes, there are more and bigger firms (especially the MNCs), more complex business arrangements (production, marketing, financing, credit, leases, pooling, merger) and usually an increased need for outside capital. Each requires more developed and complex managerial and accounting procedures and more people who can use and understand them. The issue is whether the educational system is producing enough of these people at each stage of development. ${ }^{91}$

Also the extent and depth of business administration is a determinant of the use of the modern managerial techniques. The availability and utilization of individuals with modern managerial techniques, negotiation skills, and problems solved by scientific method will have a significant bearing on managerial performance. Wherever there is a shortage of

\footnotetext{
90 David L Loudon, 1975, Pp.100-103

${ }^{91}$ Jeffrey S. Arpan \& Lee H. Radebaugh, Op. Cit., P.17
} 
people with such modern techniques and skills, the activity will either be carried out poorly or not performed at all. ${ }^{92}$

The characteristics of the educational system of the country reinforce and reflect the population values. It seems that in many of the less developed countries, the educational systems are unresponsive to the manpower requirements of their economies. Business administration education is rare in underdeveloped countries and when it is present, the emphasis is largely on the legal and accounting aspects while essential features of modern management services are neglected. This fact will have an important influence on management's ability to conduct its activities such as strategic planning and modern marketing research, as well as its perception of the need for the technology. Also we can say that the educational philosophy and nature of the learning process in a country influence quite directly the perception of need for modern and developed technology.

\subsubsection{Attitudes toward Business}

The attitudes toward business may range from distrust and antagonism to wholehearted support and trust. Distrust generates demands for more information and closer scrutiny of business operations and procedures, and it causes more bureaucracy. All this need more time, effort, cost, and consequently negative influence on the performance of company. Also distrust and antagonism towards business generate a shortage of transparency and disclosure which are important and necessary for the business world, especially in the current time.

On the other side, the government support of society's wishes can lead to establishing and regulating the economic policies and procedures and practices of business administration and accounting.

Furthermore, the attitude towards the accounting profession affects the statues of the profession, the type of person who enters it, its credibility, and the work that accountants perform. In many countries, accounting is still regarded as a low-status occupation filled with thieves and irresponsible people. As it can be expected, the most skilled people in these countries do not aspire to be accountants. This may be a self-fulfilling prophecy; perhaps only distrustful and other undesirable workers become accountants in these countries. In other countries, accountants occupy a highly respected place in society and as

\footnotetext{
${ }^{92}$ David L Loudon, Op. Cit., P.102
} 
a result accounting attracts high-calibre individuals. Accountants in these countries tend to lead the world to development of accounting theory, procedures, and practices. Germany, The Netherlands, the United Kingdom, and the United States are representative examples. $^{93}$

\subsubsection{Secrecy}

The society's degree of secrecy most directly affects the amount of disclosure and transparency an enterprise is willing to make in its external reporting: the greater the level of secrecy or distrust of outsiders is, the lower the level of disclosure and transparency. Internally, a high level of distrust makes it more difficult to implement a system of internal control and performance evaluation, because no one wants to have his or her activities scrutinized. Secrecy also affects the audit function, making it more difficult to obtain necessary supportive information, verification, and corroboration of the accounting data supplied by the enterprise.

In some countries, secrecy affects the marketing research; it is very difficult to obtain the necessary information at surveying such as marketing research especially in the developing countries, and it constraints the performance of the managers. In other countries, like Japan, in certain circumstances a high degree of trust may cause similar problems, for example, to question someone's word are to question his or her honour (a serious insult and definitely a bad manner). Thus, every one who attempts to obtain information in this way will be in a difficult and uncomfortable position and certainly unlikely to find friends. Also business organizations are quite concerned with competitive secrecy and hence very protective of their information; such an environment impedes business organizations, especially marketing research. ${ }^{94}$

\subsubsection{Conservatism}

The society's degree of conservatism influences the degree of people acceptance to every new development. The company employees will oppose the modern managerial methods, if they have a high degree of conservatism. They think that every innovation would cancel their traditions, they hold on to and which is quite an issue for them.

\footnotetext{
${ }^{93}$ Jeffrey S. Arpan \& Lee H. Radebaugh, Op. Cit., P.18

${ }^{94}$ David L Loudon, Op. Cit., P.104
} 
The society's degree of conservatism also influences a number of accounting principles and practices, especially valuation and profit determination. For example, the use of historical cost reflects a degree of conservatism. As do the lower-of-cost-or-market principles, the recording of contingent liabilities, the over allowance for bad debts, and the practice of using a wide variety of special reserves. These last two practices also generally result in lower reported profits, reflecting a higher level of conservatism and often a desire to make a firm appear less profitable than it actually is. ${ }^{95}$

\subsection{Social Factors}

There are more social factors in the environment of every country, and they may differ among countries. These factors affect the economic activity and business. The most important social factors are habits, traditions, conventions, religious beliefs, and society viewpoint toward foreigners, especially to foreign companies and their products.

\subsubsection{Habits, Traditions, and Conventions}

The habits, traditions, and conventions of the people in every society play an important role in the nature of the relationship between the people and business organizations, and they affect the performance of economic activities and business organizations.

In most countries, for example in Egypt, the people in rural and urban areas are seeking to reassert the importance of traditional values and customs facing the pressure and complexity of modern civilization. The most prominent virtue of the Egyptian is his devotion to his family and children. He is profoundly aware of belonging to a family and no aspect of his life is adaptable if the family, in which every individual is embedded, is left out of account. Thus, the Egyptian's prime loyalty is to his family. As an example for the loyalty to the family, the employee may not go to his work when his wife, child, father, mother, brother, or sister is ill, and this may cause some matters for the business organizations and affects the performance of companies. Hence, some companies try to introduce the health care and social protection for both the employees and their families, to ensure their concentration at work, which costs the company much money.

Some societies also tend to have a high degree of secrecy and less degree of transparency. In such cases, it is difficult to obtain the necessary information from the people, and it constrains some activities of the companies, especially the marketing research, and it

\footnotetext{
${ }^{95}$ Jeffrey S. Arpan \& Lee H. Radebaugh, Op. Cit., p.17
} 
affects the performance of managers. If the people have a high level of distrust, it will be difficult to implement a system of internal control and performance evaluation, because no one wants to have his or her activities scrutinized.

\subsubsection{The religious beliefs and trends}

The religious beliefs and trends play an important role in influencing the economic activities and the performance of companies, and these beliefs and trends are different from country to country according to religion. It is known that Moslems do not eat pig and do not drink alcohol because it is forbidden in their religion; therefore, the food companies operating in Islamic countries consider that their products must be free from pork and alcohol.

The religious beliefs and trends affect the people's point of view of the scientific method, in countries, which have strongly been influenced by the protestant Calvinist philosophy tend to have the most favourable attitudes towards scientific method. While countries with strong Catholic traditions considerably have had more difficulty in accepting scientific method as an operating force in their cultures as an operating force. And the societies which are extensively Moslem, Buddhist, and Hindu have also been much more reluctant to view scientific method as being compatible with their religions and cultures. ${ }^{96}$ If a country has a strong traditional religious and cultural bias toward non-scientific behaviour, it will prove to be difficult to introduce modern managerial methods, which are based on the same type of predictive, rational view of world like the more purely technical devices are.

The predominant religious beliefs and trends in a country can have an effect on some activities of the company, especially on marketing research. The effect of religion on the use of marketing research is largely through the attitude of the culture toward spiritualism versus materialism. For example, Buddhism and Hinduism tend to exalt spiritual values and deemphasize the value of material possessions. In such an environment asceticism is a virtue and unnecessary consumption is vulgar. Moreover, in a country where people are not materialistically oriented, businesses will rely more on non-monetary forms of reward, such as titles or job security, in order to attract and motivate their employees. ${ }^{97}$

\footnotetext{
${ }^{96}$ David L Loudon, Op. Cit., P.102

${ }^{97}$ Jeffrey S. Arpan \& Lee H. Radebaugh, Op. Cit., Pp.13-14
} 
The Churches and Mosques are interested in some matters such as business hours, especially with regard to religious days of rest and holidays. The Churches and Mosques are also a mighty economic power, and in most respects they appear to be more powerful today than they have been in the past. As a part from their spiritual influence, the Churches and Mosques control great wealth and very numerous and extensive works of charity, hospitals, schools, and universities.

Host country religion also has a fundamental part to play, with each major religion having an impact on the overall attitude to business. The so-called "protestant work ethic" is a noticeable feature of Christianity; however, not only is this rather obviously shared by Roman Catholics, but it also finds a resonance in Confucianism. MNCs operating in Islamic countries have to be keenly aware that Moslems pray at five specific times during the day, and that there must be no requirement to work during these intervals. The concept of the (extremely) extended family is important to Hindus, and includes support of all family members in the business world; thus, MNC managers have to be extra sensitive to the problems of pay, promotion, discipline and dismissal. Buddhists lay little stress on material wealth, and so are much less susceptible to western methods of motivating the workforce. Animism is probably the oldest religion and is widespread in Africa and Latin America. The Animist puts all problems down to the action of evil spirits which must be exorcized; this can cause some odd situations for the expatriate production manager who has to cope with the Animist response to defective quality, machine breakdowns, and industrial accidents ${ }^{98}$

\subsubsection{The viewpoint of society toward the foreigners}

The point of view of society toward foreigners, especially to foreign companies and their products, is affecting among the social factors the performance of MNCs. The point of view of people toward foreigners and foreign companies may include distrust and antagonism or wholehearted support and trust. People in some countries, especially which were occupied by other countries, have distrust and antagonism towards foreign business organizations and they do not buy their products. People believe that these foreign companies did not come to invest but to despoil their resources, like in the past. Some foreign companies may also face some problems, because their government's position

\footnotetext{
98 Taggart, James H. \& McDermott, Michael C., Op. Cit. Pp. 42-43
} 
towards some issues. For example, most Arabs boycott the products of USA companies because of the American policies toward Palestine, Iraq, and Afghanistan.

\subsection{Political Factors}

The political environment has an influence on economic activities and business organizations. The political organization of a country influences the nature of the economic system in the country, and hence strongly influences the economic activities and business organizations. The political organization also has an effect on the government's attitude towards business, particularly foreign business.

In Communist countries, the state owns all production facilities, makes most of the economic and business decisions, and controls virtually all operations through a central planning and control system. While in other countries, there is predominantly private ownership, with greater individual freedom in economic activity and decision making. ${ }^{99}$

The political stability of a country and the surrounded areas also has a significant influence on economic activity and business organizations, particularly foreign business. In some countries where there is no political and security stability, the cost of insurance, cargo, and transport is very expensive.

The risk of nationalization and expropriation - especially in the developing countries is also a political factor which has a big influence on the business organizations, especially on foreign business.

The principal concept used by international businessmen in appraising the political environment is known as political risk. This expresses itself through government-inspired events and actions that impact on the international companies working within a particular state. The political risk is defined as "the risk of loss of assets, earning power, or managerial control due to events or actions that are politically based or politically motivated". The immediate association of political risk is with developing countries in terms of nationalization and expropriation of assets, but it is also present in industrialized countries. Perhaps the most difficult political risk assessment the MNC must make is when

\footnotetext{
${ }^{99}$ Jeffrey S. Arpan \& Lee H. Radebaugh, Op. Cit., Pp.20-21
} 
it contemplates its initial entry into a particular country. The main political factors for the primary appraisal are: ${ }^{100}$

- What is the political structure of the country?

- Under what type of economic system does the country operate?

- Is my industry in the public or private sector?

- If it is in the public sector, does the government also allow private competition in that sector?

- If it is in the private sector, is there any tendency to move it toward public ownership?

- Does the government view foreign capital as being in competition or in partnership with public or local private enterprises?

- In what ways does the government control the nature and extent of private enterprise?

-How much of a contribution is the private sector expected to make in helping the government formulate overall economic objectives?

If the situation is especially complex, or if the new foreign investment is very large, most MNCs would move beyond such a simple assessment and call on the assistance of specialist political risk assessment consultants, most of whom have had extensive previous experience working with or within government or international bodies like the UN or the World Bank.

\subsection{Other Factors and Variables}

In addition to the previous environmental factors, economic, legal, cultural, social, and political factors, which affect the performance of MNCs at operating in the host countries, there are other factors affecting the performance at its measurement as such; transfer pricing, inflation, and change of foreign currencies exchange rat. These problems will be discussed in the following chapters.

At the end of this chapter we can say that, if the previous environmental factors have effects on the performance, the MNC must measures this effect and considers it in the performance evaluation of the foreign subsidiaries and their managers, so that, the MNC is able to measure and evaluate the real performance of foreign subsidiaries and their managers.

${ }^{100}$ Taggart, James H. \& McDermott, Michael C., Op. Cit. Pp. 39-40 


\section{Transfer Pricing and Performance Evaluation of MNCs}

As mentioned in the fourth chapter, there are many environmental factors, such as economic, legal, cultural, social, technological, and political factors, which affect the performance of MNCs during the operating in host countries, there are also other variables, which affect the performance of MNCs during the performance measurement and evaluation such as transfer pricing, inflation, and changes of currency exchange rate. In this chapter I will discuss the problem of transfer pricing and its effect on the performance measurement and evaluation of MNCs.

\subsection{The nature of transfer pricing problem}

A common reaction to the administrative complexity response by the firms that have diversified into a number of industries or that have identified a number of product and market segments within a single industry is to subdivide the company into profit centers under the direction of general managers including group general managers, division general managers, and even product managers. Since each general manager is given bottom line responsibility for one or more businesses and most of necessary resources for achieving profit objectives, the decision-making burden on the chief executive officer (CEO) and other corporate-level managers is reduced, and they can concentrate on longerterm strategic issues. However, since these lower-level general managers never have all of necessary resources, they depend on the corporate line and staff functions, other profit centers, and outside suppliers for goods and services that are not provided within the profit center.

The created interdependence, when profit centers buy from and sell to each other, necessitates a transfer price, since profit center managers are held responsible for both revenues and costs. Transfer pricing is at the heart of inter-profit center relationships, and it must be effectively managed to prevent the advantages of multiple profit center form of organization from being overwhelmed by the problems of inter-profit center relationships. The more the top management gets involved in these relationships, the less the advantages of decentralization are obtained. ${ }^{101}$

${ }^{101}$ Robert G. Eccles, 1985, P.2 
The basic concept behind responsibility accounting is that managers need to be able to control their destiny. This is difficult for vertically integrated companies, in which divisions buy and sell from each other, and the international market complicates the process dramatically ${ }^{102}$. The established price on goods and services bought and soled between related entities, such as a parent and its subsidiary, is known as a transfer price.

Transfer pricing (internal pricing) refers to the pricing of goods and services that are transferred (bought or soled) between members of the MNC group, for example from parent to subsidiaries, between subsidiaries, and from subsidiaries to parent. As such, the internal transfers include raw material, semi-finished and finished goods, allocation of fixed costs, loans, fees, royalties for use of trademarks, copyrights, and other factors.

In theory, the foreign subsidiaries are a subject to control by the parent company. Hence, theoretically, the MNC has the power to fix the level of prices applying to international trade between subsidiaries, and to deviate artificially from normal or true prices, if, against the interests of individual subsidiaries, the overall profits of the MNC can be increased, or some costs, such as overall corporate tax liabilities, be reduced. ${ }^{103}$

MNCs may use less or high transfer prices according to its benefit. The MNC may set a less transfer price to maximize global after-tax income or otherwise maneuver profits to lower-tax rate countries. Yet taxation is the most important reason why internal transfers may be priced with little consideration to actual costs. The MNC can sell under-price goods to the foreign subsidiaries, and then subsidiaries can sell them at prices that their local competitors cannot match. And if tough antidumping laws exist on final products the MNC could sell under-price components and semi-finished products to its subsidiaries. So subsidiaries could assemble or finish the final product at prices that would have been classified as dumping prices, and they had been imported directly into the country rather than produced inside. ${ }^{104}$

Furthermore, MNCs can use transfer prices in a similar manner to reduce the impact of tariffs. Tariffs increase import prices and apply to inter-corporate transfers as well as to sales to unaffiliated buyers. Although no company can do much to change tariffs, the effect of tariffs can be lessened, if the selling company under-prices the goods it exports to the

\footnotetext{
102 Jeffrey S. Arpan \& Lee H. Radebaugh, Op. Cit., P.212

${ }^{103}$ Sylvain R.F. Plasschaert, 1979, P.4

${ }^{104}$ Jeffrey S. Arpan \& Lee H. Radebaugh, Op. Cit., P.258
} 
buying company. Under-pricing inter-corporate transfers can also be used to get more products into a country that is rationing its currency or otherwise limiting the value of goods that can be imported. The subsidiary can import twice as many products, if they can be bought at half the price.

On the other side, in other situations the MNC can use artificially high transfer prices to circumvent or significantly lessen the impact of national controls. The government controls on dividend remittances can restrict the ability of the company to maneuver income out of a country. However, overpricing the goods shipped to a subsidiary in such a country makes it possible for funds to be taken out. High transfer prices can also be of a considerable value to a company if it gets a subsidy or earns a tax credit on the value of goods it exports. The higher the transfer prices on exported goods are, the greater is the earned subsidy or received tax credit.

The high transfer prices can also be desirable, when the parent company wishes to lower the apparent profitability of its subsidiary. This may be desirable because of the demands of the subsidiary's workers for higher wages or greater participation in company profits, because of political pressure to expropriate high-profit foreign-owned operations, or because of the possibility that new competitors will be lured into the industry by high profits. There are also inducements for having high-priced transfers, which go to the subsidiary when a local partner is involved; the inducement is that the increase of the parent company profits will not have to be split with the local partner. The high transfer prices may also be desired when increases from existing price controls in the subsidiary's country are based on production costs (including high transfer prices for purchases) ${ }^{105}$.

Transfer pricing can also be used to minimize losses from foreign currency fluctuations or $\mathrm{t}$ shift them to particular subsidiaries. By dictating the specific currency used for payment the parent determines whether the buying or selling company takes the exchange risk. Altering of the terms and timing of payments, and the volume of shipments cause the transfer pricing to affect the net exposure of the company.

Later on, the main problem of transfer pricing in a MNC clearly emerges when the MNC sets an optimal system of transfer pricing that has the purpose of overall profit

${ }^{105}$ Jeffrey S. Arpan \& Lee H. Radebaugh, Op. Cit., P259 
maximization of the MNC and also, at same time, has the real performance measurement and evaluation of subsidiaries and their managers.

\subsection{The Causes and Effects of Transfer Pricing}

It is necessary to discuss the important relations between transfer pricing practices and some other variables such as strategy, administrative process, performance management and evaluation, individual fairness, economic decisions, and company performance. The results of an empirical study (Eccles 1981) about how transfer pricing is managed in practice for 13 companies are summarized in the figure $(5-1)^{106}$

Figure (5 -1) shows that there are two principal determinants of transfer pricing practices: strategy and administrative process. Transfer pricing practices affect economic decisions, which in turn affect corporate performance. Transfer pricing practices also affect performance measurement, evaluation, and reward, which in turn affect perceptions of fairness by individual managers. Figure (5 -1) also shows that strategy and administrative process each directly affect economic decisions, corporate performance, performance measurement, evaluation, reward and individual fairness. The fundamental difficulty in managing transfer pricing involves establishing practices that will lead to decisions that enhance corporate performance, while at the same time the performance is measured, evaluated, and rewarded in the light of these practices in a way that managers perceive as fair.

\footnotetext{
${ }^{106}$ Robert G. Eccles, Op. Cit., Pp.7-11
} 


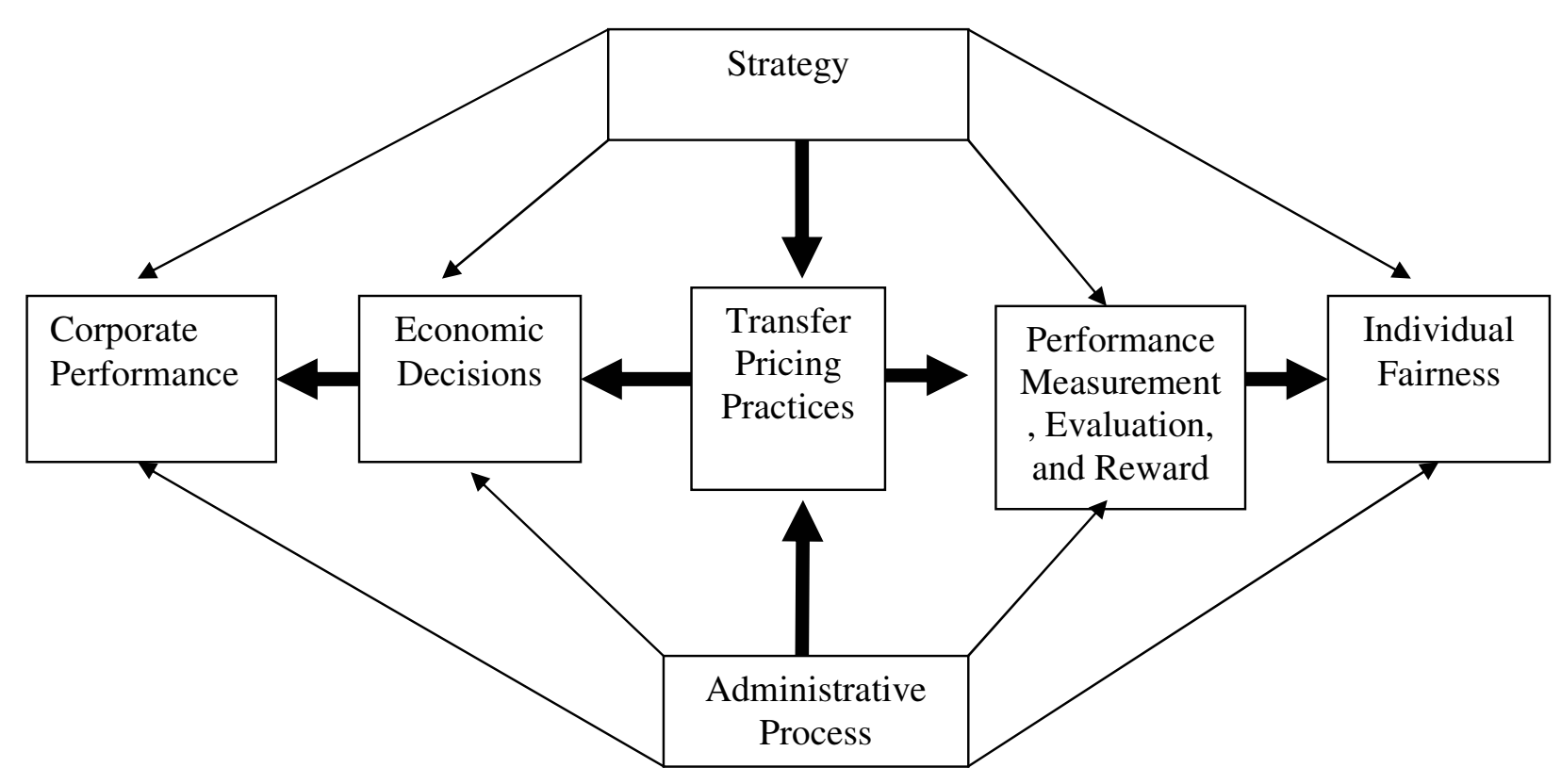

Figure (5 -1) Causes and Effects of Transfer Pricing

\subsubsection{Transfer Pricing and Company Strategy}

The first principal determinant of a company transfer pricing is the company strategy. As the figure (5 -1) shows, there is an important relationship between transfer pricing and strategy. Both company strategy and unit's strategies, such as strategies for subsidiaries, groups, divisions, or even individual products, affect transfer pricing practices. Every company in Eccles study had a general transfer pricing policy determined by its company strategy. For example, some companies had a corporate policy on inter-group transfers, but intra-group policies were left to the discretion of the group general manager. Usually a variety of practices were used according to variations in group, division, or product strategies. Further evidence of the importance of strategy was that as strategies changed, transfer pricing practices changed too.

Eccles identified three basic policies and a fourth hybrid policy that account for all transfer pricing situations described by managers in his study: exchange autonomy, full cost transfers, market-based transfers, and dual pricing. As the figure (5 -2) shows, the relationship between strategy and transfer pricing policy depends on two key aspects of strategy. The first aspect is whether there is a strategy of vertical integration for managing the interdependence between profit centers. If it is not the case, a policy of exchange 
autonomy is used. Inter-profit center transactions occur only when managers agree on them in both the buying and selling roles.

When there is a strategy of vertical integration internal transactions are mandated. If the selling profit center is only viewed as a distinct business for external sales and as a manufacturing unit for internal sales to other profit centers, these transfers are at full cost. If the selling profit center is viewed as a distinct business for both internal and external sales, transfers are market-based so that they mean profit or loss for the seller. These transfer prices may be based on external market prices, on markups, on cost that is designed to approximate market prices or on both.

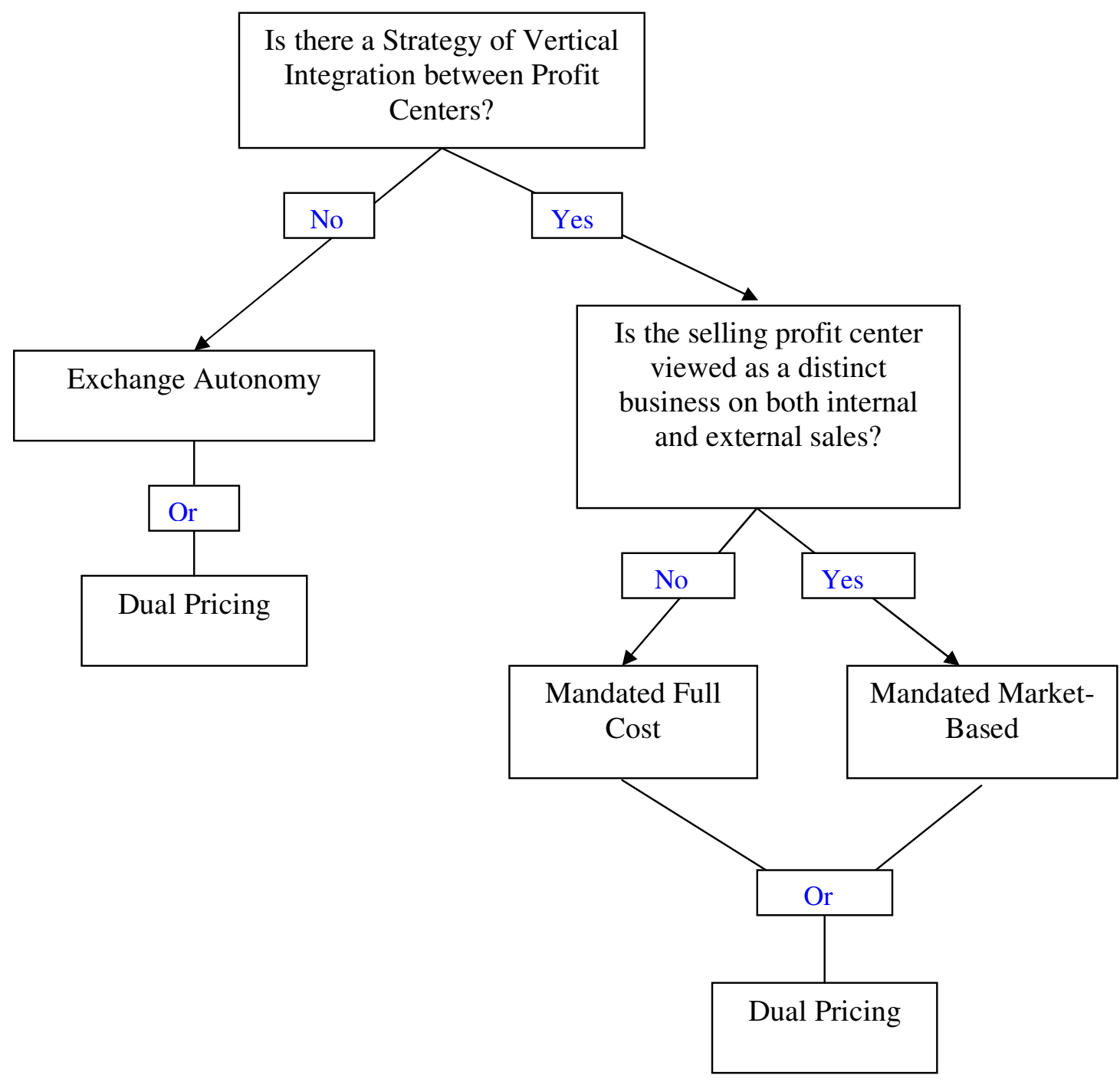

Figure (5 -2): The Relationship between Strategy and Transfer Pricing Policy 
The hybrid policy, dual pricing, is called like that because it involves two prices, full cost for the buying profit center and a market-based price for the selling profit center. Dual pricing is used when ever internal transactions are mandated and when they are not. If they are mandated this hybrid policy is designed to compensate the management of the buying profit center for the lack of authority in order to select outside vendors. If internal transactions are not mandated it is used to provide an incentive to buying profit centers in order to source internally.

The relationship between strategy and transfer pricing policy is so close that it is nearly a tautology. Without a policy of mandated transactions it is difficult to implement a strategy of vertical integration. Conversely mandated internal transactions are tantamount to a declaration of a vertical integration strategy. Similarly, when mandated transactions are transferred at full cost it is clear that all profits (or losses) on the external sales of the final good are contained in the unit receiving the transferred good, just as it would be the case, if this unit manufactured the intermediate good by itself. But when the selling unit transfers the intermediate good at a price similar to an external transaction it is held responsible for all profits and losses, just as if its entire output was sold externally. In this sense, it is identical to profit centers, which are defined in terms of distinct businesses that have no interdependencies with businesses in other profit centers.

The relationship between strategy and transfer pricing policy is the basis for the first general prescriptive statement. A company's transfer pricing policy should match its strategy, as shown in figure (5 -2). If it does not the policy it will be less effective for implementing its strategy than the appropriate policy would be.

\subsubsection{Transfer Pricing and Administrative Process}

The second principal determinant of a company's transfer pricing practices is the administrative process used for implementing its transfer pricing policy. Whereas strategy determines what a company does administrative process determines how it does it. Five major administrative process components are especially relevant for transfer pricing : (1) how the transfer price is set (from programmed to un-programmed decision making), (2) the individuals involved (different levels of general managers, financial managers, and other manager, (3) which kind of information is used (on costs, external transactions, and internal transactions), (4) when transfer prices are set (how frequently and under which 
conditions they are changed), and (5) how conflict is managed (what conflict resolution mechanisms are used and who is involved).

Although there is a relationship between the policy and the nature of the administrative process used to implement it, a great deal of variation is possible, which makes it difficult to make general prescriptive statements. Administrative process is also affected by other aspects of the company's strategy, by the management style of the involved managers, by the company culture, by technological and market characteristics of the transferred product and the products that incorporate it, and by general business conditions.

\subsubsection{Effectiveness of Transfer Pricing Practices}

There are two criteria to evaluate the effectiveness of the company's transfer pricing practices. The first criterion is whether these practices lead to economic decisions that positively affect the corporate performance including capital investment decisions, output level decisions for the intermediate and the final good, and product pricing decisions for the external sales of the intermediate and the final good. As figure (5 -1) shows, corporate performance is affected by strategy and administrative process directly and through their effect on transfer pricing practices. Although transfer pricing can affect corporate performance, Eccles suggested in his study that managing this relationship is less difficult than managing the relationship between transfer pricing practices and performance measurement, evaluation, and reward. ${ }^{107}$

The second criterion to evaluate transfer pricing practices - and the one that is the most difficult to satisfy - is whether the managers feel that they are fairly rewarded for the contribution they make to the company. If they do not they may be short- and long-term negative effects on the corporate performance. Administrative process plays an important role in reflecting the perception of fairness through its effect on transfer pricing practices, on how performance is measured, evaluated, and rewarded, and on other variables, which affect an individual's perception of how the manager is being treated.

A tension can exist between these two criteria of the effectiveness of the company's transfer pricing practices, since transfer pricing practices that lead to the best economic decisions for corporate performance may not result in perception of fairness regarding how

${ }^{107}$ Ibid, P.11 
the performance is measured, evaluated, and rewarded, and vice versa. In such cases, the solution for transfer pricing problems is not to change transfer pricing practices but the other factors that influence economic decisions or how performance is measured, evaluated, and rewarded.

\subsection{Transfer Pricing Practices and Economic Theory}

In economic theory the role of prices is to allocate resources in the market. Similarly, the role of transfer prices is to allocate resources within the firm under the assumption that managers are motivated to maximize the profits of their division because some of their rewards are tied to the divisional financial performance. The objective is to find the price that will lead both the selling and buying divisions to choose output levels that maximize the total firm's profit. Autonomy is preserved in setting output levels but not in establishing transfer prices.

The first formal treatment of the transfer pricing problem based on economic theory was made by Hirshleifer (1956), who approached it as a problem in marginal analysis. He implicitly assumed that the selling division was not operating at full capacity. He used the marginal cost as a transfer price between two divisions and showed that the market price was only correct when the transferred or intermediate good was traded in a perfectly competitive market; here the price was determined by the market.

In practice, a small percentage of transferred goods are traded in perfectly competitive markets. But the use of marginal cost faces two major difficulties: the marginal cost is difficult to calculate from information collected by cost accounting systems, and no provision is made for fixed costs, overhead and profit for the selling division. One of the biggest disparities between theory and practice is that economists regard fixed costs as "sunk costs," whereas businessmen expect to be reimbursed for them

The solution of marginal cost, says Hirshleifer can be only applied when there are two conditions. The first one is that the operating costs of each division are independent from those of the other divisions (the assumption of technological independence). The second condition is demand independence, whereby an external sale by either division has no effect on the other's demand. He also concluded his analysis with the qualification that transfer prices only applied to short-term decisions, without a change in the existing capacity. 
Abdel-khalik and Lusk (1974) criticized the marginal cost approach for many reasons, with its assumptions of (1) temporal stability, such as in cost relationships, (2) technological independence, and (3) linear production functions. They also criticized it for its susceptibility to gaming by division general managers, for permitting inefficiencies in the selling division to be passed on to the buying division, for providing no cost-benefit analysis for a marginal cost-pricing system, and for being applicable to two divisions only.

Figure (5 -3) illustrates the definition of the transfer pricing problem according to economic theory. It ignores strategy, since it does not ask what kind of business a company chooses or how it chooses to compete in these businesses. Instead of that, it focuses on profit maximization under the un-stated assumption that the factors are given. Although it focuses on economic decisions, it does so primarily in terms of output levels. It ignores the effect of transfer prices on product pricing for external transactions and on capital investment decisions and it ignores the necessary administrative process for implementing the recommended policies of marginal cost. Finally, it does not address of all the implications of these policies for performance measurement, evaluation, and reward in terms of the perception of individual fairness. This is a critical omission, since these policies restrict the autonomy of managers to set transfer prices by themselves and since the given transfer prices by the corporate headquarters do not reflect the profits and losses, which would be achieved in market price transfers. 


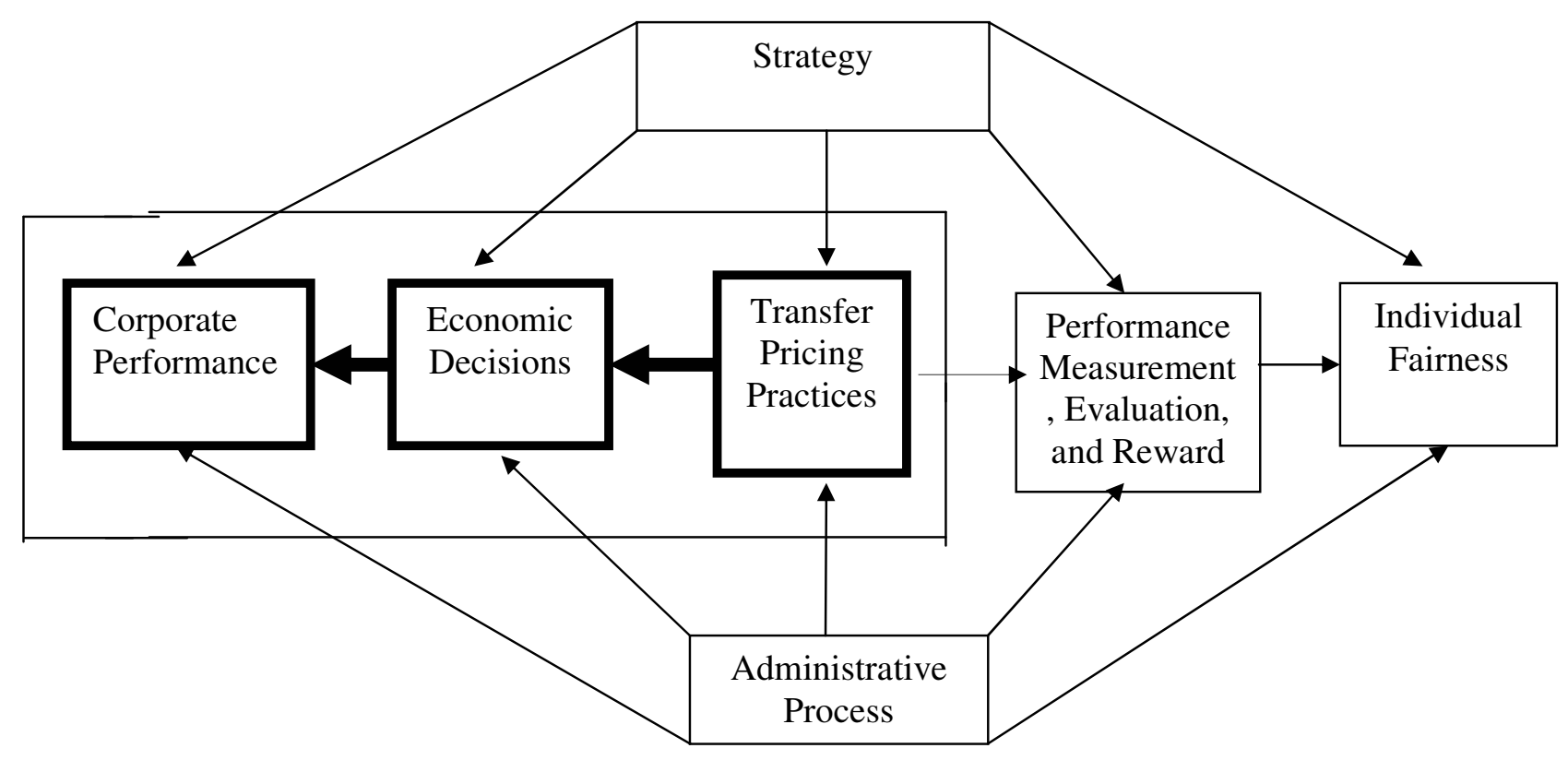

Figure (5 -3): Economic Theory's Definition of the Transfer Pricing Problem

\subsection{Transfer Pricing Practices and Accounting Theory}

Both practicing and academic accountants have extensively written on the transfer pricing problem. Like for economists, their objective is to find a way to determine the transfer price that will result in decisions at the divisional level, which are optimal for the firm as a whole, by using the same assumptions about motivation and incentives. The accounting theorists assume that transfer prices affect resource allocation decisions, as the amount of intermediate product that the selling division transfers, the amount that the buying division internally source, output levels of both divisions, make-or-buy decisions, capital budgeting decisions, decisions for which products are dropped, and pricing of final goods. But they are equally concerned about the effects of transfer prices on performance measurement and evaluation. Furthermore, they are especially aware that transfer prices that lead to profit maximization for the firm as a whole interfere with the objective of measuring divisions as independent profit centers. This creates the potential problem that most of the motivational advantage of a profit center can be lost.

The debate in accounting theory focuses on whether market price or standard variable cost should be used. The market price is the best to evaluate the divisional performance, and standard variable cost is the best way to maximize profits. The debate in accounting theory 
is also about the issue whether divisions should be free to choose between internal and external transactions.

Figure (5 -4) summarizes the definition of the transfer pricing problem in accounting theory. Like economic theory accounting theory focuses on how transfer prices affect economic decisions and thus one aspect of corporate performance. It is also concerned about such economic decisions like product pricing of externally sold goods, a largely ignored aspect by the economic theory. But accounting theory also pays more attention to the role of transfer prices in measuring and evaluating divisional performance, even if this implies some sacrifice in profit maximization. by doing so, it recognizes, that policies, which optimize short-term profits may not be optimal over the longer term. However, strategy does not play a role in the accounting theory of transfer pricing. In accounting theory, there is also little recognition of the criterion of individual fairness, although it is somewhat implicit in the treatment of performance measurement and evaluation. Finally, administrative processes are only considered to a limited extent.

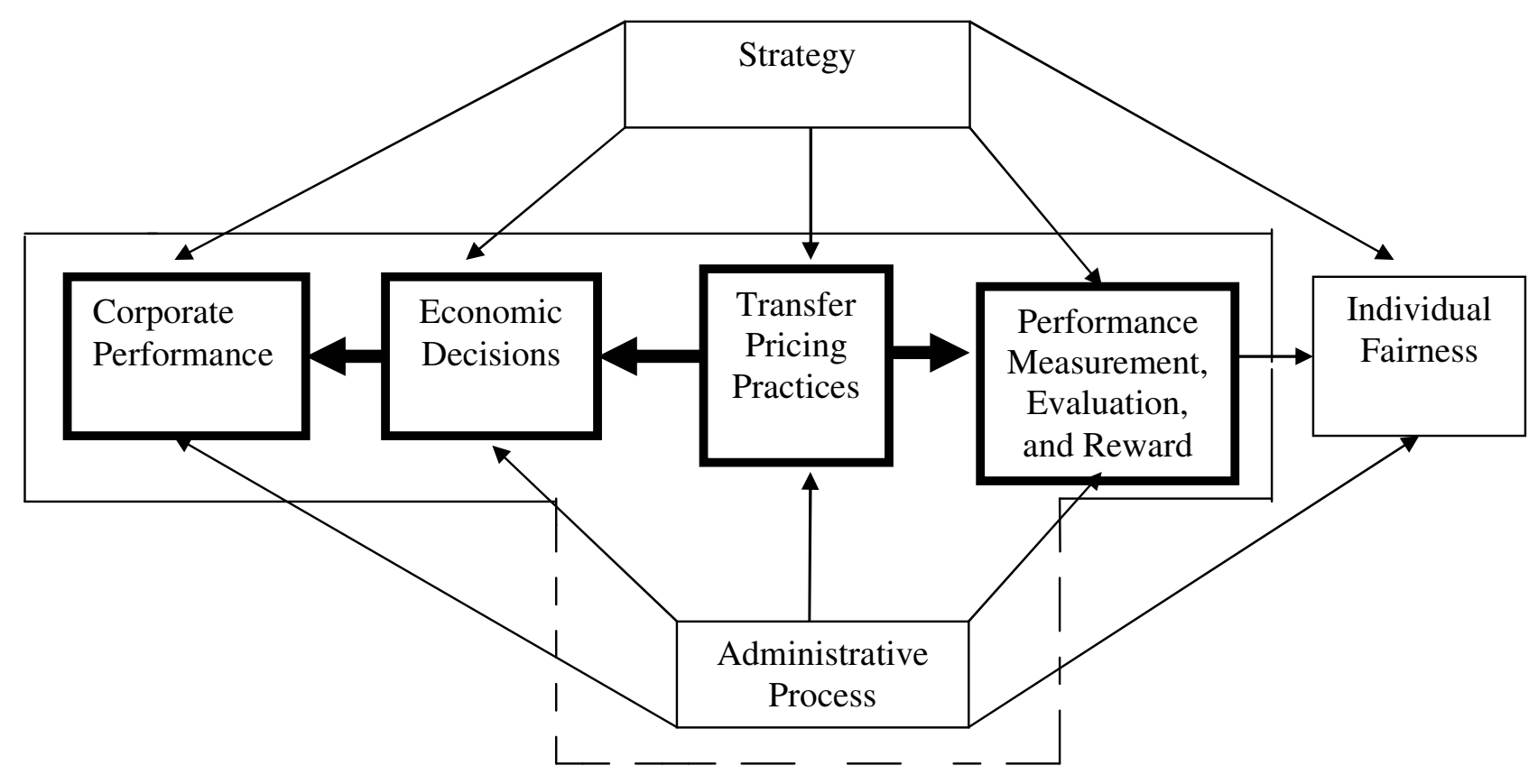

Figure (5 -4): Accounting Theory's Definition of the Transfer Pricing Problem 


\subsection{Transfer Pricing Practices and Management Theory}

In the field of management, primarily academics in the fields of business policy and organizational behaviour regarded the relationship between transfer pricing practices and administrative process. They replace the strict profit maximizer with a profit satisficer and do not tie rewards strictly to the divisional financial performance. They also regarded transfer pricing as an attempt to substitute arbitrarily for the missing market mechanism in order to get each division to behave as if it were independent from the others. They emphasized the social and political processes involved in strategy formulation and saw transfer pricing as one particular way of a communicating corporate strategy. They conducted that the process of devising pricing rules, procedures, and prices may be as important in achieving some degree of organizational control as the rules, procedures, and prices themselves. Whereas the profit maximizing perspective completely ignores the problem of process, they suggested that the processes are more important than the transfer price itself. By doing so, they recognized the role of transfer pricing in establishing a shared set of beliefs, which in turn may form the basis for structure and control.

The behavioural studies emphasized the importance of the exercise of subjective judgment by division managers. They identified the problem of fairness as one of the three criteria for the design of a transfer pricing system, and they regarded this criterion together with profit-maximizing economic decision making, as more important than evaluating divisional profitability. ${ }^{108}$

Some researchers examined the problem of managing conflict between divisions, and decided that transfer pricing contributed to both differentiation and integration. They thought that it enhanced differentiation because it pinpointed at the responsibility of profit centers, and they believed that proper determination of transfer prices would facilitate integration of the divisions' efforts.

Figure (5 -5) summarizes the management theory perspective of the transfer pricing problem. The primary focus is on individual fairness and administrative process, and managing conflict is the central concern in the administrative process. Other process questions, such as, what kind of information is used, who is involved, and when transfer prices are set, receive much less attention. Similarly, little attention is given to performance measurement, evaluation, and reward, although this is how fairness is ensured. Strategy is

${ }^{108}$ Ibid, P.38 
also included in the management theory's treatment of the transfer pricing problem, but to a very limited extent. Finally, economic decisions and the corporate performance are almost completely ignored.

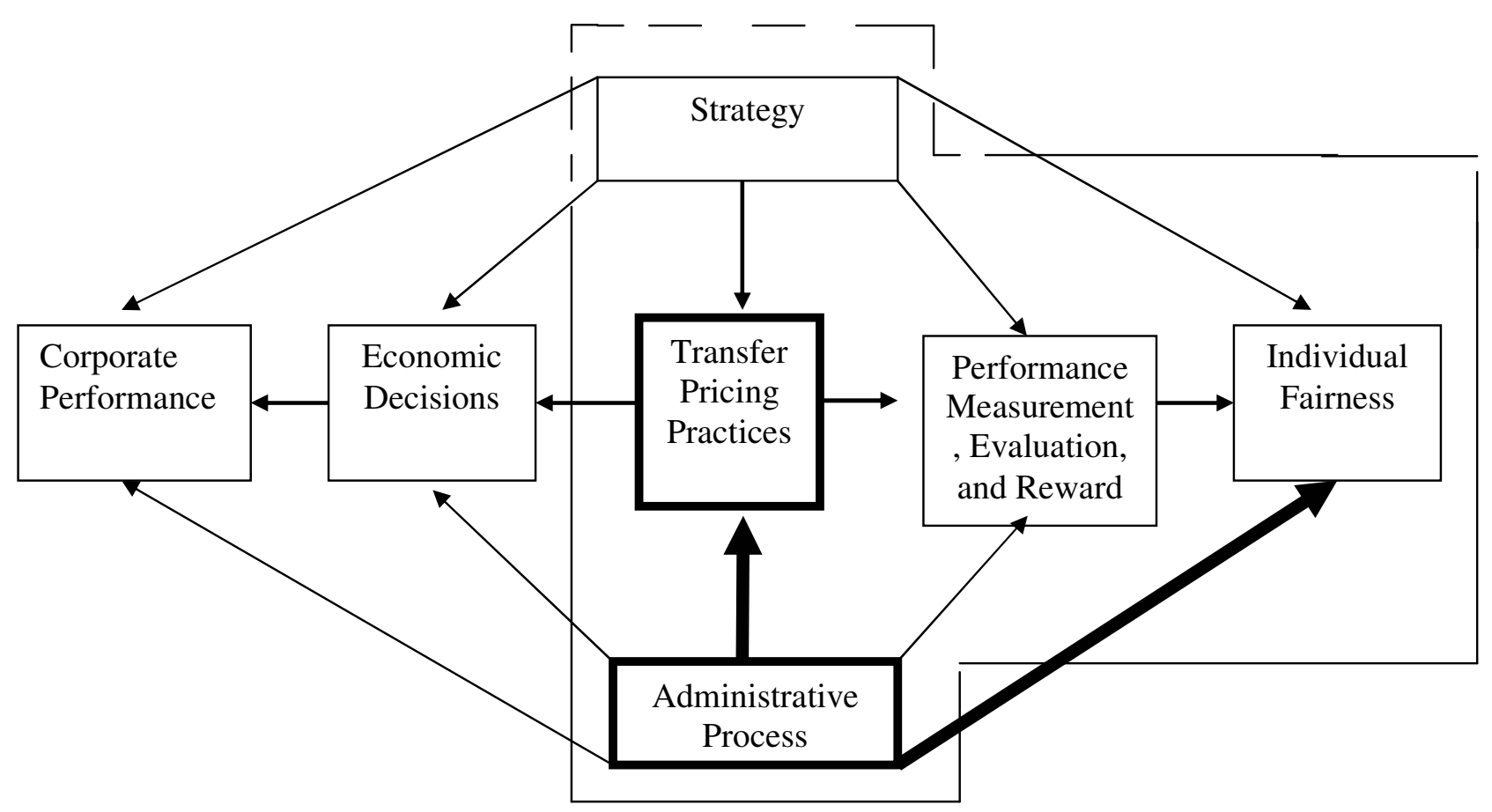

Figure (5 -5) management Theory's Definition of the Transfer Pricing Problem

In the light of all advances in economic theory, accounting theory, and management theory, it is surprising that the transfer pricing problem has remained so vexing. Some managers and academics have described it as intractable. In general, the transfer pricing system represents a managerial challenging situation to the company management. It must address the two criteria of corporate performance, beyond short-term profit maximization, and individual fairness. It also incorporates complex variables of strategy and administrative process.

\subsection{Objectives of Domestic Transfer Pricing System}

It is generally agreed about that the transfer pricing system for a domestic corporation should accomplish certain objectives including (1) the communication of information resulting in desirable decision making by managers, (2) providing a report of divisional 
profits that reasonably measures the economic performance of the division, and (3) enhancing goal congruence (coordination) ${ }^{109}$.

Achieving these objectives may be difficult. If a manager makes a decision that increases the profit of his or her particular profit center, it may affect the profit of a competing profit center negatively. An example of such a decision is charging a inflated transfer price for goods, which are transferred to a division. The first profit center will show increased sales and a higher profit, however, the second profit center would have increased costs of purchases and a lower profit.

The companies, which develop domestic internal transfer pricing systems must be aware of this potential dilemma, and should attempt to create a system that helps managers not to make undesirable decisions. Ideally, the manager acts in the best interests of the company as a whole, even at the expense of the reported profit of his or her own division. To gain this ideal behaviour, the system of performance evaluation must reward a manager who favours company-wide goal congruence over divisional performance.

\subsection{Objectives of International Transfer Pricing System}

The development of a transfer pricing system in a MNC is far more complex than to develop a domestic system. As with a domestic corporation the MNC pricing system should help managers for desirable decision making to enhance goal congruence. Providing a reasonable measure of a subsidiary's economic performance is often an irrelevant transfer pricing objective, if one deals with an MNC.

The pricing system of MNC must attempt to meet the objectives of the strategic plan, the management control system, and the system of performance evaluation. The international transfer pricing system must also attempt to accomplish objectives that are irrelevant in a purely domestic operation. These objectives include (1) worldwide income tax minimization, (2) minimization of worldwide import duties; (3) avoidance of financial restrictions, (4) managing currency fluctuations; and (5) winning approval of host country government. It is unlikely that an MNC would be able to accomplish all objectives with a single transfer pricing strategy. MNC strategies may vary as environmental variables change.

${ }^{109}$ G. G. Mueller, H. Gernon, G. Meek, Op. Cit., P.167 


\subsubsection{Worldwide Income Tax Minimization}

The transfer pricing system can be used to shift taxable profits from a country with a high tax rate to a country with a low tax rate; the result is that after taxes the MNC retains more profits. Unless the performance evaluation system is compatible with the transfer pricing system, undesirable decision making can occur at the subsidiary manager level. If each subsidiary is evaluated as an independent profit center, the transfer pricing policies must be considered in the evaluation of the manager's performance, or other conflicts between subsidiary and MNC goals may result. Thus, transfer prices are often effective measurements of minimizing the tax burden of the $\mathrm{MNC}$ as a whole by controlling income, which is operated in and taxed by the various host countries ${ }^{110}$.

\subsubsection{Minimization of Worldwide Import Duties}

Transfer prices can reduce tariffs. Import duties are usually applied to inter-company transfers as well as to sales to unaffiliated buyers. If the goods are transferred at low prices the resulting tariffs will be lower. The same pricing strategy may be used if a country places a ceiling on the value of goods that are allowed to. By valuing at low transfer prices, a subsidiary may be able to import a larger quantity of goods and services. If a country had a low tariff on imports a higher transfer price could be charged.

Tariffs also interact with income taxes. Low import duties are often associated with a country with high income tax rates. The opposite may also be found, high import duties with low income tax rates. The MNC must deal with the customs officials and income tax administrators of the importing country and with the income tax administrators of the exporting country. A higher import tariff would result in a lower remaining profit for determining income taxes. The MNC has to evaluate the benefits of a lower (higher) income tax in the importing country against a higher (lower) import tariff, as well as the potentially higher (lower) income tax paid by the $\mathrm{MNC}$, in the exporting country.

\subsubsection{Avoidance of Financial Restrictions}

When the foreign government places economic restrictions on MNC operations, transfer prices may mitigate the impact of these national controls. One assumes that a country restricts the amount of cash that may leave its boundaries in form of dividend payments. Setting a high transfer price on imported goods into the country may facilitate the desired

${ }^{110}$ Elwood L. Miller, Op. Cit., P.174 
movement of cash because the importing subsidiary must remit payment. However, cash transfers are not easily accomplished in a country that watches import and export prices closely.

Some countries allow a tax credit or subsidy based on the value of exported goods. In this case, a high transfer price on exported products is followed by a larger tax credit or higher subsidy. This kind of a tax credit reduces the corresponding tax liability to the host country dollar for dollar and more than offsets the higher taxable income. A subsidy is generally a payment from the government to the subsidiary.

Restrictions may be placed on the MNC by disallowing a foreign subsidiary to deduct certain expenses provided by the parent against taxable income. Common examples include research and development expenses, general and administrative expenses, and royalty fees. By inflating the transfer price of imports to the subsidiary such expenses can be recovered.

If the MNC desires to show lower (higher) profitability, high (low) transfer prices on imports to subsidiaries may be used. The MNC sometimes want to appear less profitable in order to discourage potential competitors from entering the market. Higher profits may lead the subsidiary's employees to demand higher wages or even to request some type of profit-sharing plan. Expropriation (takeover) of highly profitable foreign-owned subsidiaries may also be avoided, if they appear less profitable.

Lower transfer prices on imports should improve a subsidiary's financial position. This may be desirable when the MNC wants to finance its foreign subsidiary with funds from the local lender rather than to commit its own capital. In this instance, the lender would probably require that the subsidiary has a positive financial condition. Lower transfer prices can also allow the subsidiary to enjoy a competitive edge during its initial stages of growth.

\subsubsection{Managing Currency Fluctuations}

A country, which suffers from balance-of-payments problems, could decide to devalue its national currency. The losses from devaluation may be avoided by using inflated transfer prices to transfer funds from the country to the parent or to some other affiliate. 
Balance-of-payments problems often cause from an inflationary environment. Inflation erodes the purchasing power of the MNC's monetary assets. By using inflated transfer prices on imported goods to such an environment may cause a timely cash removal method.

\subsubsection{Winning Host-Country Government Approval}

The manipulation of transfer prices has not proceeded unnoticed. Generally, there is an increased government concern about intra-corporate pricing and its effect on reported profits. When the MNC is concerned about justifying its existence, it is a good idea to maintain positive relations to host government.

Most governments are becoming more sophisticated and aware of the results of using high or low transfer prices. Using unfavourable prices to a country's detriment may result in the loss of goodwill. It is beneficial to develop in the long run transfer pricing policies that satisfy the foreign authorities, even though it means to sacrifice some profits.

In summary, after we have discussed the transfer pricing objectives that MNCs must consider, and which are not applicable to a purely domestic corporation, the MNCs may resort to maintain a separate set of financial information for the foreign governments and another set for the headquarters for using in the management control process and the performance evaluation system. Unfortunately, the information provided for the foreign government is often used to evaluate the performance of subsidiary that has been told to produce a low profit to minimize income taxes. If headquarters overlooks the fact that low profits are due to an unfavourable transfer price, tensions between subsidiary managers and headquarters may come up. It may also cause subsidiary managers to act undesirably. In the long run moral problems could develop and destroy the short-run effect of tax minimization.

Ideally, the objectives of the management control process should be separated from those of MNC transfer pricing. Headquarters must realize that the performance evaluation system should provide information that distinguishes between subsidiary performance and worldwide corporate performance. 


\subsection{Methods of Transfer Pricing}

In the theory and practice there is a multiplicity of different transfer price forms. They can completely be summarized into the following three types: ${ }^{111}$

1-Cost-Based Methods

2- Market-Based Methods

3- Negotiated or Bargained prices

\subsubsection{Cost-Based Methods}

Dependent subunits usually use methods based upon cost. Cost-based methods are commonly applied to both vertical transfers (for successive levels of production or distribution) and horizontal transfers (for similar levels of production or distribution) by captive units (that are not free to buy and sell as they want). Consequently, transfers at cost tend to be favoured by the more centralized firms as the basis for control, decision making, and performance evaluation. Problems arise when a division's output is soled to external customers, as well as when it is transferred within the organization.

In general, transfer prices based upon cost are simple and inexpensive. Cost data are routinely available with accounting systems, are comprehensible, and often represent the only practicable choices, where external markets for the goods or services do not exist or are not realistic. Generally, cost-based prices are considered to be the only logical means to account for internal transfers from cost centers.

There are four types of cost-based methods: (1) full cost (standard or actual); (2) full cost plus; (3) variable cost (standard or actual); and (4) variable cost plus.

\subsubsection{Full-Cost Methods}

Full-cost (standard or actual) methods have several advantages: 1) standard costs prevent normal variances from being passed on to transferees, yet it permits the addition of unusual costs, such as those caused by special or rush orders, 2) fixed costs are included to assist in long-run decisions, 3) they are easy to defend internally (less friction) and externally (to government and regulatory agencies), 4) they are compatible with normal cost and budget systems, and 5) they facilitate systematic use over time.

But the disadvantages of full-cost prices are that they can be inadequate for decision making by transferees (unless variable costs are reflected separately); profits cannot be

${ }^{111}$ Raupach A. (hrsg.), 1999, Pp. 41-47. 
used as motivators for transferors, if intermediate transfers are based on cost, only selling units (final transferees) will record any profit; they exclude cost of capital employed by transferors; they are incompatible with decentralization of intermediate operations; and actual costs pass inefficiencies along to final transferees and may adversely affect their competitive positions.

\subsubsection{Full-Cost-plus Methods}

Full-cost-plus methods attempt to overcome some of the full cost disadvantages by the addition of increments in order to cover costs of capital and/or to represent pseudo profits. The latter action can be used to simulate market conditions and to obtain the profit benefits as a motivator, albeit artificial. In tax cases and similar situations where pricing practices must be defended cost-plus methods often satisfy arm's length criteria. But full cost-plus prices, however, only increase the inadequacies of full-cost data for decision making purposes.

\subsubsection{Variable-Cost Methods}

Variable-cost (standard or actual) prices are advantageous insofar as control and decision making are concerned: 1) they enhance systematic control of relevant costs (those that tend to change with volume of activity), 2) they assist lowest-cost input decisions and minimize the possibilities of outside purchases at higher costs for the organization, 3) they facilitate cost aggregation and pricing as well as output decisions by vertically integrated firms, and 4) they are essential for consideration of special orders, make-or-buy decisions, and distress pricing.

But the valid criticisms of variable-cost methods include: 1) lack of consideration of fixed expenses and employed capital, which may reduce long-term profitability, 2) profit cannot be used to motivate or evaluate, 3 ) they can lead to dumping charges, since prices are not representative of economic substance nor arm's length criteria, and 4) they are furthest removed from sensibility to market factors ${ }^{112}$

\subsubsection{Variable-Cost-Plus Methods}

While variable costs represent powerful tools for decision making in the short-run, all costs plus a reasonable economic return must be covered, if the entity is supposed to survive over time. Additives applied to variable costs, regardless of their intended purposes, serve

$\overline{{ }^{112} \text { Elwood L. Miller, Op. Cit., P.170 }}$ 
to blunt their capacities as decision tools. Consequently, this approach tends to be reserved for the handling of special purpose activities and usually represents the floor, or the lowest amount that can be used within a schedule of possible transfer prices.

\subsubsection{Market-Based Methods}

The benefits attached to market-based transfer prices are dependent on the assumption that a perfectly competitive external marketplace exists and functions. Assuming that a reasonably competitive market exists, market-based transfer prices have the following advantages: 1) units may be operated as autonomous entities, 2) advantages of decentralization may be obtained, with an increasing productivity and market share, 3) profits determined by external markets are less subject to internal manipulation and are reasonable measures of performance, 4) market prices serve as ceilings for transfers, when they are operated close to full capacity, since opportunity costs are spotlighted, when internal transfers are considered, 5) market factors increase the management's awareness of consumer needs and encourage innovation, 6) competitive market prices stimulate control of costs and encourage efficiency, and 7) market-based prices comply with arm'slength and other guidelines for fair business practices.

But as mentioned earlier, most of shortcomings of market-based transfer prices are the result of market imperfections: 1) market-based prices are impractical wherever no intermediate or final market exists at the transfer point, or where the markets are illstructured or imperfect in other respects, 2) they are inappropriate where list/nominal prices are only vaguely representative of real market prices, 3) under normal operating conditions (at less than full capacity), decisions regarding internal transfers may not be congruent with the best interests of the total enterprise, 4) overemphasis on market prices may result in lack of adequate attention to control of costs, 5) market prices are susceptible to collusion, if they are based upon what the market can bear, and 6) if market prices are not adjusted to market variables unfair schemes, such as zone pricing, can result.

\subsubsection{Negotiated or Bargained prices}

These prices represent refinements of market-based transfer prices. By definition amounts agreed upon by negotiation between the involved subunits, they represent most closely arm's length prices. Bargaining can adjust to unusual or inappropriate aspects of the marketplace and, in some cases, can simulate market conditions where none exist. Negotiation can improve the use of economic resources where an excessive capacity exists, 
if both parties are open to reasonable concessions. A negotiated transfer price is compatible with profit decentralization. It restores the divisional manager's freedom of action and thereby increases their accountability for profits. ${ }^{113}$

The problems related to negotiation in general also apply to bargained transfer prices. The process consumes expensive management time. All parties must be knowledgeable of market factors. Units must bargain from positions of similar strength, which means that each unit must be free to buy and sell. Captive units generally have a significant disadvantage in such negotiations. Transfer prices, which depend on future agreements, do not lend themselves to systemization.

\subsubsection{Dual Pricing}

Dual transfer prices represent a combination of the three preceding transfer price systems. These systems mean that the company uses two transfer prices ${ }^{114}$. One is used for the buying (or receiving) division for the transfers, whereas the selling (or receiving) division is credited with another. As an example of dual pricing, Drebin proposed that the buying division should be charged with marginal cost whereas the selling division should be credited for selling price minus profits and cost of completion. ${ }^{115}$

One of the key arguments for using dual pricing is that two sets of transfer prices would accomplish more objectives than a single transfer price would do. Nevertheless, some authors caution against the use of dual pricing, where the looseness of dual pricing may gradually induce unwelcome attitudes and practices.

\subsection{Selecting a Transfer Price}

A headquarters management team takes a global perspective while considering the tradeoffs between the costs and benefits of setting transfer prices for their operations throughout the world. Each pricing decision affects the entire multinational corporate system. It is extremely difficult to quantify the trade-offs, because each environment is different, and the variables are constantly changing. The decision makers must consider the tax rate, tariffs, inflation, foreign exchange controls, government price controls and government

\footnotetext{
${ }^{113}$ Roger Y. W. Tang, 1979,P.12

${ }^{114}$ Raupach, A., Op. Cit. P.47.

${ }^{115}$ Roger Y. W. Tang, Op. Cit. P.12
} 
stability. Transfer pricing decisions also affect individual subsidiaries and the MNC system simultaneously. ${ }^{116}$

In making transfer pricing decisions, the headquarters management team only considers the profits maximization of the whole MNC group regardless of other important considerations such as the real performance evaluation of subsidiaries and their managers. Thus, these practices of transfer pricing within the MNC group is not based on the arm's length principle, and it is not relevant to performance evaluation. If the MNCs want to make a good evaluation of the real performance of subsidiaries and their managers, they must apply the arm's length principle to transfer pricing. Thus, Section 482 of IRC (Internal Revenue Code) in the United States stated that all MNCs doing business in the United States must consider Section 482 of IRC in pricing inter company transactions.

\subsection{The Internal Revenue Code (IRC) and Transfer Pricing}

Section 482 of IRC in the United States gives the Internal Revenue Service (IRS) the authority to reallocate income and deductions among subsidiaries, if it determines that this is necessary to prevent tax evasion, illegal reduction of taxes, or to clearly reflect the income of a subsidiary. Inter-company sales of goods must show be priced at arm's length market values. In addition, the IRS also scrutinizes the transfer of services, intangibles (such as trademarks, patents, and basic research), and R\&D cost sharing arrangements among commonly controlled entities.

Being required to use arm's length transfer prices does not always allow an MNC to pursue the objective of worldwide profit maximization. But it allows evaluating the real performance of subsidiaries and their managers. The MNC pursuing tax minimization must be careful to use transfer prices that appear to reflect arm's length sales in order to avoid IRS scrutiny. IRC and related regulations allow three pricing methods considering arm's length: (1) the comparable uncontrolled price method (better known as market price); (2) the resale price method (received sales price for the property by the reseller is less than an appropriate mark-up; and (3) the cost-plus method (better known as cost-based transfer price). Other methods are allowed, if the MNC can show they approximate arm's length.

The transfer price MNC uses and the one required by the IRS may be the same, but not in every case. The IRS's objective is to determine the MNC's tax liability. The MNC's

${ }^{116}$ G. G. Mueller, H. Gernon, G. Meek, Op. Cit., P.171-172 
objective is after-tax profit maximization. The two objectives are not always compatible. Thus, the U.S. MNC may use one transfer price for internal reporting purposes and another for computing its U.S. tax liability. ${ }^{117}$

\subsection{Transfer Pricing and the Arm's Length Principle}

The arm's length principle is an international standard for determining transfer prices for tax purposes, which is set forth in Article 9 of the OECD Model Convention as follows: "where conditions are made or imposed between two enterprises in their commercial and financial relations, which differ from those which would be made between independent enterprises, then any profits which would, but for those conditions, have accrued to one of the enterprises, but, by reason of those conditions, have not so accrued, may be included in the profits of that enterprise and taxed accordingly". 118

The arm's length principle follows the approach of treating the members of the MNC group as operate entities rather than as inseparable parts of a single unified business. Because the separate entity approach treats the members of the MNC group as if they were independent entities, the attention is on the nature of dealing between those members.

There are several reasons why OECD member countries and other countries have adopted the arm's length principle. A major reason is that the arm's length principle provides broad parity of tax treatment for MNCs and independent enterprises. Because the arm's length principle puts associated and independent enterprises on a more equal footing for tax purposes, it avoids the creation of tax advantages or disadvantages that would otherwise distort the relative competitive positions of either type of entity ${ }^{119}$. By removing these tax considerations from economic decisions, the arm's length principle promotes the growth of international trade and investment. ${ }^{120}$

Finally, if the MNCs want to evaluate the real performance of their subsidiaries, they must apply the arm's length principle for transfer pricing between the members of the MNC group, because the arm's length principle deals with all entities within the MNC group as independent entities and it avoids the creation of tax advantages or disadvantages that would otherwise distort the relative competitive positions of either type of entity.

\footnotetext{
${ }^{117}$ Ibid, p. 174

118 OECD, 1994, P.19

${ }^{119}$ Oestreicher, A., 2003, P. 49.

${ }^{120}$ OECD, Op. Cit., P.27
} 


\section{Inflation and Performance Evaluation of MNCs}

Inflation is one of the environmental factors, which affecting the performance of multinational companies. It is considered as one of the variables (problems) that are out of control of subsidiary management. During inflation periods, the figures and information in the financial statements and reports are misrepresentative and may mislead the decision makers; consequently, they affect the performance of the company. Thus, the multinational company must consider the effect of inflation on the financial statements and reports of the company, if it wants to measure and evaluate the real performance of foreign subsidiaries in the host countries. Therefore, this chapter deals with some important points concerning inflation, such as: definition of inflation, causes of inflation and its effects on accounts of the company, ways to account for inflation, international approaches to accounting for inflation, and the relevant method to account for inflation for measuring and evaluating the real performance of multinational companies.

\subsection{Definition of Inflation}

Inflation, as defined from an economic standpoint, is an increase in the price of goods in terms of money. This implies that prices can rise for other reasons than changes in the nature of the product, technological advances, and so forth. Thus, the supply of money is increasing in relation to the excess supply of products in the market. ${ }^{121}$ Inflation also may be loosely defined as a decline of the purchasing power of money, due to an increase of the general level of prices ${ }^{122}$

Most people (although they are not technically correct) tend to look at inflation as a sustained increase in the price index from one period to the next. Because attitudes vary from country to country, it might be more accurate to say that inflation occurs when the price index increases above a tolerable level. Most countries express inflation as the quarterly or annual change in the consumer price index, which is based on a broad basket of consumer goods. The wholesale price index and the gross national product (GNP) deflator, and other indices, are also used in some countries.

The major reason for inflation is that there is too much money chasing for few goods. In other words, the demand for products exceeds the supply. Sometimes the money supply

\footnotetext{
${ }^{121}$ Arthur B. Laffer and Mark A. Miles, 1982, Pp. 258-259.

122 Geoffrey Whittington, 1991, P.4.
} 
expands too rapidly, by putting plenty of money in people's hands when there are not enough goods for them to buy. This pushes up the prices on available goods. Thus, government monetary policy is critical. Fiscal policy can also be putting more purchasing power in people's hands without an expansion of the goods production. Also, supply bottlenecks in one sector of the economy can create shortages in other sectors, which leads to price increases as demand outstrips the supply. A trade deficit can contribute to inflation.

Some of these examples of the reasons for inflation are related to cost-push inflation, in which an increase of the costs of production factors such as oil or labour tends to push up the price of products, which use those factors. Other examples relate to demand-pull inflation, in which an excessive demand and purchasing power pull up the price of products consumers want. Thus, while discussing the ways to account for inflation, one can consider the distinction between a general rise of the price level and price increases in specific sectors of the economy or even for specific products. ${ }^{123}$

\subsection{The Impact of Inflation on the Company}

Inflation affects the balance sheet and the income statement, which results in some strange operating decisions by managers who understand inflation and by those who do not. In terms of the balance sheet, financial assets, such as cash, lose value during inflation because their purchasing power diminishes. For example, if a business holds cash during a period when inflation rises by $10 \%$, that cash buys $10 \%$ less goods at the end of the period than at the beginning. Conversely, holding financial liabilities, such as trade payables, is wise, because the business would be paying its obligations with cheaper cash in the future. The one caveat here is that financial liabilities, such as short and long term bank notes, often carry very high interest rates in inflationary economies.

The effect of inflation on non-monetary assets is reflected in the income statement as well as in the balance sheet. During a period of rising prices to replace inventory and fixed assets becomes increasingly expensive. This could lead to higher profits, because current dollars sales are matched with inventory that may have been purchased several months earlier and with depreciation that is computed on property, plant, and equipment that may have been purchased several years ago.

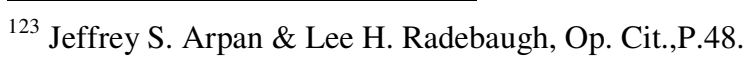


These effects of the balance sheet and income statement could lead the firm into liquidity crunch as the generated cash from revenues is consumed by the ever-increasing replacement cost of assets. The overstatement of profits that results from matching old costs with new revenues could lead to demands from shareholders for more dividends, even though the firm is watching its cash dwindle.

The tax consequence of inflation is also obvious. As profits rise, so does a firm's tax liability, it causes a further outflow of cash. We can say that the inflated financial statements misrepresent a firm's real operating position. The concern is that analysts and investors cannot make wise financial decisions without understanding the impact of inflation. If the government decides to slow down inflation by raising interest rates, reducing the money supply, or imposing wage and price controls the liquidity crisis may become more severe and the operating problems are compounded as the firm complies with government regulations.

Beside some other factors such as level interest rates, exchange rates, economic conditions etc, inflation influences developing the return on investment. According to this, the inflation risk has an effect on the real return of investment. ${ }^{124}$

\subsection{Ways to Account for Inflation}

There are two philosophies on accounting for inflation: adjustment for general price level changes (General Purchasing Power) and adjustment for specific price changes. General price level or constant dollar accounting is concerned that the value of the money has gone down, whereas specific price or current cost accounting is deals with the cost of specific assets has gone up. It is possible to apply these approaches to all items of financial statements, which can be adjusted, or only to some of the items. Furthermore, General Purchasing Power Accounting and Current Cost Accounting can be used separately or in conjunction with each other. Whatever the applied approach is, it is necessary to identify, which accounts have to be adjusted, what should be the basis for the adjustment, and where the adjustment should be reflected in the financial statements?

${ }^{124}$ Raimond Maurer \& Steffen Sebastian, No.51, Mai 2000, P.17. 


\subsubsection{General Purchasing Power (GPP) Accounting}

The general purchasing power approach is related to the concept of maintaining real financial capital, and reflects the effects of changes in the general purchasing power of the monetary unit, as measured by some general price index. The financial statements are restated in monetary units of the same general purchasing power, using the measuring unit current at the balance sheet date. ${ }^{125}$

The general philosophy that supports general purchasing power accounting (GPPA) is to report assets, liabilities, revenues, and expenses in units of the same purchasing power. The attitude is that the measurement unit should be uniform but the basis of measuring the financial statements (e.g., historical cost) should not change.

In most countries of the world financial statements are prepared on a historical costnominal currency basis. This means that the statements are not adjusted for changes in the general price level. Under general purchasing power accounting the non-financial items in the financial statements (inventory, plant, and equipment), are restated to reflect a common purchasing power, usually at the ending balance sheet date.

For example, assumingly a firm purchased a machine on January $1^{\text {st }}$, 2005, for $\$ 100,000$ and that the general price level (as measured by the consumer price index) increased by 15\% during the year. On December 31 the machine would appear on the balance sheet at $\$ 115,000\{100,000+(100,000 * 15 \%)\}$ less accumulated depreciation. The amount implies that it would take $\$ 115,000$ of the end-of-year purchasing power to buy what $\$ 100,000$ bought on January $1^{\text {st }}$. By the end of year the financial assets and liabilities (cash, receivables, and payables) would not be adjusted because they are already stated in terms of the December 31 purchasing power, but all other assets, liabilities, revenues, and expenses would be adjusted. When the 2004 and 2005 financial statements are compared, however, all the accounts of the year 2004 (including the financial assets and liabilities) would be restated to December 31, 1985, purchasing power in order to compare with 1985's financial statements.

There are some tendencies that general purchasing (GPP) accounting should be applied to financial assets and liabilities as well. For example, cash loses purchasing power during an inflationary period because it cannot purchase as much at the end of the period as it did at

${ }^{125}$ David Alexander \& Simon Archer. 2001, P. 8.08. 
the beginning. Debtors benefit during inflation period because they can pay their debts at the end of the period with cash, whose purchasing power decreased. Therefore, a firm that increases its net financial assets position during an inflationary period suffers a loss in purchasing power, whereas a firm that increases its net financial liabilities position enjoys a gain in purchasing power. ${ }^{126}$

Under general purchasing power (GPPA) accounting, a firm can realize a gain from holding an asset during an inflationary period. Now the question is: Where should the holding gains and holding losses be recognized? They could be reflected in the income statement as a holding gain or loss, or they could be reflected in the balance sheet as an adjustment to invested capital. Both approaches are used worldwide.

For measuring inflation the consumer price index is one of the most common used element to measure inflation. It measures the changes in prices for a broad range of consumer goods and services that are purchased for final consumption. This index is very broad and reflects the general change in prices and therefore in a currency's purchasing power.

In making the adjustments to the financial statements from a comprehensive standpoint, the historical cost values of non-monetary items are adjusted to changes in the price level. Non-monetary items such as inventory, property, plant, and equipment, are defined as financial statements' items that do not provide a right to receive or an obligation to pay a fixed sum of money. Income statement items are generally restated to constant dollars by using the average price index for that period. Depreciation expense and cost of sales would be restated by using the index in effect when the assets were purchased. ${ }^{127}$

\subsubsection{Current Cost Accounting}

Current cost accounting is concerned with the rise in the cost of specific assets, and not with the overall loss of purchasing power of a currency. In this concept, the income is not considered to be earned until the firm has maintained the replacement cost of its productive capacity. With current cost accounting, a new basis for valuing assets replaces the traditional historical cost.

\footnotetext{
${ }^{126}$ Jeffrey S. Arpan \& Lee H. Radebaugh, Op. Cit., P.50.

${ }^{127}$ Ibid., P.50-51
} 
There are two major approaches to current cost accounting: (1) replacement cost (or current entry price) and (2) net realizable value (or current exit price). The replacement cost (current entry price), the most widely accepted method, is used for most categories of non-monetary assets. Under this approach, assets are valued at what it would cost to replace them. Whether the value should reflect the same asset being replaced, or a similar asset performing the same function but with a newer technology, it has been the subject of considerable discussion.

The net realizable value (or current exit price) approach values assets, especially finished goods inventory, at what they could be sold less costs to complete and sell the items.

Current cost accounting results in holding gains and losses whenever non-monetary assets are re-valued. The gains and losses in these holdings can either be taken into the income statement or be reflected in the balance sheet as a capital adjustment account.

The current values are determined as the following: For the inventory, suppliers' lists are most commonly used because they reflect the most current prices for the items. Fixed assets are more complex. Property and plant are usually re-valued according to a specific index, such as a construction cost index. Equipment could be re-valued on the basis of a supplier list or engineering estimates - especially for machinery that is designed and built. Appraisal values are also a possibility for fixed assets. It is obvious that current cost accounting is more complex to administer because it requires a mixture of actual prices, estimates, appraisal values, and indices for homogeneous groups assets. ${ }^{128}$

\subsection{International Approaches to Account for Inflation}

Some countries and their scientific and professional institutions are interested in the problem of inflation and its effect on the accounts, financial statements and reports of the companies. It is very important to present some of the efforts of these countries and their institutions.

\subsubsection{The United States of America (U.S.A.)}

In 1922, Professor Paton noted that comparison of historical cost financial statements can be misleading during periods, in which the purchasing power of dollar is changing. Some

${ }^{128}$ Ibid, P. 52 
American institutions such as APB (Accounting Principle Board), SEC (Securities and Exchange Commission), and FASB (Financial Accounting Standard Board) did some efforts to account for inflation. These efforts are as the following:

6.4.1.1 Accounting Principle Board (APB): The first major comprehensive pronouncement concerning accounting for inflation was the Statement No.3 of the APB "Financial Statements Related for General Price Level Changes" issued in June 1969. Although the Statement recommended the historical cost-GPP financial statements it did not require that those statements be presented to investors and creditors. Thus, few companies actually put those principles into practice.

6.4.1.2 The Securities and Exchange Commission (SEC): In 1976, the Securities and Exchange Commission dropped a bombshell on the corporate world with Accounting Series Release (ASR) 190 on replacement cost accounting. ASR 190 required the disclosure of the following information in the 10-K report (an annual report that must be filed with the SEC) ${ }^{129}$ :

1- The current cost (both gross and net accumulated depreciation) of newly replacing the productive capacity of property, plant and equipment at the end of each year, for which a balance sheet was required.

2- The current replacement cost inventories at the end of each year for which a balance sheet was required.

3- The amount of depreciation (using the straight line method) for the two most recent financial years based on the average current cost of productive capacity.

4- The approximate amount, of which the cost of sales would have been for the two most recent financial years, if it had been calculated by estimating the replacement cost of goods and services at the time sales took place. ${ }^{130}$

The main objective of these regulations was to provide information for investors to assist them in obtaining an understanding of the current costs of the business. The information was supplemental to the primary historical cost financial statements and needed to be disclosed only in the $10-\mathrm{K}$ that had to be included in the annual report to shareholders.

\footnotetext{
${ }^{129}$ Ibid, P. 53

${ }^{130}$ Christopher Nobes \& Robert Parker, 1995, P.423-426.
} 
ASR 190 was issued because of the relatively high levels of inflation experienced in the United States during the early 1970s and the fact that the accounting profession did not do anything substantive in order to provide information for users about the impact of inflation on the financial statements. However, ASR 190 received significant negative reactions from a variety of sources.

ASR 190 had an important impact, because firms were forced to experiment with collecting and reporting the data. As noted in a study on ASR 190 by the Financial Executives Research Foundation (FERF), "management is almost unanimously opposed to present replacement cost disclosure," and "sophisticated investors and professional analysts do not believe that present disclosure of replacement cost is useful in making investment and credit decision" 131 .

6.4.1.3 The Financial Accounting Standards Board (FASB) ${ }^{132}$ : In September 1979, the Financial Accounting Standard Board (FASB) issued Statement 33 "Financial Reporting and Changing Prices. In this statement the board expressed concern management, creditors, current and prospective investors, and the general public. Then the board identified four ways, which should help users: (1) assessing future cash flows, (2) assessing enterprise performance, (3) assessing erosion of operating capability, and (4) assessing erosion of general purchasing power.

The Financial Accounting Standard Board (FASB) indicated that the Statement 33 applies to all public enterprises, which have inventories and property or plant and equipment (before accumulated depreciation) amounting to more than $\$ 125$ million, or total assets amounting to more than $\$ 1$ billion (after deducting accumulated depreciation). The adjusted information with inflation is to be published as supplementary financial information, because the traditional historical cost statements are to remain as the primary financial statements.

Statement 33 requires a combination of constant dollar and current cost information in order to encourage experimentation and help assess the impact of different kinds of information. The Financial Accounting Standard Board (FASB) noted that in response to its exposure draft issued in 1978, "many preparers and public accounting firms emphasized

\footnotetext{
${ }^{131}$ Jeffrey S. Arpan \& Lee H. Radebaugh, Op. Cit., P.54

${ }^{132}$ FASB: Financial Accounting Standard Board, FAS No.33, New York, Sept. 1979.
} 
the need to deal with the effects of general inflation; users generally preferred information dealing with the effects of specific price changes."

In order to comply with Statement 33, the following supplementary information needs to be disclosed:

1- Information on income from containing operations on historical cost/constant dollar basis.

2- The purchasing power gain or loss on net monetary items.

3- Information on income from continuing operations (cost of good sold and depreciation and amortization expense of property, plant, and equipment) on a current cost basis.

4- The current cost amount of inventory and property, plant, and equipment.

5- Increases or decreases in the current amount of inventory and property, plant, and equipment.

According to Statement 33, there are four major methods of determining replacement cost for a productive capacity: Direct pricing, indexing, unit pricing, and functional pricing. Direct pricing applies current prices to assets or homogeneous groups of assets. Direct pricing could come from actual invoices of recently purchased items, price lists of suppliers, or standard costs that reflect current prices. Some firms prefer to use an index, which serves as a surrogate for specific prices changes and can be applied to a homogeneous group of assets rather than to a specific asset. The assumption is that the specific prices of the assets move in the same direction and magnitude, and can be represented by the index. Unit pricing is a variation of direct pricing, in which a current cost per unit is applied to the number of units that are re-valued. Functional pricing applies a current cost per unit of a processing function times the number of units being processed.

The Financial Accounting Standard Board (FASB) prefers the use of the direct pricing method to make adjustments. But the review of the annual reports of U.S. companies reveals a variety of approaches for disclosing the inflation adjusted information, although most companies would fall within the guidelines set up by Statement No. 33

\subsubsection{The United Kingdom (UK)}

During the 1970s, the British accounting profession and the British government were active in generating proposals on methods to account for inflation in the annual accounts of British firms. The first major effort to account for inflation was a provisional standard 
issued in 1974 by the Accounting Standards Committee (ASC) of the English Institute of Chartered Accounts (EICA), which recommended supplemental price level, adjusted financial statements. ${ }^{133}$

In 1975, the Sandilands Committee on inflation accounting, a government-sponsored committee, issued a recommendation that favoured eliminating historical cost statements completely and instead current value accounting. Revaluations were to be based on a set of government-published indices for 52 classes of capital assets and inventory.

In 1976, the Accounting Standards Committee (ASC) of the Institute of Chartered Accounts of England an Walls (EICA) responded with Exposure Draft 18 (ED 18) (better known as Son of Sandilands), which also recommended the adoption of current value accounting but with an additional disclosure on the impact of inflation on monetary assets and liabilities.

In 1980, the Accounting Standards Committee (ASC) of the English Institute of Chartered Accounts (EICA) issued the Statement of Standard Accounting Practice 16 (SSAP 16) "current cost accounting". SSAP 16 was adopted by firms whose accounting period started on or after January 1, 1980. SSAP 16 demands that the following current cost information must be presented in the annual report: a current cost profit and loss account, a current cost balance sheet, and the current cost earning per share.

In 1982, the Imperial Chemical Industries (ICI), one of the largest chemical companies in the world, provided supplementary current cost information consistent with SSAP 16. It also provided 1981 financial statements, which were adjusted for general price level changes in order to compare them with the 1982 financial statements.

\subsubsection{The Netherlands}

The Dutch have been aware of current cost accounting for a long time, and there is a clear preference for it. Professor Theodore Limperg, often called the father of replacement value theory, focused on the strong relationship between economics and accounting and felt that income should not be earned without maintaining the source of income of the business from a going concern standpoint. Therefore, income is a function of revenues and

\footnotetext{
${ }^{133}$ Jeffrey S. Arpan \& Lee H. Radebaugh, Op. Cit., 58.
} 
replacement costs rather than historical costs. Also, he felt that current cost information should be used by all decision makers-management as well as shareholders.

In 1974, the preference for current cost accounting was reemphasized with the comment that current cost information on profit and equity should be contained in the footnotes to financial statements based on historical cost.

N.V. Philips, a big Dutch multinational company, uses current cost with some constant dollar adjustments to monetary items. Under its current cost accounting system both balance sheet and income statement accounts are justified. ${ }^{134}$

\subsubsection{The International Accounting Standards Committee (IASC)}

The first reaction of the International Accounting Standards Committee (IASC) to inflation accounting appeared in International Accounting Standard No.6 (IAS 6), "Accounting Responses to Changing Prices", in 1977. The IAS 6 required the disclosure of the effect of any procedures which are applied to reflect the impact of specific or general price changes. ${ }^{135}$

In 1981, the International Accounting Standards Committee (IASC) issued the International Accounting Standard No. 15 (IAS 15), "Information Reflecting the Effects of Changing Prices". The IAS 15 required the use of restatement on the basis of either the general price level or current costs when the reporting currency was subject to a significant degree of inflation. ${ }^{136}$

Also in 1989, the International Accounting Standards Committee (IASC) issued the International Accounting Standard No. 29 (IAS 29), "Financial Reporting in Hyperinflationary Economics," which requires general price level restatement, if the reporting currency is subject to hyperinflation. ${ }^{137}$

The IAS 29 requires financial statements to be restated in units of the same purchasing power, using the measuring unit current at the balance sheet date. According to IAS 29, paragraph 37 , this restatement should be made to use a "general price index that reflects

\footnotetext{
${ }^{134}$ Ibid., ,P. 63

${ }^{135}$ David Alexander \& Simon Archer, 2001, P.8.04.

${ }^{136}$ Ibid., P.8.04

${ }^{137}$ Ibid., P.8.04
} 
changes in general purchasing power," and it is preferable that the same index is used by all enterprises that report in the currency of the same economy. ${ }^{138}$

\subsubsection{The European Economic Committee (EEC)}

On July 25, 1987, the Council of Ministers of the European Economic Committee (EEC) adopted the Fourth Directive on Company Law dealing with company accounts. This directive deals with the layout of annual financial statements, valuation methods, contents of the annual reports, and provision concerning publication of the financial statements; and it also contains a section that deals with inflation accounting.

Although the historical cost accounting is considered to be the main basis for establishing account values by the Fourth Directive. The fourth directive allows the departure from the historical cost in the following three instances: (1) revaluation of tangible fixed assets and financial fixed assets, (2) replacement value accounting for tangible fixed assets with limited useful lives and for inventories, and (3) other accounting methods designed to take account of inflation. ${ }^{139}$

The inflation dimension to the Fourth Directive is designed to improve disclosure rather than to set a definitive standard on how to account for inflation.

\subsubsection{Some Other Countries}

Germany: In West Germany, a statement on inflation accounting was issued in October 1979 by a committee of German Institute of Accountants (Institut der Wirtschaftsprüfer). This document recommended that the effect of changing prices on profit should be shown in supplementary notes included in the annual reports and accounts. The supplementary information was expected to be audited. No adjustments were allowed in the main financial statements, although comments have occasionally been included in accompanying notes; for example, Siemens commented on the effect of price changes on profits on several occasions.

Although the academics have carried out a considerable amount of research on accounting inflation, the accounting inflation has not been used in Germany because of low rates of

\footnotetext{
${ }^{138}$ Ibid., P.8.06 - 8.07

139 Jeffrey S. Arpan \& Lee H. Radebaugh, Op. Cit.,P. 68
} 
inflation and the lack of taxation incentives. There was also a feeling in government circles that countries should attack inflation rather than introduce inflation accounting. ${ }^{140}$

Chile: The firms in Chile are required for tax and financial purposes to adjust certain accounts for inflation. The system is called a monetary correction system, and it involves adjustments of non-monetary assets and liabilities, as well as net worth. Inventory is adjusted to replacement cost, but the other adjustments all involve the use of the consumer price index. One of the interesting aspects of the Chilean system is that adjustments to asset and liability accounts are taken to the income statement rather than to an equity account. $^{141}$

Brazil: Since Brazil is known, for many years, for having one of the highest inflation rates in the world, Brazilian developed a complex system of indexing that involves maintaining purchasing power of certain monetary assets and liabilities, as well as adjusting certain financial statement items for the effects of inflation.

Argentina: The accountancy profession in Argentina has been heavily involved in the development of inflation accounting proposals, and a statement was issued in 1972 recommending the publication of supplementary General Purchasing Power (GPP) financial statements from 1973 onwards. It was envisaged that eventually these statements would replace historical cost information. ${ }^{142}$ Initially compliance was poor, as was shown by a study of companies listed on the Buenos Aires Stock Exchange, which showed that only $11 \%$ provided inflation-adjusted financial information and only $4 \%$ disclosed an adjusted profit figure. From 1993, current replacement costs are used for some parts of adjustment process.

\subsection{The Relevant Method to Account for Inflation to Measure and Evaluate the Real Performance of Foreign Subsidiaries}

After reviewing the methods and approaches to account for inflation, we can note that they are two approaches: The first approach is the current cost accounting, which depends on

\footnotetext{
${ }^{140}$ Christopher Nobes \& Robert Parker, 1995, P.423-424.

${ }^{141}$ Jeffrey S. Arpan \& Lee H. Radebaugh Op. Cit., P. 65,66

${ }^{142}$ Argentina Technical Institute of Public Accountants, (1972), Dictamen No. 2: sited in: Christopher Nobes \& Robert Parker, Op. Cit., P. 432.
} 
re-evaluation of the value of some assets affected with inflation by using the general or specific indexes.

The second approach is the purchasing power accounting, which the IAS No.29 adopted. This approach depends on an integrated system to adjust all the items of income and balance sheet accounts of the branches and subsidiaries to face the devaluation of the purchasing power. This approach also depends on the general or specific indexes to adjust all items.

Although the use of the specific index is more accurate and gives more acceptable results, it is more difficult than the use of the general index, because it requires accurate statistics and indexes about different kinds of assets, liabilities, and expenses. But this may be only available in the developed countries, and not in the developing countries.

I advocate the second approach to account for inflation (purchasing power accounting) which the IAS No.29 adopted in order to adjust the accounts with the inflation effects ${ }^{143}$, because this approach represents an integrated system. According to this approach, all items of income and balance sheet accounts of branches and subsidiaries are adjusted to face the effects of inflation by using the general indexes, because it is very difficult to obtain specific indexes, especially in the developing countries.

This approach the IAS No.29 adopted distinguishes between the monetary and nonmonetary items of assets and liabilities. Where the monetary items are not affected the price level changes in the date of preparing the balance sheet. While the non-monetary items are affected the price level change, thus, must be adjusted to the inflation effects.

\subsection{Restate - Translate or Translate - Restate Approach}

When the MNC adjusts the financial statements of subsidiaries to reflect the inflation effects, it has two options, either it begins with adjusting the financial statements of foreign subsidiaries to reflect the inflation effects and after that translating these financial statements into the currency of the mother company (Restate - Translate Approach), or it begins with translating the financial statements of foreign subsidiaries into the currency of the mother company and after that adjusting these financial statements to reflect the

\footnotetext{
${ }^{143}$ David Alexander \& Simon Archer, Op. Cit., P.8.07
} 
inflation effects (Translate - Restate Approach). Every approach gives different results than those obtained from the other mentioned before. The figure (6-1) shows the two options.

In the Restate - Translate Approach, the MNC starts at first with adjusting the financial statements of foreign subsidiaries by using general prices indexes. After adjusting the financial statements, the MNC translates the values of the adjusted financial statements into the currency of the mother company by using relevant exchange rate.

According to the Translate - Restate Approach, the MNC translates the financial statements of the foreign subsidiaries into the currency of the mother company by using relevant exchange rate, and after that the $\mathrm{MNC}$ adjusts the translated financial statements of foreign subsidiaries by using the general prices indexes in the mother country

For measuring and evaluating the real performance of foreign subsidiaries it is preferable to use the Restate - Translate Approach. It means that the MNC starts with adjusting the financial statements of foreign subsidiaries by using general prices indexes, and after that translating the values of the adjusted financial statements into the currency of the mother company by using relevant exchange rate.

The Restate - Translate Approach is a preferable approach, because this approach has the following advantages: (1) this approach reflects the inflation effects in the host countries on the results of subsidiaries, (2) This approach provides the mother company with data that enable it to evaluate the effect of exchange rate fluctuations on the results of subsidiaries, (3) this approach reveals the net effects of the results of transactions, inflation, and currency fluctuation. Consequently, it enables the Headquarters management to evaluate the relative performance of its subsidiaries in a good way. 


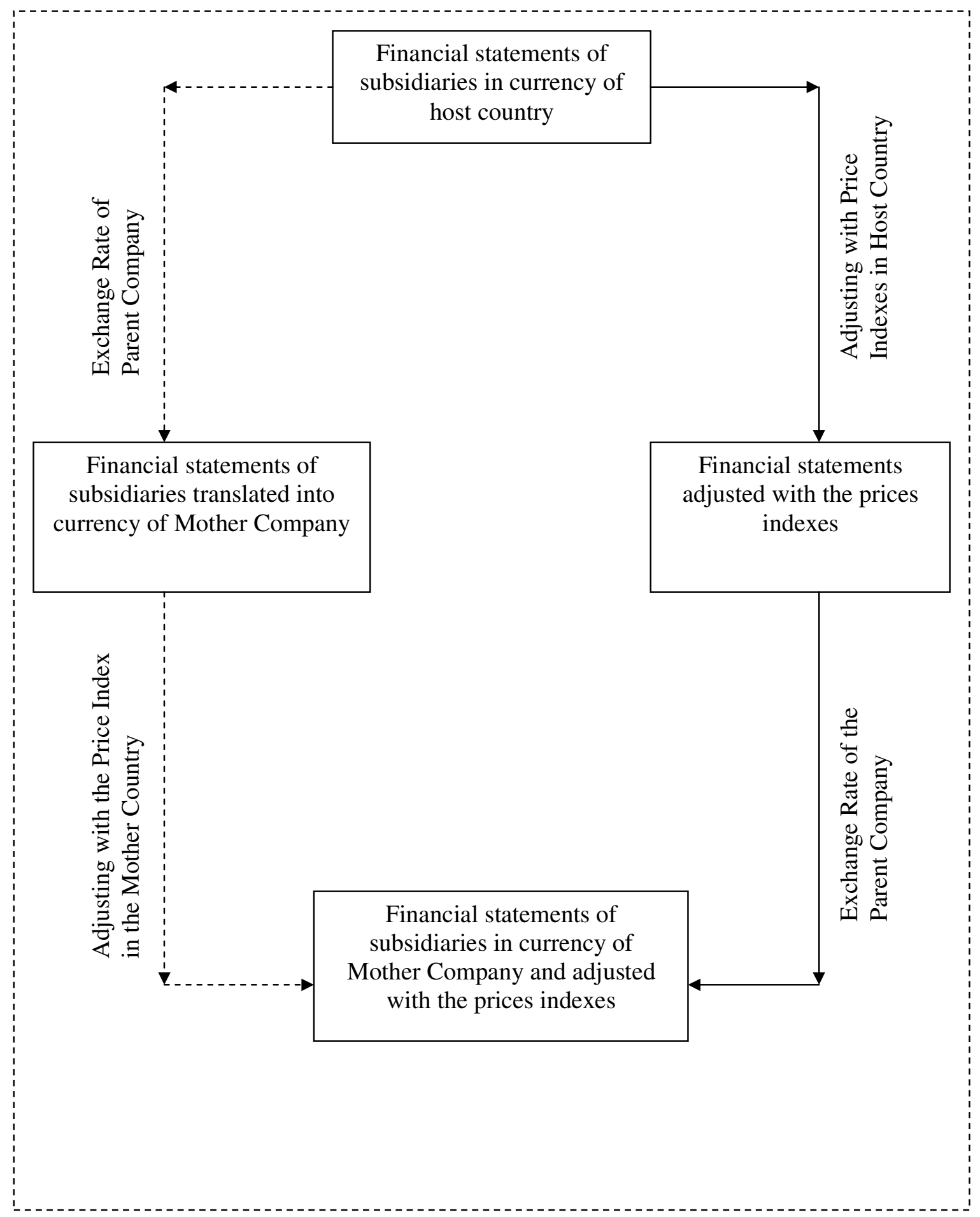

Figure (6-1): Options of Restate and Translation of Financial Statements of Foreign Subsidiaries

The Restate - Translate Approach

The Translate - Restate Approach 
In the end, we can say that before the MNC measures and evaluates the performance of the foreign subsidiaries. It must adjust the financial statements of the foreign subsidiaries with general indexes, which express the changes in the general purchasing power, consequently, to reflect the inflation effect on the financial statements and disclosing the real information that enables the MNC to measure and evaluate the real performance of foreign subsidiaries and their managers. 


\section{Foreign Currency Exchange Rate and its Effect on the Performance Evaluation of Foreign Subsidiaries}

The MNC needs to translate the financial statements of its foreign subsidiaries for many reasons $^{144}$ : (1) to record the transactions that are measured in a foreign currency, (2) to prepare consolidated financial statements which report on the economic entity as a whole, (3) to evaluate the operations of a foreign business segment, (4) to evaluate the performance of the management of the foreign subsidiaries, (5) to direct and control the foreign operations, and (6) for the convenience of users whether they are internal or external users.

\subsection{The Problem of Translating the Accounts of Foreign Subsidiaries}

When the MNC translates the financial statements of its foreign subsidiaries for any of the previous mentioned reasons, the translation presents some problems because the foreign currency exchange rates are not fixed. For example, the figure (7-1) shows the exchange rate of the Egyptian pound (EGP) against the American dollar (USD), and the figure (7-2) shows the exchange rate of the Egyptian pound (EGP) against the Euro.

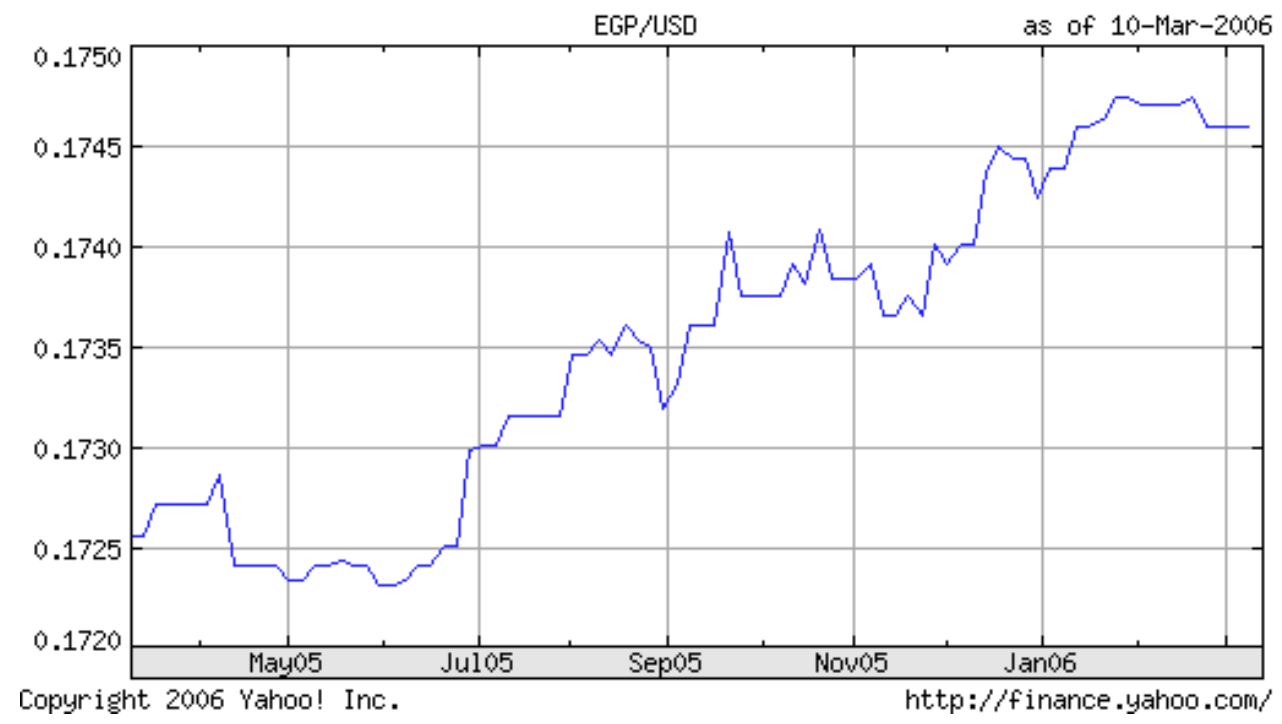

Figure (7-1) shows the exchange rate of the Egyptian pound (EGP) against the American dollar (USD)

\footnotetext{
${ }^{144}$ Elwood L. Miller, Op. Cit., Pp. 144-148.
} 
The fact that exchange rates are not fixed creates some problems ${ }^{145}$ for the accountant such as:

(1) What is the appropriate rate to use in translating the assets and liabilities denominated in a foreign currency?

(2) How should one account for the gain or loss that arises when exchange rates change?

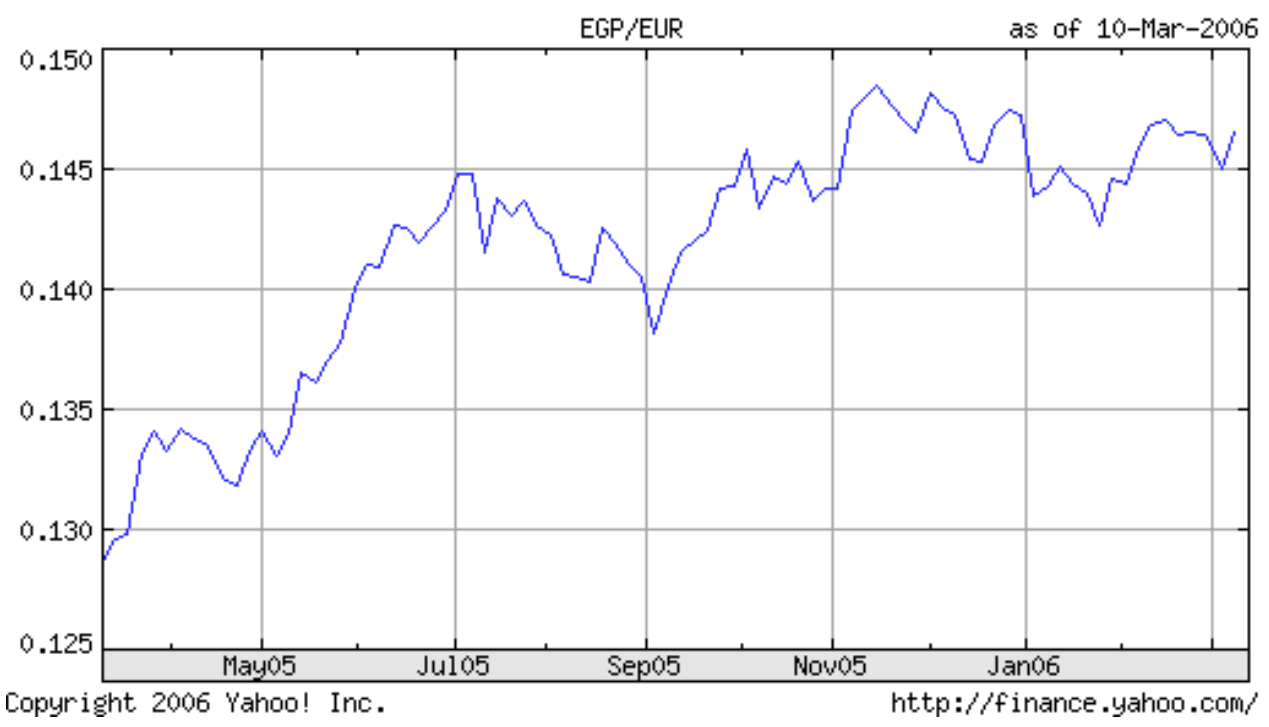

Figure (7-2) shows the exchange rate of the Egyptian pound (EGP) against Euro

The first problem is more significant, since it concerns the value that has to be placed on the assets and liabilities of the company. This does not only affects the balance sheet but also, ultimately, the calculation of profit, since the company's profit is the increase in its net worth over a period. Consequently, this problem affects the measuring and evaluating the real performance of foreign subsidiaries and their managers.

The second problem is mostly concerned with presentation, how should the gain or loss be described, and where should it be placed in the financial statements? This problem is quite significant. The treatment to be accorded to the gain or loss in the financial statements will affect many important accounting variables such as net profit and earnings per share. Then, it affects the indicators used to measure and evaluate the performance of foreign subsidiaries and their managers.

${ }^{145}$ Christopher Nobes \& Robert Parker, op. cit., P. 348-350. 


\subsection{Methods to Translate the Accounts of Foreign Subsidiaries}

In practice, the items of financial statements of foreign subsidiaries are translated by using either the historic rate or the closing rate (current rate). However, there is no worldwide agreement on which rate should be used to translate the items of financial statements of foreign subsidiaries. But we can say that there are four different methods, which have been used to translate the items of financial statements as the following ${ }^{146}$ :

\section{(1) Current / Non-current method \\ (2) Monetary / Non-monetary method \\ (3) Temporal method \\ (4) Closing rate (current rate) method}

\subsubsection{Current / Non-current method}

The current / non-current method is the oldest translation approach officially approved for use in the United States of America. Originating in the 1930s, this method of translating the foreign- currency statements emphasized on conservatism and the subordinate nature of foreign operations following the depression years.

According to the current / non-current method, current assets and current liabilities (working capital) were translated at the closing rate (current rate). While non-current balance sheet items (plant, equipment, and other assets; long-term liabilities; and equity accounts) were translated at the historic rates (the rates exiting on the transaction dates. Income statement items (revenues and expenses) were translated at average rates for the period, except for depreciation, which is translated at the historic rates of the particular assets.

In effect, translation gains or losses were based upon the net current or working capital position of the foreign operations. Changes in non-current items were not recognized, since it was assumed that the usefulness of plant and equipment was not affected as foreign currencies weakened versus the dollar. Conservatism directed that any potential gains on lower dollar-translated long-term liabilities be deferred until they were realized at the time of payment.

$\overline{{ }^{146} \text { Elwood L. Miller, Op. Cit., P.148 }}$ 
Also, Conservatism was reflected in several other ways. For example, net translation losses had to be reflected in the income for the period, whereas net gains were deferred and used to offset future translation losses. Since most foreign currencies weakened versus the dollar, translated inventories (at the closing rates) reflected lower, more conservative dollar costs.

\subsubsection{Monetary / non-monetary method}

In the 1950s, the monetary / non-monetary method was suggested by Professor Samuel R. Hepworth (University of Michigan) ${ }^{147}$, when he suggested that the items of the financial statements of foreign subsidiaries must be translated according to their nature rather than the date of maturity. He suggested that the items of the financial statements are considered as monetary or non-monetary rather than current or non-current.

Under the monetary / non-monetary method, monetary assets and liabilities are translated at the closing rates (current rates), and non-monetary assets and liabilities and stockholders' equity are translated at historic rats. The monetary / non-monetary method was indorsed by the National Association of Accountants in 1960. The method is a radical departure from the current / non-current method in the areas of inventory, long-term receivables, and long-term payables ${ }^{148}$.

The philosophy behind the monetary / non-monetary method is that monetary or financial assets and liabilities have similar attributes, in which their value represents a fixed amount of money whose reporting currency equivalent changes each time the exchange rate changes. Therefore, these monetary items (accounts) should be translated at the closing (current) exchange rate. In the current / non-current method, some current assets are monetary (e.g., cash) and some are non-monetary (e.g., inventory carried at cost), and yet all are translated at the closing (current) exchange rate. The proponents of the monetary / non-monetary method consider it more meaningful to translate assets and liabilities on the basis of attributes instead of time.

\subsubsection{Temporal Method}

The temporal method was originally proposed in Accounting Research Study 12 by the American Institute of Chartered Public Accounts (AICPA) and formally required in

\footnotetext{
${ }^{147}$ Samuel R Hepworth, 1956: as cited in:

Jeffrey S. Arpan \& Lee H. Radebaugh, Op. Cit., P127.

${ }^{148}$ Ibid., p.127-128.
} 
Statement No.8. The temporal method attempt to retain the aspect of time related with transactions. According to the temporal method, cash, receivables, and payables (both current and non-current) are translated at the current rate other assets and liabilities may be translated at current or historic rates, depending on their characteristics. Assets and liabilities carried at past exchange prices are translated at historic rates. For example, a fixed asset carried at the local currency price at which it was purchased would be translated into the reporting currency at the exchange rate in effect when the asset was purchased. Assets and liabilities carried at current purchased or sales exchange prices or future exchange prices would be translated at the current rather than the historic rate.

The attractiveness of the temporal method is lies in its flexibility. The theoretical attractiveness of the temporal method is that the subsidiaries and branches of a U.S. company would be translated into dollars in such a way that the dollar would be the single unit of measure. Some have the opinion that this means the firm would be treating the transactions of foreign operations, as if they had all taken place in dollars. Others disagree with this assessment but they feel that the temporal method simply expresses the cost of foreign currency transactions in dollars ${ }^{149}$.

\subsubsection{Closing (current) rate method}

According to the closing (current) rate method, all assets and liabilities are translated at the closing (current) exchange rate. Only net worth would not be translated at the closing (current) exchange rate. Thus, the closing (current) rate method is easiest to apply. It is easier to use than the others, because a firm would not have to keep track of various historical exchange rates. The closing (current) rate method results in translated statements that retain the same ratios and relationships, which exist in the local currency. For example, the ratio of net income to sales in the local currency is rarely the same in dollars under other translation methods because a variety of closing (current), historic, and average exchange rates are used to translate the income statement. Because all accounts would be translated at a single exchange rate under the closing (current) rate method, the net income to sales would remain the same reporting currency as in the local currency.

The closing (current) rate method has long been preferred by Canadian, U.K., and European accountants. In fact the closing (current) rate method is often called the

${ }^{149}$ Jeffrey S. Arpan \& Lee H. Radebaugh, Op. Cit., P129. 
European method ${ }^{150}$. European and others favoured the closing (current) rate method because it treated foreign operations as if they existed separate and apart from the parent company. The closing (current) rate method was also argued that the historical cost of an item acquired with foreign currency could only be expressed in that foreign currency. The closing (current) rate method was most probably used because it was simple and cheap to apply.

\subsection{International Efforts to Translate the Accounts of Foreign Subsidiaries}

\subsubsection{The American Initiative}

The Americans were the first to do something concrete about the translation problem of the financial statements of foreign subsidiaries. There are some of evolutionary developments of the translation standard in the U. S. A. In 1934, the American Institute of Accountants, the forerunner of the AICPA, recommended that U.S. firms use the current / non-current method of translation.

In 1965, the Accounting Principles Board (APB) of the American Institute of Chartered Public Accounts (AICPA) partially acknowledged this in APB 6 by allowing long-term debt to be translated at closing (current) rates. Under current generally accepted accounting principles of historical cost accounting in the United Stats of America, the monetary / nonmonetary method provides essentially the same results as the temporal method.

In October 1975, the Financial Accounting standard Board (FASB) issued the Statement No.8 (FAS 8), which made the use of the temporal method obligatory for financial statements relating to the accounting years beginning on or after 1 January 1976. With the application of the temporal method, American multinational companies were obliged to report translation losses on foreign currency borrowings (even long term borrowings), whilst no translation gains could be reported in respect of foreign fixed assets that had been acquired with the proceeds of these borrowings. Under other translation methods such losses are not reported. Under the current / non-current method, no gain or loss is reported on either the fixed assets or the long term liabilities. Under the closing (current) rate method, the gain on the assets offsets the loss on the liabilities. Many American companies did not like the enforced change. Thus, after 1975, they began a spirited public debate over

${ }^{150}$ Elwood L. Miller, Op. Cit., P.150. 
the temporal method, that started in America and spread out the rest of the world ${ }^{151}$. The Statement 8 of FASB required that all foreign exchange transactions and translation gains and losses are taken directly to the income statement. This meant that translated earnings were widely fluctuating depending on what was happening to the exchange rate.

There is some criticism of the Statements 8 of FASB. The first: translating the inventories at the historical cost in dollars is expensive to apply. The second: because of the inventory was translated at the historical rate it was possible for an exchange rate change in one quarter to impact on earnings in a subsequent quarter, if inventory flowed through the cost of sold goods. Thus the managers felt that this was distorting the operating performance of each quarter ${ }^{152}$. The criticism is related to the disposition of the gain or loss on long term debt. Many firms felt that because the foreign currency debt was generally being liquidated by foreign currency earnings, there was really no dollar exposure. As the result of these criticisms, the Financial Accounting standard Board (FASB) felt that the Statement 8 of FASB must be improved, and the board issued a new standard, FAS 52, which effectively reversed FAS 8 and prescribed the use of the closing (current ) rate method under most circumstances.

In December 1981, the Financial Accounting standard Board (FASB) issued the Statement No.52 (FAS 52) "Foreign Currency Translation". The Statement 52 of FASB has adopted new objectives of translation of the financial statements of the foreign subsidiaries. The stated objectives are: (1) to provide information that is generally compatible with the expected economic effects of a rate change on an enterprise's cash flows and equity, (2) to reflect in consolidated entities as measured in their functional currencies in conformity with U. S. generally accepted accounting principles. ${ }^{153}$

The Statement 52 of FASB used the term functional currency. This is a new concept introduced for the first time in FAS 52, which gives the following definition: "the currency of the primary economic environment in which the firm operates" ${ }^{\prime 54}$. The foreign currency is any currency other than the functional currency. The local currency is the country's currency where the firm operates, and the reporting currency is the currency in which the

\footnotetext{
${ }^{151}$ Christopher Nobes \& Robert Parker, Op. Cit., P. 362.

152 Jeffrey S. Arpan \& Lee H. Radebaugh, Op. Cit., P132.

${ }^{153}$ FASB: Financial Accounting Standard Board, FAS 52, P. 3.

154 Ibid., P.3.
} 
parent company prepares its financial statements. ${ }^{155}$ It seems clear that for the great majority of foreign entities the functional currency is the local currency; for these cases FASB 52 provides for the straightforward application of the closing (current) rate method except: (1) where the foreign operations are a direct and integral component or extension of the parent company, in this case it is felt that the primary economic environment is that of the parent company; (2) where the foreign entity operates in a highly inflationary economy, in this case, FAS 52 prescribes the completely arbitrary rule that the functional currency has to be the one of the parent company.

In the exceptional cases where the financial statements of the foreign subsidiaries are not expressed in its functional currency, they must be translated into the functional currency using the temporal method. FAS 52 used the term "re-measurement" for this process. This caused an opposition between the temporal method and the closing (current) rate method. This opposition is probably the most important aspect of the translation problem.

In effect, FAS 52 is based on the principle that in general the parent company and its foreign subsidiaries should be considered as distinct and separate entities. The FASB resolve the argument of the closing (current) rate versus temporal method by changing the nature of the consolidated accounts of multinational companies. It took this step to resolve the problem that American companies faces in the quite exceptional foreign exchange conditions in the late $1970 \mathrm{~s}^{156}$.

In the United States, quoted companies have universally followed FAS 52. They were also obliged to do so according to the Securities and Exchange Commission (SEC) rules. The main interest in the USA is to asses the extent companies have decided on, that a foreign subsidiary's currency is not the functional currency and hence have applied the temporal method. This is relatively common for the translation of South American subsidiaries.

\subsubsection{The British Approach}

Relating to the research on a solution for the translation problem, the British have tended to play the second fiddle to the Americans. In fact, the Accounting Standard Committee (ASC) had not issued a standard on the subject of translation problem until after FAS 52 showed the way. Before the Second World War, most British companies used the current / non-current method. But because of its shortcomings British accountants did not follow it

\footnotetext{
155 Jeffrey S. Arpan \& Lee H. Radebaugh, Op. Cit., P126.

${ }^{156}$ Christopher Nobes \& Robert Parker, Op. Cit., P. 370.
} 
and it never became widely used in Britain. Instead, there was a marked swing towards the closing (current) rate method. In 1978, the Survey of Published Accounts reported that 251 out of 267 companies, which gave information on the translation problem used the closing (current) rate method.

In May 1983, the Accounting Standard Committee (ASC) issued Statement of Standard Accounting Practice No 20 (SSAP 20), which, in relation to the translation of assets and liabilities, is very virtually identical to FAS 52. SSAP 20 specifies the closing (current) rate method for most situations and the temporal method where the trade of the foreign enterprise is more dependent on the economic environment of the investing company's currency than on its own reporting currency.

In Britain, it is clear that the closing rate method has established itself as virtually the universal method. A survey of the 1990 accounts of 300 large and medium sized British companies showed that, among the companies with evidence of foreign operations, all used the closing (current) rate method for translating balance sheet items, except for three companies that did not disclose the method. In a survey on the operation of SSAP 20, about thirty major opinion formers in the field of accountancy (companies, firms and professional bodies) were asked, whether they accepted the objectives and approach of SSAP 20 which imposes the closing (current) rate method.

Fore most thoughtful British accountants the position is rather humiliating. Britain has played a very minor role in the great debate on translation. And when finally the Accounting Standard Committee (ASC) dared to issue a standard it was virtually a copy of the American standard. It would seem like that in this field at least. ${ }^{157}$

\subsubsection{Some Other Practices in Europe}

In Europe practice is rather more diverse. This reflects the fact that the EU has not yet succeeded in harmonizing methods of translation. The seventh Directive on consolidated accounts (adopted on 13 June 1983) makes no reference to translation methods except in the requirement that the bases of foreign currency translation must be disclosed in the notes of accounts. Thus, in most parts of Europe the choice is left to the company. The following are evidences of practice from three countries.

${ }^{157}$ Ibid, P. 371. 
In France a survey of 100 large groups showed that from companies with foreign subsidiaries, $95 \%$ used the closing (current) rate method, $3 \%$ used the temporal method and $2 \%$ used the pure historic rate method. ${ }^{158}$

In the Netherlands a survey of 120 quoted companies reported that, from those with foreign activities, $77 \%$ used only the closing (current) rate. The remaining $23 \%$ used a variety of methods; only $10 \%$ used some form of the historic rate. ${ }^{159}$

In Germany a survey of 100 consolidated accounts showed that $47 \%$ used the closing (current) rate method and $33 \%$ gave no information on translation methods. The remainder $(20 \%)$ made some use of non-current rates for balance sheet items, for example valuing the assets at the lower of the historic rate and the closing (current) rate ${ }^{160}$. Thus, it would seem that, only in Germany there is a significant number of adherents to methods based on historic rates and that, even there, they are a minority.

\subsection{The Relevant Translation Method for Measuring and Evaluating the Performance of Foreign Subsidiaries}

The review of the translation methods of the financial statements of foreign subsidiaries indicated that there are four methods to translate the financial statements of the foreign subsidiaries from the local currency of the host country into the currency of the parent company. These methods are the current / non-current method, monetary / non-monetary method, temporal method, and the closing (current) rate method. But what is the relevant translation method for measuring and evaluating the performance of foreign subsidiaries?

I think that the relevant translation method of the financial statements of foreign subsidiaries for performance evaluation is the method that provides the objectivity in the financial data used to evaluate the performance. Objectivity is available in the financial data when: (1) the translated financial statements reflect the economic facts and circumstances of the host country, (2) the translated financial statements reflect the real performance of foreign subsidiaries, and the translation method does not lead to misstating the relation between the individual items in the financial statement. ${ }^{161}$

\footnotetext{
${ }^{158}$ Information Finaciere (1993), as sited in: Ibid, P. 372.

${ }^{159}$ NIVRA (1989), as sited in: Christopher Nobes \& Robert Parker, Op. Cit., P. 372.

${ }^{160}$ Treuarbeit (1990), as sited in: Christopher Nobes \& Robert Parker, Op. Cit., P. 372

${ }^{18}$ Christopher Nobes \& Robert Parker, Op. Cit., P. 364.
} 
To balance between the four methods of translation according to the objectivity of the financial data to choose the relevant translation method for performance evaluation, the following example illustrates the translation of the financial statements of a subsidiary operating in Egypt from the currency of the host country (Egyptian Pound) into the currency of the parent company U.S. dollar) by using the four methods of translation under three probabilities: (1) constancy of the currency exchange rate, (2) increase of the currency exchange rate at (20\%), and (3) decrease of the currency exchange rate (20\%)

After the translation process of the financial statements of the subsidiary I examined the results of translation to determine which translation method provides translated financial statements and reflect the economic facts and circumstances of the host country, and also reflect the real performance of foreign subsidiaries; and examine which translation method that does not lead to misstating the relation between the individual items in the financial statement.

\section{(1) The First Probability: Constancy of the Currency Exchange Rate}

\begin{tabular}{|l|c|c|c|c|c|}
\hline & $\begin{array}{c}\text { Value in } \\
\text { Currency of } \\
\text { Host Country }\end{array}$ & $\begin{array}{c}\text { Current / } \\
\text { Non-current } \\
\text { Method }\end{array}$ & $\begin{array}{c}\text { Monetary / } \\
\text { Non-monetary } \\
\text { Method }\end{array}$ & $\begin{array}{c}\text { Temporal } \\
\text { Method }\end{array}$ & $\begin{array}{c}\text { Current } \\
\text { Rate } \\
\text { Method }\end{array}$ \\
\hline Cash and receivable & 25680 & 5136 & 5136 & 5136 & 5136 \\
Inventory & 20912 & 4182 & 4182 & 4182 & 4182 \\
Fixed assets & 35796 & 7159 & 7159 & 7159 & 7159 \\
\hline Total & 82388 & 16478 & 16478 & 16478 & 16478 \\
\hline Creditors \& payables & 34948 & 6990 & 6990 & 6990 & 6990 \\
Long-term liabilities & 27736 & 5547 & 5547 & 5547 & 5547 \\
Stockholders' equity & 19704 & 3941 & 3941 & 3941 & 3941 \\
\hline Total & 82388 & 16478 & 16478 & 16478 & 16478 \\
\hline Translation Gain (Loss) & - & - & - & - & - \\
\hline
\end{tabular}

Table (7-1): Translated Balance Sheet of Subsidiary (Value in Thousands)

Not: Exchange rate of Egyptian Pound (EGP) to U.S. Dollar (USD): Closing Rate (CR) $=.20$ Historic Rate $(\mathrm{HR})=.20$ 


\begin{tabular}{|l|c|c|c|c|c|}
\hline & $\begin{array}{c}\text { Value in } \\
\text { Currency of } \\
\text { Host Country }\end{array}$ & $\begin{array}{c}\text { Current / } \\
\text { Non-current } \\
\text { Method }\end{array}$ & $\begin{array}{c}\text { Monetary / } \\
\text { Non-monetary } \\
\text { Method }\end{array}$ & $\begin{array}{c}\text { Temporal } \\
\text { Method }\end{array}$ & $\begin{array}{c}\text { Current } \\
\text { Rate } \\
\text { Method }\end{array}$ \\
\hline Sales & 141948 & 28390 & 28390 & 28390 & 28390 \\
Cost of Sales & $(119224)$ & $(23845)$ & $(23845)$ & $(23845)$ & $(23845)$ \\
Operating Income & 22724 & 4545 & 4545 & 4545 & 4545 \\
Other Costs & $(11796)$ & $(2359)$ & $(2359)$ & $(2359)$ & $(2359)$ \\
Income before Taxes & 10928 & 2186 & 2186 & 2186 & 2186 \\
Income Taxes & $(4372)$ & $(874)$ & $(874)$ & $(874)$ & $(874)$ \\
Income after Taxes & 6556 & 1312 & 1312 & 1312 & 1312 \\
\hline Translation Gain (Loss) & - & - & - & - & - \\
\hline
\end{tabular}

Table (7-2): Translated Income Statement of Subsidiary (Value in Thousands)

Not: Exchange rate of Egyptian Pound (EGP) to U.S. Dollar (USD): Closing Rate (CR) $=.20$

Historic Rate $(\mathrm{HR})=.20$

(2) The Second Probability: Increase (20 \%) of the Currency Exchange Rate

\begin{tabular}{|l|c|c|c|c|c|}
\hline & $\begin{array}{c}\text { Value in } \\
\text { Currency of } \\
\text { Host Country }\end{array}$ & $\begin{array}{c}\text { Current / } \\
\text { Non-current } \\
\text { Method }\end{array}$ & $\begin{array}{c}\text { Monetary / } \\
\text { Non-monetary } \\
\text { Method }\end{array}$ & $\begin{array}{c}\text { Temporal } \\
\text { Method }\end{array}$ & $\begin{array}{c}\text { Current } \\
\text { Rate } \\
\text { Method }\end{array}$ \\
\hline Cash and receivable & 25680 & 6163 & 6163 & 6163 & 6163 \\
Inventory & 20912 & 5019 & 4182 & 4182 & 5019 \\
Fixed assets & 35796 & 7159 & 7159 & 7159 & 8591 \\
\hline Total & 82388 & 18341 & 17504 & 17504 & 19773 \\
\hline Creditors \& payables & 34948 & 8388 & 8388 & 8388 & 8388 \\
Long-term liabilities & 27736 & 5547 & 6657 & 6657 & 6657 \\
Stockholders' equity & 19704 & 4406 & 2459 & 2459 & 4728 \\
\hline Total & 82388 & 18341 & 17504 & 17504 & 19773 \\
\hline Translation Gain (Loss) & & 466 & $(1481)$ & $(1481)$ & 788 \\
\hline
\end{tabular}

Table (7-3): Translated Balance Sheet of Subsidiary (Value in Thousands)

Not: Exchange rate of Egyptian Pound (EGP) to U.S. Dollar (USD): Closing Rate (CR) $=.24$ Historic Rate $(\mathrm{HR})=.20$ 


\begin{tabular}{|l|c|c|c|c|c|}
\hline & $\begin{array}{c}\text { Value in } \\
\text { Currency of } \\
\text { Host Country }\end{array}$ & $\begin{array}{c}\text { Current / } \\
\text { Non-current } \\
\text { Method }\end{array}$ & $\begin{array}{c}\text { Monetary / } \\
\text { Non-monetary } \\
\text { Method }\end{array}$ & $\begin{array}{c}\text { Temporal } \\
\text { Method }\end{array}$ & $\begin{array}{c}\text { Current } \\
\text { Rate } \\
\text { Method }\end{array}$ \\
\hline Sales & 141948 & 31229 & 31229 & 31229 & 34068 \\
Cost of Sales & $(119224)$ & $(26136)^{*}$ & $(23845)$ & $(23845)$ & $(28614)$ \\
Operating Income & 22724 & 5093 & 7384 & 7384 & 5454 \\
Other Costs & $(11796)$ & $(2595)$ & $(2595)$ & $(2595)$ & $(2831)$ \\
Income before Taxes & 10928 & 2498 & 4789 & 4789 & 2623 \\
Income Taxes & $(4372)$ & $(962)$ & $(962)$ & $(962)$ & $(1049)$ \\
Income after Taxes & 6556 & 1536 & 3827 & 3827 & 1574 \\
\hline Translation Gain (Loss) & & 167 & 2515 & 2515 & 262 \\
\hline
\end{tabular}

Table (7-4): Translated Income Statement of Subsidiary (Value in Thousands)

* Cost of sales was translated at average rate accept depreciation was translated at historic rate

Not: Exchange rate of Egyptian Pound (EGP) to U.S. Dollar (USD): Closing Rate (CR) $=.24$

Historic Rate $(\mathrm{HR})=.20$

Average Rate $(\mathrm{AR})=.22$

(3) The Third Probability: Decrease (20\%) of the Currency Exchange Rate

\begin{tabular}{|l|c|c|c|c|c|}
\hline & $\begin{array}{c}\text { Value in } \\
\text { Currency of } \\
\text { Host Country }\end{array}$ & $\begin{array}{c}\text { Current / } \\
\text { Non-current } \\
\text { Method }\end{array}$ & $\begin{array}{c}\text { Monetary / } \\
\text { Non-monetary } \\
\text { Method }\end{array}$ & $\begin{array}{c}\text { Temporal } \\
\text { Method }\end{array}$ & $\begin{array}{c}\text { Current } \\
\text { Rate } \\
\text { Method }\end{array}$ \\
\hline Cash and receivable & 25680 & 4109 & 4109 & 4109 & 4109 \\
Inventory & 20912 & 3346 & 4182 & 4182 & 3346 \\
Fixed assets & 35796 & 7159 & 7159 & 7159 & 5727 \\
\hline Total & 82388 & 14614 & 15450 & 15450 & 13182 \\
\hline Creditors \& payables & 34948 & 5592 & 5592 & 5592 & 5592 \\
Long-term liabilities & 27736 & 5547 & 4438 & 4438 & 4438 \\
Stockholders' equity & 19704 & 3475 & 5420 & 5420 & 3152 \\
\hline Total & 82388 & 14614 & 15450 & 15450 & 13182 \\
\hline Translation Gain (Loss) & & $(465)$ & 1480 & 1480 & $(788)$ \\
\hline
\end{tabular}

Table (7-5): Translated Balance Sheet of Subsidiary (Value in Thousands)

Not: Exchange rate of Egyptian Pound (EGP) to U.S. Dollar (USD): Closing Rate (CR) $=.16$ Historic Rate $(\mathrm{HR})=.20$ 


\begin{tabular}{|l|c|c|c|c|c|}
\hline & $\begin{array}{c}\text { Value in } \\
\text { Currency of } \\
\text { Host Country }\end{array}$ & $\begin{array}{c}\text { Current / } \\
\text { Non-current } \\
\text { Method }\end{array}$ & $\begin{array}{c}\text { Monetary / } \\
\text { Non-monetary } \\
\text { Method }\end{array}$ & $\begin{array}{c}\text { Temporal } \\
\text { Method }\end{array}$ & $\begin{array}{c}\text { Current } \\
\text { Rate } \\
\text { Method }\end{array}$ \\
\hline Sales & 141948 & 25551 & 25551 & 25551 & 22712 \\
Cost of Sales & $(119224)$ & $(21554)^{*}$ & $(23845)$ & $(23845)$ & $(19076)$ \\
Operating Income & 22724 & 3997 & 1706 & 1706 & 3636 \\
Other Costs & $(11796)$ & $(2123)$ & $(2123)$ & $(2123)$ & $(1887)$ \\
Income before Taxes & 10928 & 1874 & $(417)$ & $(417)$ & 1749 \\
Income Taxes & $(4372)$ & $(787)$ & $(787)$ & $(787)$ & $(700)$ \\
Income after Taxes & 6556 & 1087 & $(1204)$ & $(1204)$ & 1049 \\
\hline Translation Gain (Loss) & \multicolumn{7}{|c|}{} & $(131)$ & $(2516)$ & $(2516)$ & $(263)$ \\
\hline
\end{tabular}

Table (7-6): Translated Income Statement of Subsidiary (Value in Thousands)

* Cost of sales was translated at average rate accept depreciation was translated at historic rate

Not: Exchange rate of Egyptian Pound (EGP) to U.S. Dollar (USD): Closing Rate (CR) = .16 Historic Rate $(\mathrm{HR})=.20$ Average Rate $(\mathrm{AR})=.18$

\begin{tabular}{|c|c|c|c|c|}
\hline \multirow[t]{2}{*}{ Translation Methods } & \multirow{2}{*}{$\begin{array}{l}\text { Value of } \\
\text { ROI in } \\
\text { Currency } \\
\text { of Host } \\
\text { Country } \\
\text { (EGP) \% }\end{array}$} & \multicolumn{3}{|c|}{$\begin{array}{l}\text { Value of ROI in Currency of the Parent } \\
\text { Company (USD) }\end{array}$} \\
\hline & & $\begin{array}{c}\text { Constancy } \\
\text { of Exchange } \\
\text { Rate } \%\end{array}$ & $\begin{array}{c}\text { Increase of } \\
\text { Exchange } \\
\text { Rate \% }\end{array}$ & $\begin{array}{c}\text { Decrease } \\
\text { of } \\
\text { Exchange } \\
\text { Rate } \%\end{array}$ \\
\hline Current / Non-current Method & 7.96 & 7.96 & 8.38 & 7.43 \\
\hline Monetary / Non-monetary Method & 7.96 & 7.96 & 21.86 & $(7.79)$ \\
\hline Temporal Method & 7.96 & 7.96 & 21.86 & $(7.79)$ \\
\hline Closing (Current) Rate Method & 7.96 & 7.96 & 7.96 & 7.96 \\
\hline
\end{tabular}

Table (7-7): Return on Investment (ROI) of Subsidiary under the three Possibilities

By examining the translation results (the financial statements and return on investment (ROI) before and after the translation as shown in the previous tables (7-1) - (7-7)), they indicate to:

Firstly, concerning to the ability of the translation methods on reflecting the economic facts in the host countries, it appears that: 
(1) In the income statement the translated net income of subsidiary with the currency of the parent company in all the translation methods under the probability of decrease of the currency exchange rate (as shown in Table (7-6) is less than the net income under the probability of constancy of the currency exchange rate (as shown in Table (7-2)). Also, the translated net income of the subsidiary under the probability of increase of the currency exchange rate (as shown in Table (7-4)) is higher than the translation net income under the probability of constancy of the currency exchange rate (as shown in Table (7-2)). It means that the all translation methods are affected by the increase and decrease of the currency exchange rate, thus, they provide results agree with the economic facts in the host countries.

(2) In the balance sheet, under the probability of decrease of the currency exchange rate (as shown in Table (7-5)), there is a translation gain in the monetary / non-monetary method and the temporal method, while there is a translation loss in the two methods under the probability of increase of the currency exchange rate (as shown in Table (7-3)). It means that both methods (the monetary / non-monetary method and the temporal method) provide results contrary to the economic facts in the host countries.

Therefore, concerning the ability of the translation methods on reflecting the economic facts in the host countries we can say that the monetary / non-monetary method and the temporal method have the ability to show the economic facts in the host countries.

Secondly, concerning the ability of the translation methods to maintain the financial relations between the individual items in the financial statements of a subsidiary, the following appeared:

(1) Under the current / non-current method, the return on investment (ROI) decreased from $7.96 \%$ to $7.43 \%$ with ratio of $6.7 \%$, because of the decrease of the currency exchange rate with ratio of $20 \%$. Also, the return on investment (ROI) increased from $7.96 \%$ to $8.38 \%$ with ratio of $5.3 \%$, because of an increase of the currency exchange rate with ratio of $20 \%$ (as shown in Table (7-7)). It means that the current / non-current method does not maintain the financial relations between the individual items in the financial statements of a subsidiary. Consequently, the performance evaluation indicators are affected with fluctuations in the currency exchange rate under this method. 
(2) Under the monetary / non-monetary method, the return on investment (ROI) decreased from $7.96 \%$ to -7.79 with ratio of $198 \%$ because of the decrease of the currency exchange rate with $20 \%$. Also, the return on investment (ROI) increased from $7.96 \%$ to $21.86 \%$ with ratio of $175 \%$ because of increase of currency exchange rate with ratio of $20 \%$ (as shown in Table (7-7)). It shows that, the monetary / non-monetary method leads to misstating the relation between the individual items in the financial statements of the subsidiary; consequently, the performance evaluation indicators of the subsidiary are affected by fluctuations in the currency exchange rate under this method.

(3) Under the temporal method as shown in Table (7-7), we can notice that the return on investment is affected by fluctuations in the currency exchange rate. This method misstates the relation between the individual items in the financial statements of the subsidiary and affects the performance evaluation indicators of the subsidiary.

(4) Under the closing (current) rate method as shown in Table (7-7), we can notice that the return on investment (ROI) did not change under all probabilities (constancy, increase, and decrease of currency exchange rate). It means that this method expresses the real performance of subsidiary.

Finally, we can say that the closing (current) rate method is considered as the more relevant method for translating the financial statements of foreign subsidiaries from the currency of the host country into the currency of the parent company; because of this method is the only one that reflects the economic facts in the host countries. In addition to this, it expresses the real performance of the subsidiary and does not lead to misstating the relation between the individual items in the financial statements of the subsidiary. 


\section{Developing the Performance Evaluation of MNCs Operating in Egypt}

The performance of the foreign subsidiaries is affected by the dominant environmental factors in the host countries. Some of the environmental factors affect the performance of foreign subsidiaries at operating such as: economic, legal, social, cultural, technological and political factors. In addition to this some problems, which affect the measurement and evaluation of the performance such as the problem of transfer prices between subsidiaries or between headquarters and subsidiaries, the problem of multi-foreign currencies and change of their exchange rate, and the problem of inflation. These environmental factors are out of control of the management of foreign subsidiaries. Because of the effect of these environmental factors, it is likely to have a good management performance despite poor subsidiary, and vice-versa.

The proper measurement and evaluation of the real performance of foreign subsidiaries and their managers require considering the effect of the environmental factors on the performance of the foreign subsidiaries and their managers. Thus, if the MNC wants to measure and evaluate the real performance of the foreign subsidiaries and their managers, it must take account of the effect of the environmental factors on the performance at the operating, as well as the effect of transfer pricing, foreign currencies, and inflation on the measurement and evaluation of the performance.

For the problem of transfer pricing and its effect on performance measurement and evaluation of the foreign subsidiaries and their managers, discussed in the fifth chapter in this research, I suggest that, the transfer pricing based upon "the arm's length principle" is the relevant method for measuring and evaluating the real performance of the foreign subsidiaries and their managers.

According to the problem of inflation and its effect on the performance measurement and evaluation of foreign subsidiaries and their managers, discussed in the sixth chapter of this research study, I suggest that, the MNC must use the method of current cost to adjust the financial statements of the foreign subsidiaries for inflation accounting for measuring and evaluating the real performance of the foreign subsidiaries and their managers.

For the problem of foreign currencies and the different methods of translation of financial statements of foreign subsidiaries, discussed in the seventh chapter of this research, I propose that, the relevant translation method of financial statements of the foreign 
subsidiaries for measuring and evaluating the real performance of e foreign subsidiaries and their managers is the method of current exchange rate.

But on the problem of the effect of environmental factors (economic, legal, social, cultural, technological and political factors) on the performance of foreign subsidiaries and their managers I try to measure the effect of these environmental factors on the performance of foreign subsidiaries and their managers. For this, an empirical study will be done to measure the effect of the environmental factors on the performance of foreign subsidiaries and their managers in the following.

\subsection{Measuring the Effect of the Environmental Factors on the Performance of MNCs Operating in Egypt (an Empirical Study)}

For measuring and evaluating the real performance of the foreign subsidiaries and their managers, MNCs must consider the effect of environmental factors in the host country on the performance of foreign subsidiaries and their managers in the performance measurement and evaluation, (because of excluding these environmental factors makes the financial criteria used to the performance evaluation subjective), since they don't reflect the surrounded circumstances of the foreign subsidiaries. Thus, if the MNC wants to measure and evaluate the real (which considers the effect of the environmental factors) performance of foreign subsidiaries and their managers it must measure the effect of environmental factors on the performance and consider it. It will be done in this empirical study.

This empirical study aims to measure the effect of environmental factors on the performance of the MNCs operating in Egypt, and to exclude this effect of environmental factors on the performance for developing the performance measurement and evaluation

\subsubsection{Definition of the Environmental Factors and their Effect on the Performance of MNCs Operating in Egypt}

For this purpose, I have prepared a questionnaire to find out about the environmental factors and their effect on the performance of MNCs operating in Egypt. The questions covered different environmental factors (economic, legal, social, cultural, and political factors) that may have an effect on the performance of the foreign subsidiaries and their 
managers operating in Egypt. In this questionnaire I asked about the following environmental factors.

1- The economic system applied in Egypt and its effect on the company's performance.

2- The fiscal and monetary policies applied in Egypt, especially concerning the interest rate and the currencies exchange and their effect on the company's performance.

3- The quality, availability, and price of the production elements in Egypt and their effect on the company's performance.

4- The economic ties and agreements of Egypt with the other countries and their effect on the company's performance.

5- The level of services and infrastructure in Egypt and their effect on the company's performance.

6- The tax law in the Egypt and its effect on the company's performance.

7- The custom law and policies in Egypt and its effect on the company's performance.

8- The importation and exportation law in Egypt and its effect on the company's performance.

9- The monetary law and procedures of money transfer from and to Egypt and their effect on the company's performance.

10- The investment law in Egypt and its effect on the company's performance.

11- The labor and employment law in Egypt and its effect on the company's performance.

12- The level of bureaucracy in dealing with formal departments in Egypt and its effect on the company's performance.

13- The degree of the political and security stability in the Middle East in general, and specifically in Egypt and their effect the company's performance.

14- The level and quality of education of the employees in the company and their effect on the company's performance.

15- Cleverness and the technology training level of employees in the company and their effect on the company's performance.

16- Habits, traditions, conventions and other factors of the Egyptian people and their effect on the company's performance.

17- The religious beliefs of the Egyptian people and their effect on the company's performance.

18- The view of Egyptian people towards of foreigners, especially to foreign companies and their products and their effect on the performance of the company. 
19- The competition of similar companies and their effect on the performance of the company.

\subsubsection{The Study Sample}

The questionnaire was focused on the managers of the MNCs operating in Egypt. The study covered 30 randomly chosen MNCs operating in Egypt. But, the sample is selected on the factor that the foreign contribution (share) is at least $51 \%$ of the company's capital. Table (8-1) illustrates the selected MNCs of the study sample. 


\begin{tabular}{|c|c|c|c|c|}
\hline Nr. & Company & $\begin{array}{c}\text { Capital } \\
\text { (in Thousands) }\end{array}$ & $\begin{array}{c}\text { Foreign } \\
\text { Investment } \\
\%\end{array}$ & $\begin{array}{c}\text { Local } \\
\text { Investment } \\
\%\end{array}$ \\
\hline 1 & Meratex & 108500 & 61 & 39 \\
\hline 2 & Fine & 140000 & 55 & 45 \\
\hline 3 & XEROX & 15602 & 81 & 19 \\
\hline 4 & Novartis & 33750 & 75 & 25 \\
\hline 5 & Proctel \& Gampel & 154847 & 100 & 0 \\
\hline 6 & SEPCO & 44080 & 90 & 10 \\
\hline 7 & Nestle & 73000 & 100 & 0 \\
\hline 8 & Power Egypt & 44000 & 54 & 46 \\
\hline 9 & Arabian Company for Cinematic Production & 200000 & 65.5 & 34.5 \\
\hline 10 & National Alex. for Steel & 1366776 & 52 & 48 \\
\hline 11 & Cadbury & 31665 & 70 & 30 \\
\hline 12 & Egyptian Cement Company & 812000 & 75 & 25 \\
\hline 13 & Arabian for Animal Production & 30500 & 80 & 20 \\
\hline 14 & Peugeot & 38485 & 60 & 40 \\
\hline 15 & IPM & 60000 & 55 & 45 \\
\hline 16 & Ideal Standards & 25975 & 85 & 15 \\
\hline 17 & Henkel & 112000 & 60 & 40 \\
\hline 18 & Arabian for Computer Manufacture & 70000 & 70 & 30 \\
\hline 19 & Menatel & 70000 & 80 & 20 \\
\hline 20 & Easterners for polyester Manufacture & 60000 & 60 & 40 \\
\hline 21 & EMAC & 47000 & 80 & 20 \\
\hline 22 & Emantite Misr for Fiberglass & 50000 & 63 & 37 \\
\hline 23 & Misr International for Nutritional Industries & 50000 & 71 & 29 \\
\hline 24 & Inter. PAB & 34550 & 68 & 32 \\
\hline 25 & Chipsy & 54217 & 87 & 13 \\
\hline 26 & Sovisat & 77000 & 55 & 45 \\
\hline 27 & Gonson and Gonson & 26400 & 82 & 18 \\
\hline 28 & Nile Communication & 35000 & 73 & 27 \\
\hline 29 & Cairo for Chiken & 50400 & 57 & 43 \\
\hline 30 & Sky Petroleum Services & 317200 & 79 & 21 \\
\hline
\end{tabular}

Table (8-1): The selected MNCs of the study sample ${ }^{162}$

\footnotetext{
${ }^{162}$ General Authority for investment \& Free Zones (GAFI), Cairo - Egypt, 2004.
} 


\subsubsection{Results of the Questionnaire}

The answers of the managers of the MNCs operating in Egypt about the environmental factors and their effect on the performance of their companies show the following results:

1. According to the economic system applied in Egypt and its effect on the performance of the company (Q01), the results indicated that $67 \%$ of the managers of selected MNCs stated that it has a negative effect on the performance of their companies, while $33 \%$ of the managers of the selected MNCs answered that it has a positive effect on the performance of their companies.

2. To the fiscal and monetary policies applied in Egypt, especially concerning the interest rate and the currencies exchange and their effect on the performance of the company (Q02) the results indicated that $77 \%$ of the managers of selected MNCs answered that they have a negative effect on the performance of their companies, while $23 \%$ of the managers of the selected MNCs answered that they have a positive effect on the performance of their companies.

3. About the quality, availability, and price of the production elements in Egypt and their effect on the performance of the company (Q03), the results indicated that $84 \%$ of the managers of selected MNCs answered that they have a positive effect on the performance of their companies, while $13 \%$ of the managers of the selected MNCs answered that they have a negative effect on the performance of their companies, and 3\% of the managers of the selected MNCs answered that they have no effect on the performance of their companies.

4. Considering the economic ties and agreements of Egypt with the other countries and their effect on the performance of the company (Q04), the results indicated that $87 \%$ of the managers of selected MNCs answered that they have a positive effect on the performance of their companies, while $10 \%$ of the managers of the selected MNCs answered that they have a negative effect on the performance of their companies, and 3\% of the managers of the selected MNCs answered that they have no effect on the performance of their companies.

5. About the level of services and infrastructure in Egypt and their effect on the performance of the company (Q05), the results indicated that $87 \%$ of the managers of selected MNCs answered that they have a positive effect on the performance of their 
companies, while $13 \%$ of the managers of the selected MNCs answered that they have a negative effect on the performance of their companies.

6. To the tax law in the Egypt and its effect on the performance of the company (Q06), the results indicated that $17 \%$ of the managers of selected MNCs answered that it has a negative effect on the performance of their companies, while $83 \%$ of the managers of the selected MNCs answered that it has a positive effect on the performance of their companies.

7. According the custom law and policies in Egypt and its effect on the performance of the company (Q07), the results indicated that $70 \%$ of the managers of selected MNCs answered that they have a negative effect on the performance of their companies, while $30 \%$ of the managers of the selected MNCs answered that they have a positive effect on the performance of their companies.

8. On the importation and exportation law in Egypt and its effect on the performance of the company (Q08), the results indicated that $77 \%$ of the managers of the selected MNCs answered that it has a negative effect on the performance of their companies, while $13 \%$ of the managers of the selected MNCs answered that it has a positive effect on the performance of their companies, and $10 \%$ of the managers of the selected MNCs answered that it has no effect on the performance of their companies.

9. For the monetary law and procedures of money transfer from and to Egypt and their effect on the performance of the company (Q09), the results indicated that $84 \%$ of the managers of the selected MNCs answered that they have a negative effect on the performance of their companies, while $13 \%$ of the managers of the selected MNCs answered that they have a positive effect on the performance of their companies, and $3 \%$ of the managers of the selected MNCs answered that they have no effect on the performance of their companies.

10. For the investment law in Egypt and its effect on the performance of the company (Q10), the results indicated that $83 \%$ of the managers of the selected MNCs answered that it has a positive effect on the performance of their companies, while $17 \%$ of the managers of the selected MNCs answered that it has a negative effect on the performance of their companies. 
11. For the labor and employment law in Egypt and its effect on the performance of the company (Q11), the results indicated that $88 \%$ of the managers of the selected MNCs answered that it has a positive effect on the performance of their companies, while $6 \%$ of the managers of the selected MNCs answered that it has a negative effect on the performance of their companies, and 6\% of the managers of the selected MNCs answered that they have no effect on the performance of their companies.

12. For the level of bureaucracy at the dealing with the formal departments in Egypt and its effect on the performance of the company (Q12), the results indicated that the majority (97\%) of managers of selected MNCs answered that it has a very big negative effect on the performance of their companies.

13. For Degree of the political and security stability in the Middle East generally, and in Egypt especially and their effect on the performance of the company (Q13), the results indicated that $83 \%$ of the managers of the selected MNCs answered that it has positive effect on the performance of their companies, while $17 \%$ of the managers of the selected MNCs answered that it has negative effect on the performance of their companies

14. For the level and quality of education of the employees in the company and their effect on the performance of the company $(\mathrm{Q} 14)$, the results indicated that $80 \%$ of the managers of the selected MNCs answered that it has a positive effect on the performance of their companies, while $17 \%$ of the managers of the selected MNCs answered that it has a negative effect on the performance of their companies, and $3 \%$ of the managers of the selected MNCs answered that they have no effect on the performance of their companies.

15. For the Cleverness and the technology training level of employees in the company and their effect on the performance of the company (Q15), the results indicated that $87 \%$ of the managers of the selected MNCs answered that it has a positive effect on the performance of their companies, while $13 \%$ of the managers of the selected MNCs answered that it has a negative effect on the performance of their companies.

16. For Habits, traditions, conventions, and other factors of the Egyptian people and their effect on the performance of the company (Q16), the results indicated that $87 \%$ of the managers of the selected MNCs answered that it has no effect on the performance of their companies, while $10 \%$ of the managers of the selected MNCs answered that it has a positive effect on the performance of their companies, and $3 \%$ of the managers of the 
selected MNCs answered that it has a negative effect on the performance of their companies.

17. For the religious beliefs of the Egyptian people and their effect on the performance of the company (Q17), the results indicated that $94 \%$ of the managers of the selected MNCs answered that it has no effect on the performance of their companies, while $3 \%$ of the managers of the selected MNCs answered that it has a positive effect on the performance of their companies, and 3\% of the managers of the selected MNCs answered that it has a negative effect on the performance of their companies.

18. For the view of Egyptian people towards of the foreigners, especially the foreign companies and their products and their effect on the performance of the company (Q18), the results indicated that $44 \%$ of the managers of the selected MNCs answered that it has no effect on the performance of their companies, while $33 \%$ of the managers of the selected MNCs answered that it has a positive effect on the performance of their companies, and $23 \%$ of the managers of the selected MNCs answered that they have a negative effect on the performance of their companies.

19. For the competition of the similar companies and their effect on the performance of the company (Q19), the results indicated that $64 \%$ of the managers of the selected MNCs answered that it has a positive effect on the performance of their companies, while $23 \%$ of the managers of the selected MNCs answered that it has a negative effect on the performance of their companies, and $13 \%$ of the managers of the selected MNCs answered that they have no effect on the performance of their companies.

The table (8-1) summarizes the results of the answers about the effect of the environmental factors on the performance of MNCs operating in Egypt: 


\begin{tabular}{|c|c|c|c|c|c|c|c|c|c|c|c|c|c|c|c|c|}
\hline Variables & \multicolumn{2}{|c|}{ No effect } & \multicolumn{6}{|c|}{ Positive effect } & \multicolumn{6}{|c|}{ Negative effect } & \multicolumn{2}{|c|}{ Total } \\
\hline X02 & - & - & 1 & 5 & 1 & - & 7 & 23 & 2 & 12 & 6 & 2 & 23 & 77 & 30 & 100 \\
\hline X04 & 1 & 3 & 3 & 13 & 7 & 3 & 26 & 87 & - & 3 & - & - & 3 & 10 & 30 & 100 \\
\hline X05 & - & - & 1 & 16 & 9 & - & 26 & 87 & - & 2 & 1 & 1 & 4 & 13 & 30 & 100 \\
\hline X07 & - & - & - & 2 & 5 & 2 & 9 & 30 & 2 & 13 & 3 & 3 & 21 & 70 & 30 & 100 \\
\hline X08 & 3 & 10 & - & 2 & - & 2 & 4 & 13 & 2 & 14 & 5 & 2 & 23 & 77 & 30 & 100 \\
\hline X09 & 1 & 3 & - & - & 3 & 1 & 4 & 13 & 1 & 11 & 7 & 6 & 25 & 84 & 30 & 100 \\
\hline $\mathrm{X} 10$ & - & - & - & 11 & 13 & 1 & 25 & 83 & - & 2 & 2 & 1 & 5 & 17 & 30 & 100 \\
\hline $\mathrm{X} 11$ & 2 & 6 & - & 10 & 12 & 4 & 26 & 88 & 1 & - & - & 1 & 2 & 6 & 30 & 100 \\
\hline X15 & - & - & 4 & 17 & 2 & 3 & 26 & 87 & - & - & 2 & 2 & 4 & 13 & 30 & 100 \\
\hline X16 & 26 & 87 & - & 1 & - & 2 & 3 & 10 & - & 1 & - & - & 1 & 3 & 30 & 100 \\
\hline X17 & 28 & 94 & - & - & - & 1 & 1 & 3 & - & 1 & - & - & 1 & 3 & 30 & 100 \\
\hline X18 & 13 & 44 & 2 & 4 & 1 & 3 & 10 & 33 & 2 & 4 & - & 1 & 7 & 23 & 30 & 100 \\
\hline X19 & 4 & 13 & 1 & 6 & 9 & 3 & 19 & 64 & - & 1 & 2 & 4 & 7 & 23 & 30 & 100 \\
\hline
\end{tabular}

Table (8-2): The effect of the environmental factors on the performance of the MNCs operating in Egypt 


\subsection{Developing the Performance Evaluation of MNCs Operating in Egypt}

According to the empirical study that included 30 MNCs operating in Egypt for asking about the environmental factors and their effect on the performance of these companies and their managers, the results of this study indicated that there are some environmental factors (economic, legal, political, technological, cultural and social), which have an effect on the performance of the MNCs operating in Egypt.

Because of these environmental factors and their effect on the performance of companies, the performance of MNCs does not reflect the real performance of foreign subsidiaries and their managers. Therefore, MNCs must develop a process for the performance measurement and evaluation to reflect the real performance of the foreign subsidiaries and their managers.

In this study, developing a process for performance measurement and evaluation of foreign subsidiaries and their managers depends on considering the effect of the environmental factors from the performance of foreign subsidiaries and their managers by studying the relationship between the performance (expressed with ROI) of MNCs operating in Egypt and the environmental factors affecting the performance of these companies.

Developing the performance evaluation of MNCs operating in Egypt in this study aims to construct a model to evaluate the performance of a company and its management. The model can be developed by studying the relationship between the return on investment (ROI) (as one of the most common criteria for performance evaluation) and the environmental factors affecting the performance of MNCs that operate in Egypt. Through this developed model of performance evaluation, the MNC can calculate a standard ratio of return on investment (ROI), which considers the effect of environmental factors affecting the performance. Consequently, it reflects the real performance of foreign subsidiaries and their managers.

Then, the MNC can compare the actual ROI calculated from the data of the foreign subsidiary with the standard ROI calculated from the developed model of performance evaluation. Thus, the MNC can evaluate the real performance of the foreign subsidiary and its managers whether good or not. 


\subsubsection{The Proposed Model for Developing the Performance evaluation of MNCs Operating in Egypt}

The proposed model for developing the performance evaluation of MNCs operating in Egypt aims to measure the effect of the environmental factors on the performance of the company through studying the relationship between the ROI (representative for the performance of the company) and the environmental factors affecting it, by using multipleregression analysis. This model aims to develop the indicator of ROI that considers the effect of the environmental factors to reflect the real performance of the company and its managers.

\subsubsection{The General Form of the Proposed Model}

The relationship between the ROI and the affecting environmental factors is studied here by using multiple-regression analysis, the general form of the proposed model for developing the performance evaluation of the MNCs operating in Egypt. The form of multiple regression equitation as the following:

$$
\mathrm{Y}=\mathrm{a}+\mathrm{b}_{1} \mathrm{X}_{1}+\mathrm{b}_{2} \mathrm{X}_{2} \ldots \ldots \ldots \ldots \ldots \ldots \mathrm{b}_{\mathrm{n}} \mathrm{X}_{\mathrm{n}}+\mathrm{e}
$$

Where:

Y : represents the dependent variable (Return on Investment (ROI) of the company). The dependent variable is sometimes called the response variable or the outcome variable.

$\mathrm{X}_{1}, \mathrm{X}_{2}, \ldots \ldots, \mathrm{X}_{\mathrm{n}}$ : represent the independent variables (the environmental factors affecting the performance of the company and its managers). The independent variables may be also called as explanatory variables, predictor variables, regressor variables, or covariates.

$b_{1}, b_{2}, \ldots \ldots \ldots, b_{n}$ : represent parameters of the independent variables, and they are called slope coefficients (the effect of the environmental factors on the performance of companies). 
a : represents a constant value, it represents the expected value of Y (ROI) when all the independent variables equal zero (when there is no effect of environmental factors on the performance of company).

e : represents a standard error (S.E). It is the estimated standard deviation of the sampling distribution of a regression coefficient.

\subsubsection{Definition of the Variables Used in Statistical Analysis}

The Dependent Variable Y: Return on investment (ROI) is the dependent variable in the model.

The Independent Variables: The independent variables in the model are the environmental factors (economic, legal, political, social, and cultural) affecting the performance of foreign subsidiaries and their managers that are expressed by $X_{1}, X_{2}$, $\ldots \ldots, \mathrm{X}_{\mathrm{k}}$. They are defined as the following:

$\mathrm{X}_{1}$ : The economic system applied in Egypt.

$\mathrm{X}_{2}$ : The fiscal and monetary policies applied in Egypt

$\mathrm{X}_{3}$ : The quality, availability, and price of the production elements in Egypt

$\mathrm{X}_{4}$ : The economic ties and agreements of Egypt

$\mathrm{X}_{5}$ : The level of services and infrastructure in Egypt

$\mathrm{X}_{6}$ : The tax law in the Egypt

$\mathrm{X}_{7}$ : The custom law and policies in Egypt

$\mathrm{X}_{8}$ : The importation and exportation law in Egypt

$\mathrm{X}_{9}$ : The monetary law and procedures of money transfer in Egypt

$\mathrm{X}_{10}$ : The investment law in Egypt

$\mathrm{X}_{11}$ : The labor and employment law in Egypt

$\mathrm{X}_{12}$ : The level of bureaucracy in Egypt

$\mathrm{X}_{13}$ : Degree of the political and security stability in Egypt

$\mathrm{X}_{14}$ : The level and quality of education of the employees in the company

$\mathrm{X}_{15}$ : The Cleverness and the technology training level of employees in the company

$\mathrm{X}_{16}$ : Habits, traditions, conventions, and other factors of the Egyptian people

$\mathrm{X}_{17}$ : The religious beliefs of the Egyptian people

$\mathrm{X}_{18}$ : The view of Egyptian people towards of the foreign companies and their products

$\mathrm{X}_{19}$ : The competition of the similar companies 


\subsubsection{Preparing the data for the statistical analysis}

The data obtained from the questionnaire represents the answers of the managers of the MNCs operating in Egypt about the effect of the environmental factors on the performance of their companies. These answers are not quantitative data, but qualitative data as the following:

- The environmental factor has no effect

- The environmental factor has a very big positive effect

- The environmental factor has a big positive effect

- The environmental factor has a middle positive effect

- The environmental factor has a little positive effect

- The environmental factor has a very big negative effect

- The environmental factor has a big negative effect

- The environmental factor has a middle negative effect

- The environmental factor has a little negative effect

Data like this are not directly used in the statistical analysis, but they must be transferred to quantitative data to be qualified for the statistical analysis, since the statistical analysis deals only with the quantitative data.

To transfer these answers to quantitative data, they were given the following values:

No effect $\quad=0$

Very big positive effect $=1$

A big positive effect $=, 75$

Middle positive effect $=, 50$

Little positive effect $\quad=, 25$

Very big negative effect $=-1$

A big negative effect $\quad=-, 75$

Middle negative effect $=-, 50$

Little negative effect $=-, 25$ 


\subsubsection{The statistical analysis technique}

As mentioned previously, the statistical technique used in the analysis is the multipleregression analysis by using SPSS (Statistical Package for Social Sciences). Multipleregression is a statistical method for studying the relationship between a single dependent variable and one or more independent variables ${ }^{163}$. It is unquestionably the most widely used statistical technique in the social sciences

There are two major usages of multiple regression make it popular: prediction and causal analysis. For the prediction studies, multiple-regression makes it possible to combine many variables to produce optimal predictions of the dependent variable. And for the causal analysis it separates the effects of independent variables on the dependent variable so that one can examine the unique contribution of each variable.

\subsubsection{Assumptions of the Model}

The proposed model is based on the following main assumption:

"There is relationship between ROI (dependent variable $Y$ ) of the company and the environmental factors (independent variables) $\mathrm{X}_{1}, \mathrm{X}_{2}, \ldots \ldots ., \mathrm{X}_{\mathrm{n}}$ ".

\subsubsection{Goodness-of-fit of the Proposed Model}

Since the used method in the statistical analysis is multiple-regression analysis the goodness-of-fit of the proposed model is determined by the following measures:

Coefficient of determination $\left(\mathrm{R}^{2}\right): \mathrm{R}^{2}$ represents the predictive power of the regression model, or the explanatory power of the independent variables. It is used to know the ability of the independent variables (environmental factors) to predict or explain the dependent variable (ROI). The value of $\mathrm{R}^{2}$ is always between the 0 and 1 . The highest $\mathrm{R}^{2}$ is the highest goodness-of-fit, and vice-versa.

Confidence intervals: Since the most applications of regression analysis include some of the possible sources of error such as measurement error, sampling error, or/and uncontrolled error; it is very important to define how long we rely on the estimations. We can evaluate the extent and importance of this error; consequently, we can measure the Goodness-of-fit of the coefficient estimates by calculating the confidence intervals.

${ }^{163}$ Paul D. Allison, 1999. P1. 
The confidence intervals give us a rang of possible values of the coefficients. It is notable that the social researchers and statisticians usually rely on the customary standards of .05 (95\%) and .01 (99\%) as confidence intervals. If the $\mathrm{p}$ value is less than .05 , it is said that the coefficient is "significant", while, if the p value is less than .01 , it is said that the coefficient is "high significant".

F-Test: It is very necessary to do the F-Test to test the significance of the model, where the F-Test measures the overall significance of the regression model.

T-Test: It is very necessary to do the F-Test to test the significant relationship between the independent variables (environmental factors) entered in the model and the dependent variable (ROI). The T-Test measures the significance between the dependent variable and the independent variables.

\subsubsection{Results of Statistical Analysis}

The results of statistical analysis of the relationship between the ROI of $30 \mathrm{MNCs}$ operating in Egypt and the environmental factors by using multiple-regression analysis with SPSS gave 6 models of the relationship between ROI and the environmental factors as shown in the table (8-3) as the following:

The first model:

$$
\begin{aligned}
& \mathrm{Y}=21.348-.482 \mathrm{X}_{1}+1.717 \mathrm{X}_{2}+2.244 \mathrm{X}_{3}+3.033 \mathrm{X}_{4}-5.588 \mathrm{X}_{5}+1.769 \mathrm{X}_{6}+5.171 \mathrm{X}_{7}- \\
& 4.319 \mathrm{X}_{8}-5.537 \mathrm{X}_{9}+6.958 \mathrm{X}_{10}-6.868 \mathrm{X}_{11}+9.361 \mathrm{X}_{12}-.424 \mathrm{X}_{13}+3.687 \mathrm{X}_{14}+ \\
& .401 \mathrm{X}_{15}+2.769 \mathrm{X}_{19} \\
& \mathrm{R}^{2}=.855 \quad \mathrm{~F}=4.79 \quad \text { S.E. }=2.67
\end{aligned}
$$

The Second model:

$$
\begin{aligned}
\mathrm{Y}= & 21.487-.502 \mathrm{X}_{1}+1.747 \mathrm{X}_{2}+2.244 \mathrm{X}_{3}+3.052 \mathrm{X}_{4}-5.614 \mathrm{X}_{5}+1.762 \mathrm{X}_{6}+5.167 \mathrm{X}_{7}- \\
& 4.309 \mathrm{X}_{8}-5.57 \mathrm{X}_{9}-6.844 \mathrm{X}_{11}+9.395 \mathrm{X}_{12}-.42 \mathrm{X}_{13}+3.685 \mathrm{X}_{14}+.395 \mathrm{X}_{15}+ \\
+ & 2.758 \mathrm{X}_{19} \\
& \mathrm{R}^{2}=.855 \quad \mathrm{~F}=5.5 \quad \text { S.E. }=2.578
\end{aligned}
$$




\begin{tabular}{|c|c|c|c|c|c|c|}
\hline \multirow{2}{*}{$\begin{array}{c}\text { Variables } \\
\text { and } \\
\text { Estimators }\end{array}$} & 1 & 2 & 3 & 4 & 5 & 6 \\
\cline { 2 - 7 } Constant & 21.348 & 21487 & 21.752 & 21.586 & 21.535 & 21.691 \\
$\mathrm{X}_{1}$ & -.482 & -.502 & -.661 & -.653 & - & - \\
$\mathrm{X}_{2}$ & 1.717 & 1.747 & 1.954 & 1.84 & 1.271 & - \\
$\mathrm{X}_{3}$ & 2.244 & 2.244 & 2.399 & 2.481 & 2.345 & 1.619 \\
$\mathrm{X}_{4}$ & 3.052 & 3.033 & -3.182 & 3.115 & 2.862 & 2.811 \\
$\mathrm{X}_{5}$ & -5.614 & -5.614 & -5.518 & -5.415 & -5.162 & -5.202 \\
$\mathrm{X}_{6}$ & 1.769 & 1.762 & -1.786 & 1.953 & 2.09 & 2.31 \\
$\mathrm{X}_{7}$ & 5.171 & 5.167 & 5.222 & 5.222 & 5.3 & 5.343 \\
$\mathrm{X}_{8}$ & -4.319 & -4.309 & -4.346 & -4.443 & -4.308 & -4.443 \\
$\mathrm{X}_{9}$ & -5.537 & -5.537 & -5.517 & -5.579 & -5.453 & -4.972 \\
$\mathrm{X}_{10}$ & 6.958 & - & - & - & - & - \\
$\mathrm{X}_{11}$ & -6.868 & -6.844 & -6.827 & -7.192 & -7.091 & -7.51 \\
$\mathrm{X}_{12}$ & 9.361 & 9.395 & 9.681 & 9.588 & 9.445 & 9.787 \\
$\mathrm{X}_{13}$ & -.424 & -.42 & -.519 & - & - & - \\
$\mathrm{X}_{14}$ & 3.687 & 3.685 & 3.787 & 3.837 & 3.918 & 4.244 \\
$\mathrm{X}_{15}$ & .401 & .395 & - & - & - & - \\
$\mathrm{X}_{19}$ & 2.769 & 2.758 & 2.62 & 2.874 & 3.064 & 3.822 \\
\hline $\mathrm{R}^{2}$ & .855 & .855 & .855 & .853 & .85 & 837 \\
$\mathrm{~F} \mathrm{Value}$ & 4.79 & 5.5 & 6.3 & 7.12 & 8.05 & 8.41 \\
$\mathrm{~S}_{\mathrm{E}} \mathrm{E}$ & 2.657 & 2.578 & 2.494 & 2.432 & 2.377 & 2.41 \\
\hline
\end{tabular}

Table (8-3): Models of Multiple-Regression Analysis of the Relationship Between ROI and the Effect of Environmental Factors

The third model:

$$
\begin{gathered}
\mathrm{Y}=21.752-.661 \mathrm{X}_{1}+1.954 \mathrm{X}_{2}+2.399 \mathrm{X}_{3}-3.182 \mathrm{X}_{4}-5.518 \mathrm{X}_{5}-1.786 \mathrm{X}_{6}+5.222 \mathrm{X}_{7}- \\
4.346 \mathrm{X}_{8}-5.517 \mathrm{X}_{9}-6.827 \mathrm{X}_{11}+9.681 \mathrm{X}_{12}-.519 \mathrm{X}_{13}+3.787 \mathrm{X}_{14}+2.62 \mathrm{X}_{19} \\
\mathrm{R}^{2}=.855 \quad \mathrm{~F}=6.3 \quad \text { S.E. }=2.494
\end{gathered}
$$

The fourth model:

$\mathrm{Y}=21.586-.653 \mathrm{X}_{1}+1.84 \mathrm{X}_{2}+2.481 \mathrm{X}_{3}+3.115 \mathrm{X}_{4}-5.415 \mathrm{X}_{5}+1.953 \mathrm{X}_{6}+5.343 \mathrm{X}_{7}-$

$$
4.443 \mathrm{X}_{8}-5.579 \mathrm{X}_{9}-7.192 \mathrm{X}_{11}+9.588 \mathrm{X}_{12}+3.837 \mathrm{X}_{14}+2.874 \mathrm{X}_{19}
$$

$$
\mathrm{R}^{2}=.853 \quad \mathrm{~F}=7.12 \quad \text { S.E. }=2.432
$$




\section{The fifth model:}

$$
\begin{aligned}
& \mathrm{Y}=21.535+1.271 \mathrm{X}_{2}+2.345 \mathrm{X}_{3}+2.862 \mathrm{X}_{4}-5.162 \mathrm{X}_{5}+2.09 \mathrm{X}_{6}+5.3 \mathrm{X}_{7}-4.308 \mathrm{X}_{8}- \\
& 5.453 X_{9}-7.091 X_{11}+9.445 X_{12}+3.918 X_{14}+3.064 X_{19} \\
& \mathrm{R}^{2}=.85 \quad \mathrm{~F}=8.05 \quad \text { S.E. }=2.377
\end{aligned}
$$

The sixth model:

$$
\begin{gathered}
\mathrm{Y}=21.691+1.619 \mathrm{X}_{3}+2.811 \mathrm{X}_{4}-5.202 \mathrm{X}_{5}+2.31 \mathrm{X}_{6}+5.27 \mathrm{X}_{7}-4.356 \mathrm{X}_{8}-4.972 \mathrm{X}_{9}- \\
7.51 \mathrm{X}_{11}+9.787 \mathrm{X}_{12}+4.244 \mathrm{X}_{14}+3.822 \mathrm{X}_{19} \\
\mathrm{R}^{2}=.837 \quad \mathrm{~F}=8.41 \quad \text { S.E. }=2.41
\end{gathered}
$$

\subsubsection{Balancing Between the Models and Selecting the Best Model}

All the previous models describe the regression relationship between ROI and the environmental factors affecting the performance of the MNCS operating in Egypt. The best model that has the highest significance (F), least standard error (S.E), and the highest explanation power $\left(\mathrm{R}^{2}\right)$.

By reviewing these models and comparing the explanation power $\left(\mathrm{R}^{2}\right)$, the significance (F), and standard error (S.E) of all models, we can say the fifth model is the best model, because this model has less standard error and high significance, as will as a good explanation power, and all independent variables have a high significant relationship to ROI except $X_{2}, X_{6}$ have a significant relationship of less than $95 \%$. Thus, I suggest that excluding these variables from this model, because it describes the relationship between ROI and the environmental factors affecting the performance of the MNCS operating in Egypt in the following form:

$$
\begin{gathered}
Y=21.535+2.345 X_{3}+2.862 X_{4}-5.162 X_{5}+5.3 X_{7}-4.308 X_{8}-5.453 X_{9}-7.091 X_{11} \\
+9.445 X_{12}+3.918 X_{14}+3.064 X_{19} \\
R^{2}=.85 \quad F=8.05 \quad \text { S.E. }=2.377
\end{gathered}
$$


(1): Y represents the estimated ROI which takes account of the effect of the environmental factors on the performance of the MNCs operating in Egypt. This value of $\mathrm{Y}$ also represents standard ROI that MNCs must use it in the performance evaluation of their foreign subsidiaries.

(2): The figure 21.535 is a constant figure, and it represents ROI when all environmental factors entered in the model equal zero, in other words, when there is no effect of the environmental factors on the performance of foreign subsidiaries.

(3) $X_{3}, X_{4}, X_{5}, X_{7}, X_{8}, X_{9}, X_{11}, X_{12}, X_{14}$, and $X_{19}$ represent the environmental factors entered in the model and they have an effect and a significant relationship to ROI. These environmental factors are:

$\mathrm{X}_{3}$ : The quality, availability, and price of the production elements in Egypt

$\mathrm{X}_{4}$ : The ties and economic relationships between Egypt and other countries

$\mathrm{X}_{5}$ : The level of services and infrastructure in Egypt

$\mathrm{X}_{7}$ : The custom law and policies in Egypt

$\mathrm{X}_{8}$ : The importation and exportation law in Egypt

$\mathrm{X}_{9}$ : The monetary law and procedures of money transfer in Egypt

$\mathrm{X}_{11}$ : The labor and employment law in Egypt

$\mathrm{X}_{12}$ : The level of bureaucracy in Egypt

$\mathrm{X}_{14}$ : The level and quality of education of the employees in the company

$\mathrm{X}_{19}$ : The competition to the similar companies

(4): The figures $3.345,2.862,-5.162,5.3,-4.308,-5.453,-7.091,9.445,3.918$, and 3.064 represent coefficients (regression slops) which determine the degree of the relationship between the environmental factors and ROI.

(5): Coefficient of determination $\left(\mathrm{R}^{2}\right)$ of the proposed model equals $85 \%$. It means that, the environmental factors $\mathrm{X}_{3}, \mathrm{X}_{4}, \mathrm{X}_{5}, \mathrm{X}_{7}, \mathrm{X}_{8}, \mathrm{X}_{9}, \mathrm{X}_{11}, \mathrm{X}_{12}, \mathrm{X}_{14}$, and $\mathrm{X}_{19}$ are able to explain 85 $\%$ from the change of ROI, which is a good ratio.

(6): This model has a high significance, where the $F$ value indicates the overall significance of the model equals 8.05; so that we can confide these estimates of this model at confidence intervals (99\%), as the results indicate. 
(7): Standard error (S.E) of this model equals 2.37, and this value is considered as an accepted value.

\subsubsection{Using the Proposed Model to evaluate the performance of the company}

Through the previous proposed model we can calculate the estimated ROI by using the data of a company of the sample and compare it with the actual ROI of the company, (for example the company nr.7) as the following:

$$
\begin{aligned}
Y= & 21.54+(2.35 * .50)+(2.86 *-.75)-(5.162 * .75)+(5.3 *-1)-(4.31 *-1)- \\
& (5.45 *-.75)-(7.09 *-1)+(9.44 *-1)+(3.92 * .75)+(3.06 * .75) \\
Y= & 22.69 \%
\end{aligned}
$$

This figure $(22.69 \%)$ represents ROI with considering the effect of environmental factors on the performance of the company, and the MNC can use this value of the estimated ROI to evaluate the real performance of its foreign subsidiary operating in Egypt by comparing it with the actual ROI. 


\section{Conclusion}

At the end of this research it is very important and useful to present a summary of the results of this research, and some important recommendations for developing controlling and performance evaluation of the foreign subsidiaries and their managers.

\subsection{Summary of the Research}

This research concentrated on developing controlling and performance evaluation of the multinational companies operating in Egypt. The development aims to consider the environmental factors and variables affecting the performance of the foreign subsidiaries in the host countries in order to evaluate the real performance of the management of these companies. Most of the literature indicated that the main problem is related to (1) the effect of the environmental factors (economic, legal, cultural, social, and political) in the host country on the performance of the foreign subsidiaries, (2) the problem of biased transfer prices and its effect on the net income of the subsidiary, (3) the problem of inflation in the host country and its effect on the reliability of the information in the financial statements of the foreign subsidiaries, and (4) the problem of translation of the accounts of the foreign subsidiaries from the currency of the host country into the currency of the parent company, and the effect of the different translation methods on the net income of the foreign subsidiaries.

Thus, the research objectives are (1) studying and investigating the environmental factors (economic, legal, social, cultural, and political) affecting the performance of MNCs and their managers operating in Egypt, measuring the effect of the environmental factors and variables on the performance, and suggesting a model to measure and evaluate the real performance of the multinational companies operating in Egypt; (2) determining the relevant transfer price which the MNC use for measuring and evaluating the real performance of the foreign subsidiaries and their managers; (3) determining the relevant translation method of the financial statements of the foreign subsidiaries for measuring and evaluating the real performance of the foreign subsidiaries and their managers; (4) and determining the relevant method to account for inflation for measuring and evaluating the real performance of the foreign subsidiaries and their managers.

The research was done at two levels, on the theoretical and practical level. On the theoretical level the research discussed and investigated the literature of the important and 
necessary points related to the main aspects of the multinational companies, performance evaluation of the multinational companies, the environmental factors and variables affecting the performance of the foreign subsidiaries, and some problems affecting the performance of the foreign subsidiaries such as transfer prices, inflation in the host country, and foreign currency exchange rates.

While at the practical level, an empirical study was done in this research to investigate the important environmental factors (economic, legal, cultural, social, and political) affecting the performance of MNCs operating in Egypt, and also to measure the effect of these environmental factors on the performance of these companies and their managers in order to develop a model that helps to measure and evaluate the real performance of the management of foreign subsidiaries. The empirical study was done by a questionnaire presented to managers of 30 multinational companies operating in Egypt.

\subsection{The Results}

O the theoretical level, the analytical review and scanning of the most literature concerning the main points of this research indicated to:

- The performance of the foreign subsidiaries and their managers is affected by the environmental factors (economic, legal, cultural, social, and political) in the host countries, and the effect of the environmental factors is different from host country to host country. The multinational company must consider the effect of environmental factor in measuring and evaluating the performance of subsidiary, if it wants to measure and evaluate the real performance of the foreign subsidiary and its management.

- The performance of the foreign subsidiaries and their managers is affected by the method of transfer pricing between the members of a multinational company group; the arm's length principle is the relevant method for transfer pricing to measure and evaluate the real performance of subsidiaries and their managers.

- Inflation in the host countries has an effect on the information of the financial statements of foreign subsidiaries, consequently, it affects the indicators used to measure and evaluate the performance of foreign subsidiaries and their managers. There are different methods to adjust the financial statements of the foreign 
subsidiaries with the effect of the inflation in the host country, and adjusting the accounts to the general indexes in order to express changes in the general purchasing power is the relevant method to adjust the accounts of the foreign subsidiary with the effect of inflation in the host country for evaluating the real performance of subsidiary and its management.

- There are different methods to translate the accounts of the foreign subsidiaries from the currency of the host country into the currency of the parent company, and each method has a different effect on the net income of subsidiary. The current rate method is the relevant method to translate the accounts of foreign subsidiaries from the currency of the host country into the currency of the parent company to evaluate the real performance of foreign subsidiaries and their managers.

On the practical level, the empirical study of this research indicated to the following results:

- Some of the environmental factors in the Egyptian environment have a positive effect on the performance of the multinational companies and their management, which operating in Egypt. For example: (1) quality, availability, and price of the production elements, (2) ties and economic relationships between Egypt and other countries, (3) the level of services and infrastructure, (4) the labour and employment law, (5) the investment law especially concerning foreign investment, (6) the degree of the political and security stability, (7) the level and quality of education of the employees in the company, (8) the competition to the similar companies.

- Some of the environmental factors in the Egyptian environment have a negative effect on the performance of multinational companies and their management operating in Egypt, for example: (1) the fiscal and monetary policies, (2) the tax laws, (3) the custom laws and policies, (4) the importation and exportation law, (5) the monetary law and procedures of money transfer, (6) the level of bureaucracy.

- Some of the environmental factors in the Egyptian environment have no effect on the performance of the multinational companies and their management operating in 
Egypt, for example: the habits, traditions, conventions, mores and religious beliefs of the Egyptians.

\subsection{The Recommendations}

- The multinational companies must consider the effect of the environmental factors on the performance of the foreign subsidiaries in the host countries in order to be able to evaluate the real performance of the subsidiary and its management.

- The arm's length principle is the relevant method of transfer pricing between the member of the multinational company group to measure and evaluate the real performance of subsidiaries and their managers. Because the arm's length principle deals with all entities within the multinational company group as independent entities, and it avoids the certain of tax advantages or disadvantages, which would otherwise distort the relative competitive positions of either type of entity.

- The multinational companies use the general indexes to adjust the accounts of the foreign subsidiaries to the effect of the foreign inflation in the host country to be able to evaluate the real performance of the subsidiary and its management.

- The multinational companies use the current exchange rate method to translate the accounts of foreign subsidiaries from the currency of the host country into the currency of the parent company, because this method provides information, which reflect economic facts and the real performance of foreign subsidiaries and their managers. 
A. A. A., Committee on International Accounting, "Report of the Committee on International Accounting", Accounting Review (Supplement to Vol. A7, 1973, PP. 120176

Abdallah, W. M. \& Keller, Donald E., "Measuring the Multinational's Performance", Management accounting, (Oct. 1985), PP.26-30

Abdallah, W. M., Firoz, Nadeem M. and Ekeledo, Ikechi, Performance Evaluation of Foreign Subsidiary Managers Using Intra Company Pricing, International Tax Journal, Vol. 31, No. 4, Fall 2005, PP. 5 - 12

Aggarwal, Raj, the Translation Problem in International Accounting: Insights for Financial Management, Management International Review, Vol. 15, No. 2-3, 1975, PP. 6779

Agrawal, Surendra P., Accounting for the Impact of Inflation on a Business Enterprise, The Accounting Review, Vol. L11, No. 4, Oct. 1977, PP. 789-809

Aiken, Leona S. \& West, Stephen G., Multiple Regression: Testing and Interpreting Interactions, SAGE Publications, London, 1991

Alexander, David \& Archer, Simon, International Accounting Standards. Guide, Harcourt, 2001, New York, PP. 8.08

Allison, Paul D., Multiple Regression, Pene Forge Press, California, 1999

Appleyard, A.R., et al., "Budgetary Control of Foreign Subsidiaries”, Sup.1990

Arpan, Jeffrey S. \& Radebaugh, Lee H., International Accounting and Multinational Enterprises, John Wiley \& Sons, New York, $2^{\text {nd }}$ Ed, 1985

Axelsonis, Kenneth S., Facing the Hard Truths about Inflation, Management Accounting, June 1980, PP. 11-14 
Bartlett, R. T. \& Kelly, T. H., Will FAS No. 33 Solve Inflation Accounting Problems?, Management Accounting, Vol. 61, April 1980, PP. 11-14

Becker, Matthias, Die Verrechnung von Entgelten für den Betrieb eines Internetservers, in: Oestreicher, A., (Hrsg.), Internationale Verrechnungspreise: Beiträge zu einer Ringveranstaltung an der Universität Göttingen im Sommersemester 2002, Herne/Berlin (NWB), 2003, PP. 95-130

Bendiner, Burton, International Labour Affairs: The World Trade Unions and the Multinational Companies, Clarendon Press, Oxford, 1987

Benke, R. L. \& Edwards, J. D., Transfer Pricing: Techniques and Uses, Management Accounting, Vol. 61, June 1980, PP. 44-46

Bloech, J., Götze, U., Huch, B., Lücke, W., and Rudolph, F., Strategische Planung: Instrumente, Vorgehensweisen und Informationssysteme, Physica-Verlag, Heidelberg, 1994

Borkowski, Susan C., Turnover in Transfer Pricing Management: Revolving Door or Opportunity for Expertise?, International Tax Journal, Vol. 31, No. 3 Summer 2005, PP. $17-30$

Breen, Richard, Regression Models: Censored, Sample Selected, or Truncated Data, Series: Quantitative Applications in the Social Sciences, SAGE Publications, London, 1996

Bremer, Seven C. \& Engler, Gerbard, Tightening of the German Transfer Pricing Documentation Requirements, International Tax Journal, Vol. 30, No. 2, Spring 2004, PP. $17-30$

Buckley, Peter J., the Theory of the Multinational Enterprise, Uppsala, 1987

Bursk, Edward C., et al. Financial Control of Multinational Operations (New York: Financial Executives Research Foundation, 1971 
Choi, Frederick D. S., Accounting and Control For Multinational Activities: Perspective on the 1990's, Management International Review, Vol. 31, 1975, PP. 97- 109

Clegg, Jeremy, Multinational Enterprise and world Competition: A Comparative Study of the USA, Japan, the UK, Sweden and West Germany, Macmillan Press LTD, London, 1987

Core, J. E., Discussion of the Roles of Performance measures and Monitoring in Annual Governance Decisions in Entrepreneurial Firms, Journal of Accounting Research, Vol. 40, No. 2, May 2002, PP. 519- 527

Curzon, G., Curzon, V. and Schwamm, H., the Multinational Enterprise in a Hostile World, The Macmillan Press LTD, London, 1977

Czechowicz, J., Choi, F.D.S. and Bavishi, V., "Assessing Foreign Subsidiary performance system", Practices of Loading Multinational Companies, (New York: Business International Corporation, 1982)

Datar, S., Kulp, S. C. and Lambert, R. A., Balancing Performance Measures, Journal of Accounting Research, Vol. 39, No. 1, June 2001, PP. 75-92

Demski, Joel S., Managerial Uses of Accounting Information, Kluwer, Boston, 2003

Dietermann, Gerard J., Evaluating Multinational Performance under FAS No.8, Accounting Management, May 1980, PP. 49-55

Donaldson, Howard M. \& Pai, Amar K., "Management Performance Evaluation", in: Managerial Accounting: An Analysis of Current International Applications, (university of Illinois, 1984)

Douglass, Merrill E., Testing a Methodology for Measuring the Interaction between Organization and Environment, Management International Review, Vol. 15, No. 1, 1975, PP. 89-97 
Dubach, Barbara, Managing Environmental Communications in Multinational Companies, Dissertation, Stäubli AG Zürich, 2000

Dunning, John H., The Multinational Enterprise, George Allen \& Irwin, London, 1971

Eccles, Robert G., The Transfer Pricing Problem "A Theory for Practice”, D.C. Heath and Company, Toronto, 1985

Engel, E., Gordon, E. A. and Hayes, Rachel M., The Roles of Performance Measures and Monitoring in Annual Governance Decisions in Entrepreneurial Firms, Journal of Accounting Research, Vol. 40, No. 2, May 2002, PP.485-518

Faiferlick, Christopher J. \& Others, Using Real Options to Transfer Price ResearchBased Intangibles, International Tax Journal, Vol. 30, No. 3, Summer 2004, PP. 111 - 120

FASB (Financial Accounting Standards Board), Accounting for the Translation of Foreign Currency Transactions and Foreign Currency Financial Statements, FAS 8, New York, October 1975

FASB (Financial Accounting Standards Board), Financial Reporting and Changing Prices, FAS 33, New York, September 1979

FASB (Financial Accounting Standards Board), Foreign Currency Translation, FAS 52, New York, December 1981

Fieldhoouse, D. K., The Multinational: a critique of a concept, (university of Cambridge) 1986

Fisher, J. G., Peffer, S. A., Sprinkle, G. B., Using Budgets for Performance Evaluation: Effects of Resources Allocation and Horizontal information Asymmetry on Budget Slack, and Performance, The Accounting Review, Vol. 77, No. 4, Oct. 2002, PP. 847-865

Garrison, Noreen, Managerial Accounting, 10 ${ }^{\text {th }}$ ed., McGraw-Hill, Irwin, 2003 
Gee, Kenneth P., Divisional Performance Measurement in an Inflationary Economy, Management International Review, Vol. 16, No. 4, 1976, PP.51-59

Götze, Uwe, Kostenrechnung und Kostenmanagement, Springer- Verlag, 3 Auf., Berlin, 2004

Götze, Uwe \& Bloech, J., Investitionsrechnung: Modelle und Analysen zur Beurteilung von Investitionsvorhaben, Springer-Verlag, Berlin, 1993

Haka, Susan F., Heitger, Dan L., International Managerial Accounting Research: A contracting framework and opportunities, The International Journal of Accounting, Vol. 39, No. 1, 2004, PP. 21-69

Haufler, A., Schjelderup, G., Transferpreissetzung im multinationalen Unternehmen und die Körperschaftsteuerreform in der OECD, in: Oestreicher, A., (Hrsg.), Internationale Verrechnungspreise: Beiträge zu einer Ringveranstaltung an der Universität Göttingen im Sommersemester 2002, Herne/Berlin (NWB), 2003, PP. 207-242

Hawkins, David F., "Controlling Foreign Operation", Financial Executive, Vol. 33, No. 2 February 1965

Hennart, Jeen-Francois, Control in Multinational Firms: the Role of Price and Hierarchy, Management International Review, Vol. 31, 1991, PP. 71-96

Ho, Daniel Hoi Ki \& Lau, Peter, Tze Yiu, An Exploratory Study of Transfer Pricing Practices by Multinationals with International Affiliates, International Tax Journal, Vol. 31, No. 4, Fall 2005, PP. 37 - 40

Holzer, H. P. \& Schoenfeld, H. M., Managerial Accounting and analysis in Multinational enterprises, de Gruyter, Berlin, 1986

Hood, N. \& Young, S., the Economics of Multinational Enterprise, Longman Inc., New York, 1979 
Hoogvelt, A., Puxty, A. G. \& Stopford, J. M., Multinational Enterprise: an Encyclopedic Dictionary of concepts and terms. Basingstoke, London: Macmillan, 1987

Hopwood, Anthony G., Problems with Using Accounting Information in Performance Evaluation, Management International Review, Vol. 13, No. 2-3, 1979, PP. 83-91

Horne, James G. Von \& Wachowicz, JR., John M., Fundamentals of Financial Management, twelfth edition, Prentic Hall (The Financial Times), 2005

Hosseini, Ahmad \& Rezaee, Zabihollah, Impact of SFAS No. 52 on Performance Measures of Multinationals, The International Journal of Accounting, Vol. 25, 1990, PP. 43-52

Hussain, Mostaque, Management Accounting Systems in Services: "Empirical Evidence with Non-Financial Performance Measurement in Finnish, Swedish and Japanese Banks and other Financial Institutions", Universitas WASAENSIS, VAASA, 2000

Imdieke, Leroy F., Smith, Charles H., International Financial Control Problems and the Accounting Control System, Management International Review, Vol. 15, No. 4-5, 1975, PP.13-27

Kaplan, Robert S., Purchasing Power Gains on Debt: The Effect of Expected and Unexpected Inflation, The Accounting Review, Vol. L11, No. 2, April 1977, PP. 369-378

Krahnert, Rolf, Verrechnungspreisbestimmung bei Auftragsproduktion, Dissertation, Universität Göttingen, ibidem -Verlag. Stuttgart, 2005

Kugel, Y., A Criterion Model for the Evaluation and Selection of International Business Models, Management International Review, Vol. 12, No. 6, 1972, PP. 3-20

Laffer, Arthur B. \& Miles, Mark A., International Economics in an Integrated World (Glenview, III.: Scott, Foresman and Company, 1982) 
Lee, James A., Cultural Analysis in Overseas Operations: to eliminate the root cause of many business problems, Harvard Business Review, Vol. 44, March-April 1966, PP. 106114

Lessard, D. R. \& Lorange P., Currency Changes and management Control: Resolving the Centralization/Decentralization Dilemma, The Accounting Review, Vol. L11, No. 3, July 1977, PP. 628-637

Lewis-Beck, Michael S., International Handbook of Quantitative Applications in the Social Sciences: "Regression Analysis”, Vol. 2, SAGE Publications, London, 1993

Li, Jain, Transfer Pricing and Double Taxation: A Review and Comparison of the New Zealand, Australia and the OECD Transfer Pricing Rules and Guidelines, International Tax Journal, Vol. 31, No. 3 Summer 2005, PP. 31 - 48

Loudon, David L., The Influence of Environmental Variables on the Use of Marketing Research, Management International Review, Vol.15 No.2-3, 1975, PP. 95-111

Maurer, Raimond \& Sebastian, Steffen, Inflation Risk Analysis of European Real Estate Securities, Working Paper Series: Finance and Accounting, Johann Wolfgang GoetheUniversität, Frankfurt am Main, No.51, Mai 2000

Mauriel, John J., "Evaluation and Control Overseas Operations", Management Accounting, (May 1969)

Mauriel, John J. \& Anthony, Robert N., Misevaluation of Investment Center Performance, Harvard Business Review, Vol. 44, March -April 1966

McCosh, Andrew M., Inflationary Adjustments of some Elements of the Planning and Control Cycle in Investment Centers, Management International Review, Vol. 16, No. 4, 1976, PP.35-49 
McInnes, J. M., Financial Control Systems for Multinational operations: An Empirical Investigation, Journal of International Business Studies, Fall 1971

Miller, Elwood L., Accounting Problems of Multinational Enterprises, D.C. Heath and Company, Toronto, 1979

Miller, Elwood L, (Ed.), Responsibility Accounting and Performance Evaluations, (New York: Van Nostrand Reinhold company, 1982)

Möller, Marius \& Bartl, Claudia, Einfluss der Verrechnungspreispolitik auf die Konzernstruktur, in: Oestreicher, A., (Hrsg.), Internationale Verrechnungspreise: Beiträge zu einer Ringveranstaltung an der Universität Göttingen im Sommersemester 2002, Herne/Berlin (NWB), 2003, PP. 265-283

Montavon, Wionczek, R., M., and Piquerez, F., the Role of Multinational Companies in Latin America: a Case Study in Mexico, Saxon House, England, 1979

Morsicato, Helen Gernon, Currency Translation and Performance Evaluation in Multinationals (Ann Arpor, Michigan: U.M.I. Research Press, 1981)

Müeller, Gerhard G., Gernon, Helen, and Meek, Gery, Accounting: an International Perspective, Business One Irwin, New York, 1994

Müller, Thomas, The Multinational Enterprise: Foreign Market Entry, Transfer of Technology, and Technology Spillovers, Ph.D. thesis, München University. 2002

Nam, Chng Woon, Effects of Tax Depreciation Rules on Firms' Investment Decision in an Inflationary Phase: Comparison of net present values in selected OECD Countries, CESifo Working Paper No. 528, Munich, Germany, August 2001

Nielsen, Soren Bo \& Others, Centralized vs. De-centralized Multinationals and Taxes, CESifo Working Paper No. 1586, Category 1: Public Financ, Nov. 2005 
Nobes, Christopher \& Parker, R. H., Comparative International Accounting, Prentice Hall, London, 4th. Edition, 1995

Noerreklit, H., Schoenfeld, H. W., Controlling Multinational Companies: An Attempt to Analyze Some Unresolved Issues, The International Journal of Accounting, Vol. 35, No. 3, 2000, PP. 415-430

OECD, Transfer Pricing and Multinational Enterprises, Report of the OECD Committee on Fiscal Affairs, Paris 1979

OECD, Transfer Pricing and Multinational Enterprises: Three Taxation Issues, Report of the OECD Committee on Fiscal Affairs, Paris, 1984

OECD, Verrechnungspreise und Multinationale Unternehmen: Drei steuerliche Sonderprobleme, Bericht des Steuerausschusses der OECD 1984, O. Schmidt, Köln, 1987

OECD, Multinational Enterprises and Disclosure of Information, Paris, 1988

OECD, Tax Aspects of Transfer Pricing within MNEs, the U.S. Proposed Regulation, Paris, 1993

OECD, Transfer Pricing Guidelines for Multinational Enterprises and Tax Administrations: Discussion Draft of Part 1, Paris, 1994

OECD, Transfer Pricing Guidelines for Multinational Enterprises and Tax Administrations, Paris, 1995

OECD, Verrechnungspreisgrundsätze für multinationale Unternehmen und Steuerverwaltungen, 2. Aufl., Köln, 2000

Oestreicher, A., Entwicklung und Rechtfertigung des Arm's Length Principle im Rahmen der Gewinnabgrenzung internationaler Konzerne, in: Oestreicher, A., (Hrsg.), Internationale Verrechnungspreise: Beiträge zu einer Ringveranstaltung an der Universität Göttingen im Sommersemester 2002, Herne/Berlin (NWB), 2003, PP. 1-51 
Oestreicher, A., (Hrsg.), Internationale Verrechnungspreise: Beiträge zu einer Ringveranstaltung an der Universität Göttingen im Sommersemester 2002, Herne/Berlin (NWB), 2003

Parker, James E., Impact of Price-Level Accounting, The Accounting Review, Vol. L11, No.1, Jan. 1977, PP. 69-90

Pearce, Robert D., the Growth and Evolution of Multinational Enterprise: Patterns of Geographical and Industrial Diversification, Edward Elgar, England, 1990

Persen, William \& Lessig, Van, Evaluating the Financial Performance of Overseas Operations, (New York: Financial Executives Research Foundation, 1979)

Plasschaert, Sylvain R.F., Transfer Pricing and Multinational Corporations: An Overview of Concepts, Mechanisms and Regulations, Preager Publishers, New York, 1979

Poensgen, Otto H. \& Straub, H., Inflation and the Corporate Investment Decision, Management International Review, Vol. 16, No. 4, 1976, PP.13-33

Porter, Michael E., the Competitive Strategy: Techniques for Analyzing Industries and Competitors, The Free Press, Macmillan, New York, 1980

Porter, Michael E., the Comparative Advantages of Nations, The Free Press, Macmillan, London, 1994

Priel, Victor Z, Some Management Aspects of Multinational Companies, Management International Review, vol.14, No. (4-5)1974, PP. 45-69

Raupach, A. \& Rohl, D., Verrechnungspreissysteme multinationaler Unternehmen in betriebswirtschaftlicher, gesellschafts- und steuerrechtlicher Sicht, Herne/Berlin (NWB), 1999 
Remman, Peter, Konzernverrechnungspreise und Konzernumlagen im Aktien- und GmbH- Recht, Dissertation, Wilhelms Universität zu Münster, Berlin: lang, 2002

Richman, Barry M., Multinational Corporations and the Communist Nation, Management International Review, Vol. 16, No. 3, 1976, PP. 9- 21

Robbins, Sidney M. \& Stobaugh, Robert B., Harvard Business Review, Vol.51 (Septemper - October 1973)

Ronge, Marius, the Role of Organisation for Multinational Companies in China, Dissertation, St. Gallen Uni. (Difo-Druck GmbH, Bamberg), 2001

Sachdev, Jagdish C., Disinvestment: A New Problem in Multinational Corporation Host Government Interface, Management International Review, Vol. 16, No. 3, 1976, PP. 23- 35

Schlag, Rene C., Accounting for Taxes of Foreign Subsidiaries: a Simplified Approach, Management Accounting, Vol.61, Dec. 1979, PP. 15-19

Schoenfeld, Hanns-Martin, Some Special Accounting Problems of Multinational Enterprises, Management International Review, Vol. 9, No. 4-5, 1969, PP. 3-11

Schomann, Marc, Wissensorientiertes Performance Measurement, DUV, Wiesbaden, 2001

Schreiber, Rolf, Verrechnungspreise bei Verlagerung von Funktionen und Risiken im internationalen Konzern, in: Oestreicher, A., (Hrsg.), Internationale Verrechnungspreise: Beiträge zu einer Ringveranstaltung an der Universität Göttingen im Sommersemester 2002, Herne/Berlin (NWB), 2003, PP. 285-342

Simonetti, Jack L., Environmental Factors Affecting American Business Subsidiary operations In Italy, Management International Review, Vol. 13, No. 1, 1973, PP. 79-85

Smith, Dan T., Financial Variables in International Business, Harvard Business Review, Vol. 44, Jan.-Feb. 1966, PP. 93-104 
Steakley, Mark E., Inflation Accounting Techniques: How They Compare, Management Accounting, Sept. 1979. PP. 16- 18

Taggart, James H. \& McDermott, Michael C, the Essence of International Business, Prentice Hall Europe, London, 1993

Tang, Roger Y. W., Transfer Pricing Practices in the United State and Japan, Preager Publishers, New York, 1979

Tsui, Winston W., Inflation Accounting and Foreign Currency Translation, Management Accounting, September 1979, PP. 23-31

Turner, R. Kerry, Pearce, D. \& Bateman, I., Environmental Economics: An Elementary Introduction, Harvester Wheatsheaf, New York, 1994

Turney, Peter B. B., Uyar, Kivilcim M., Profit Center Control for Corporate Management Information System: An Organizational Analysis, Management International Review, Vol. 14, No. 4-5, 1974, PP. $91-99$

Vormoor, Christoph, Die Eignung Öffentlicher Unternehmensdatenbanken zur Bestimmung von Verrechnungspreisen im Rahmen der Einkunftsabgrenzung im internationalen Konzern, Dissertation, Universität Göttingen, Verlag Dr. KOVAC in Hamburg, 2005

Weinshall, Theodore D., Multinational Corporations: Their Development and Universal Role, Management International Review, Vol. 15, No. 2-3, 1975, PP. 17- 28

Weinshall, Theodore D., Multinational Corporations: Their Study and Measurement, Management International Review, Vol. 15, No. 4-5, 1975, PP. 67- 76

Whittington, Geoffrey, Inflation Accounting: An Introduction to the Debate, Cambridge University Press, Cambridge, 1991 
Wilkins, Mira, the Emergence of Multinational Enterprise: American Business Abroad from the Colonial Era to 1914, Harvard University Press, 1970

Willey, Russell W., In Defense of FAS No. 8, Management Accounting, Vol. 61 Dec. 1979, PP. 36-40

Zirfas, Heidrun, Ausgewählte Planungsansätze bei Bestimmung von Verrechnungspreisen in deutschen Grußunternehmen, in: Oestreicher, A., (Hrsg.), Internationale Verrechnungspreise: Beiträge zu einer Ringveranstaltung an der Universität Göttingen im Sommersemester 2002, Herne/Berlin (NWB), 2003, PP. 243-263

\section{Arabic Literature}

Abd-Elhady, A., Measuring the Investment Climate in Host Countries, A Paper: Presented to The First National Forum about International Business Administration and Multinational Companies in Egypt, Cairo, May 1986

Abd-Elrazek, A., International Accounting and Auditing, Center of Open Education, Cairo University, 1996

Alaky, M. A., Effect of External Environmental Factors on Managerial Efficiency of the American Saudi Business Organisation: A Comparison Study due to "Farmer \& Richman" Model, Researches \& Development Center, Management \& Economy Faculty, Abd-Elaziz King University, Gedda, 1981

Albanna, B. A., Using Accounting Data in Performance Evaluation in Multinational Companies, The Egyptian Review of Commercial Studies, Commerce Faculty Almansoura University, No. 4, 1983

Alfaiomy, M., International Company: Economic and Accounting Approach, DarAlmatboat-Almasria, Alexandria, 1982

Alfar, I., Evaluating The Activity of Multinational Companies in Developing Countries, A Paper: Presented to The First National Forum about International Business Administration and Multinational Companies in Egypt, Cairo, May 1986 
Algabr, N. A. \& Abd-Elmonam, M. A., International Accounting: Theoretical and Practical framework, Saudi Accounting Association, Saudi, 1998

Algohary, Ali M., Performance Evaluation in Multinational Companies, Review of Commercial Researches, Commerce Faculty - Zagazig Uni., Vol. 9, No. 11, 1987, PP. 137

Ali, Ibrahim M., Accounting Measurement of the Exchange Rates Fluctuations Risks and their Effect on the Performance of the Foreign Subsidiaries, Review of Commercial Researches, Commerce Faculty - Zagazig Uni., Vol. 15, No. 2, 1993, PP. 1-58

Alkady, F., Some Investment Problems Facing Multinational Companies in Egypt, A Paper: Presented to The First National Forum about International Business Administration and Multinational Companies in Egypt, Cairo, May 1986

Alnagar, Fared, International Business Administration and Multinational Companies, Public Egyptian Authority of Book, Cairo, 1986

Alshafay, G., Feasibility Study of the Investmental Projects on Multinational Company, Management Review, No. 1, July, 1975

Ashoor, Asafet A., International Accounting: Theory and Practice, Ain-Shams Library, Cairo, 1997

Awad, Gamal S. M., Quantitative Approach to treat the Accounting Problem in Economic Performance Measurement and Evaluation of International Companies, Dissertation, Commerce Faculty - Cairo University, 1989

Elsharawy, M. E., The Role Multinational Companies in Economic Development in the Developing World, Dissertation, Commerce Faculty - Tanta University, 1978

Fares, Z., Suggested Development of the Model "Farmar - Richman" as a Basic to Improve Approach oh the Economic Performance Evaluation in Multinational Company, Review of Economic and Accounting, No. 15, 1981 
Fares, Z., Scientific Approach to Plan and Determine the Tax Income in Multinational Company: Applied Study on Arabic Investment Companies, Dissertation, Commerce Faculty -Almansoura University, 1980

Fayed, Metwally A. E., Standards of Evaluating and Selecting the Relevant Accounting Alternative to Translate the Foreign Financial Statements for Preparing Consolidated Statements in Multinational Companies, Review of Commercial Sciences, Commerce Faculty - Menoufia University, $4^{\text {th }}$ year No. 2, 1993, PP. 139-194

GAFI (General Authority for investment \& Free Zones), The Multinational Company Operating in Egypt, Cairo - Egypt, 2004

Ghebreal, W., Political Dimension of Multinational Companies, The International Political Review, No. 244, Cairo, 1976

Ghonaim, A. E. \& Sabry, N. M., Statistical Analysis of Data by Using SPSS, Dar-Kobaa for Printing and Publishing, Cairo, 2000

Hammad, Mohammad A., Theoretical and Practical to Prepare the Consolidated Financial Statements in Multinational Enterprises, Dissertation, Commerce Faculty - Ainshams University, 1997

Henedy, Hamed M. \& Isa, Zina A., Treating the Effect of Inflation on Consolidated Financial Statements and Reports in International Companies, Scientific Review of Economy and Commerce, Commerce Faculty - Ain-shams Uni., Cairo, No.2, 1996

Hussein, Kamal-Eldin, Controlling on the Performance in The Multinational Companies, Scientific Review of Economy and Commerce, Commerce Faculty - Ain-shams Uni., Cairo, No.2, 1987, PP. 697-732

Mostafa, S. M., Pricing Intra-Transactions of the Parts of Multinational Company, A Paper: Presented to The First National Forum about International Business Administration and Multinational Companies in Egypt, Cairo, May 1986 
Nammar, N. M., Translating Transactions and in Foreign Currency and Foreign Financial Statements in International Accounting for Reporting Purposes, Accounting, Management and Review, Commerce Faculty - Cairo University, No. 25, 1978

Osman, Ahmad S., Controlling and Performance Evaluation in Multinational Enterprises, The Egyptian Review of Commercial Studies, Commerce Faculty - Mansoura University, No. 2, 1983

Osman, Ahmad S., Conceptual Framework of International Managerial Accounting, The Egyptian Review of Commercial Studies, Commerce Faculty - Almansoura University, No. 1, 1984

Saada, Y. M., Accounting Problems of Fixed Assets Evaluation in Multinational Companies, Dissertation, Commerce Faculty - Almansoura University, 1980

Said, Mohammad E., Multinational Companies and their Economic, Social and Political Effects, Public Egyptian Authority of Book, Cairo, 1978

Salama, Salah H. A., Treating the Problems of Accounting Measurement and Performance Evaluation of Foreign Subsidiaries: An Empirical Study, The Review of Accounting Thought, Commerce Faculty - Ain-shams Uni., 2000, PP. 270-375

Tawfeek, A., Arabic Environment Characteristics and Its Reflections on Multinational Company, A Paper: Presented to The First National Forum about International Business Administration and Multinational Companies in Egypt, Cairo, May 1986

Zayed, M. E., International Accounting in Multinational Companies, Dar-Algalaa Elmansoura, 1993 
Appendixes

\section{Appendix 1: Questionnaire}

Appendix 2: Output of the Statistical Analysis 


\section{Appendix 1}

\section{Questionnaire}

Presented to the managers of MNCs operating in Egypt about the environmental factors and their influence on the performance of their companies

Co.nr 


\section{Dear Mr:}

The following questions concerning with a research presented from the researcher: Hatem Elsharawy - Ph.D. student in the economy faculty, Göttingen University, Germany.

These questions aim to determine the economic, legal, political, cultural, and social factors affecting the performance of the MNCs operating in Egypt, to consider them at performance evaluation of these companies.

I hope in some of your valuable time to answer these questions, and this will be a good contribution in this research. It is considered that, your answers and opinions will be used only for scientific research. And I will inform your company with the important results and recommendations in the end of this research. Thanks for your cooperation.

With my best regards.

Hatem Elsharawy 
Q.1: Do you think that the economic system applied in Egypt has an influence on the performance of your company?

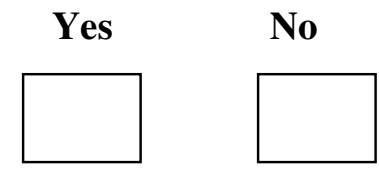

If yes, the kind and degree of the influence are:

\begin{tabular}{|l|l|l|l|}
\hline \multicolumn{4}{|c|}{ Positive } \\
\hline Very big & big & middle & little \\
\hline
\end{tabular}

\begin{tabular}{|l|l|l|l|}
\hline \multicolumn{4}{|c|}{ Negative } \\
\hline Very big & big & middle & little \\
\hline
\end{tabular}

Q.2: Do you think that the financial and monetary

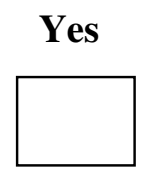

No policies applied in Egypt, especially, concerning with interest rate and the currency exchange

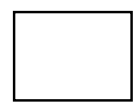
rates have an influence on the performance of your company?

If yes, the kind and degree of the influence are:

\begin{tabular}{|l|l|l|l|}
\hline \multicolumn{4}{|c|}{ Positive } \\
\hline Very big & big & middle & little \\
\hline
\end{tabular}

\begin{tabular}{|l|l|l|l|}
\hline \multicolumn{4}{|c|}{ Negative } \\
\hline Very big & big & middle & little \\
\hline
\end{tabular}

Q.3: Do you think that the production elements in Egypt, specially their quality, availability, and price have an influence on the performance of your company?

Yes

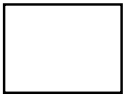

No

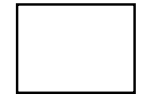

If yes, the kind and degree of the influence are:

\begin{tabular}{|l|l|l|l|}
\hline \multicolumn{4}{|c|}{ Positive } \\
\hline Very big & big & middle & little \\
\hline
\end{tabular}

\begin{tabular}{|l|l|l|l|}
\hline \multicolumn{4}{|c|}{ Negative } \\
\hline Very big & big & middle & little \\
\hline
\end{tabular}


Q.4: Do you think that the ties and economic relationships of Egypt with the other countries have an influence on the performance of your company?

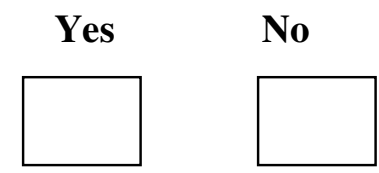

If yes, the kind and degree of the influence are:

\begin{tabular}{|l|l|l|l|}
\hline \multicolumn{4}{|c|}{ Positive } \\
\hline Very big & big & middle & little \\
\hline
\end{tabular}

\begin{tabular}{|l|l|l|l|}
\hline \multicolumn{4}{|c|}{ Negative } \\
\hline Very big & big & middle & little \\
\hline
\end{tabular}

Q.5 Do you think that the level of services and infrastructure in Egypt has an influence on the performance of your company?

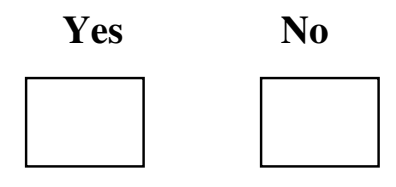

If yes, the kind and degree of the influence are:

\begin{tabular}{|l|l|l|l|}
\hline \multicolumn{4}{|c|}{ Positive } \\
\hline Very big & big & middle & little \\
\hline
\end{tabular}

\begin{tabular}{|l|l|l|l|}
\hline \multicolumn{4}{|c|}{ Negative } \\
\hline Very big & big & middle & little \\
\hline
\end{tabular}

Q.6: Do you think that the tax law in Egypt has an influence on the performance of your company?

If yes, the kind and degree of the influence are:

\begin{tabular}{|l|l|l|l|}
\hline \multicolumn{4}{|c|}{ Positive } \\
\hline Very big & big & middle & little \\
\hline
\end{tabular}

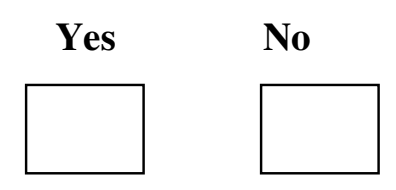

\begin{tabular}{|l|l|l|l|}
\hline \multicolumn{4}{|c|}{ Negative } \\
\hline Very big & big & middle & little \\
\hline
\end{tabular}


Q.7: Do you think that the custom law and policies have

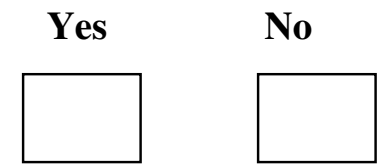

If yes, the kind and degree of the influence are:

\begin{tabular}{|l|l|l|l|}
\hline \multicolumn{4}{|c|}{ Positive } \\
\hline Very big & big & middle & little \\
\hline
\end{tabular}

\section{Negative}

\begin{tabular}{|l|l|l|l|}
\hline \multicolumn{4}{|c|}{ Negative } \\
\hline Very big & big & middle & little \\
\hline
\end{tabular}

Q.8: Do you think that the importation and exportation law has an influence on the performance of your company?

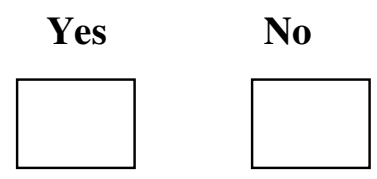

If yes, the kind and degree of the influence are:

\begin{tabular}{|l|l|l|l|}
\hline \multicolumn{4}{|c|}{ Positive } \\
\hline Very big & big & middle & little \\
\hline
\end{tabular}

\begin{tabular}{|l|l|l|l|}
\hline \multicolumn{4}{|c|}{ Negative } \\
\hline Very big & big & middle & little \\
\hline
\end{tabular}

Q.9: Do you think that the monetary law and procedures

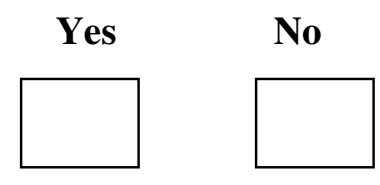
on the performance of your company?

If yes, the kind and degree of the influence are:

\begin{tabular}{|l|l|l|l|}
\hline \multicolumn{4}{|c|}{ Positive } \\
\hline Very big & big & middle & little \\
\hline
\end{tabular}

\begin{tabular}{|l|l|l|l|}
\hline \multicolumn{4}{|c|}{ Negative } \\
\hline Very big & big & middle & little \\
\hline
\end{tabular}


Q.10: Do you think that the investment law in Egypt, especially the foreign investment, has an influence on the performance of your company?

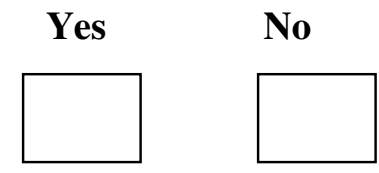

If yes, the kind and degree of the influence are:

\begin{tabular}{|l|l|l|l|}
\hline \multicolumn{4}{|c|}{ Positive } \\
\hline Very big & big & middle & little \\
\hline
\end{tabular}

\begin{tabular}{|l|l|l|l|}
\hline \multicolumn{4}{|c|}{ Negative } \\
\hline Very big & big & middle & little \\
\hline
\end{tabular}

Q.11: Do you think that the labour and employment law in Egypt have an influence on the performance of your company?

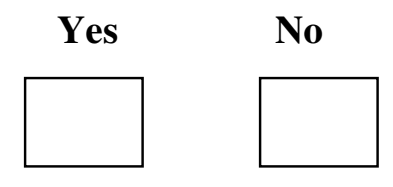

If yes, the kind and degree of the influence are:

\begin{tabular}{|l|l|l|l|}
\hline \multicolumn{4}{|c|}{ Positive } \\
\hline Very big & big & middle & little \\
\hline
\end{tabular}

\begin{tabular}{|l|l|l|l|}
\hline \multicolumn{4}{|c|}{ Negative } \\
\hline Very big & big & middle & little \\
\hline
\end{tabular}

Q.12: Do you think that the level of bureaucracy in the dealing with formal departments in Egypt has an influence on the performance of your company?

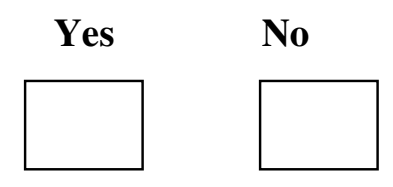

If yes, the kind and degree of the influence are:

\begin{tabular}{|l|l|l|l|}
\hline \multicolumn{4}{|c|}{ Positive } \\
\hline Very big & big & middle & little \\
\hline
\end{tabular}

\begin{tabular}{|l|c|c|c|}
\hline \multicolumn{4}{|c|}{ Negative } \\
\hline Very big & big & middle & little \\
\hline
\end{tabular}


Q.13: Do you think that degree of the political and security stability in the Middle East generally, and in

Egypt especially t has an influence on the performance

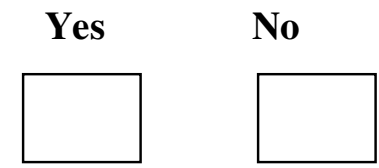
of your company?

If yes, the kind and degree of the influence are:

\begin{tabular}{|l|l|l|l|}
\hline \multicolumn{4}{|c|}{ Positive } \\
\hline Very big & big & middle & little \\
\hline
\end{tabular}

\begin{tabular}{|l|l|l|l|}
\hline \multicolumn{4}{|c|}{ Negative } \\
\hline Very big & big & middle & little \\
\hline
\end{tabular}

Q.14: Is the level and quality of education of employees

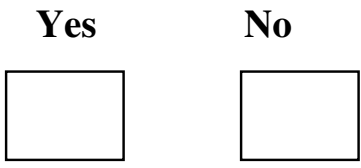

If yes, the kind and degree of the influence are:

\begin{tabular}{|l|l|l|l|}
\hline \multicolumn{4}{|c|}{ Positive } \\
\hline Very big & big & middle & little \\
\hline
\end{tabular}

\begin{tabular}{|l|l|l|l|}
\hline \multicolumn{4}{|c|}{ Negative } \\
\hline Very big & big & middle & little \\
\hline
\end{tabular}

Q.15: Is the cleverness and level of technology training

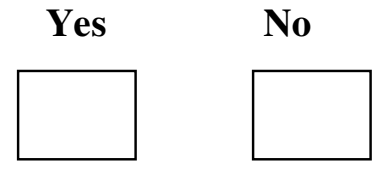
your company?

If yes, the kind and degree of the influence are:

\begin{tabular}{|l|l|l|l|}
\hline \multicolumn{4}{|c|}{ Positive } \\
\hline Very big & big & middle & little \\
\hline
\end{tabular}

\begin{tabular}{|c|c|c|c|}
\hline \multicolumn{4}{|c|}{ Negative } \\
\hline Very big & big & middle & little \\
\hline
\end{tabular}


Q.16: Do you think that the habits, traditions, conventions,

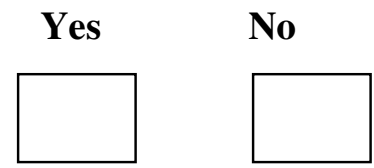
performance of your company?

If yes, the kind and degree of the influence are:

\begin{tabular}{|l|l|l|l|}
\hline \multicolumn{4}{|c|}{ Positive } \\
\hline Very big & big & middle & little \\
\hline
\end{tabular}

\begin{tabular}{|l|l|l|l|}
\hline \multicolumn{4}{|c|}{ Negative } \\
\hline Very big & big & middle & little \\
\hline
\end{tabular}

Q.17: Do you think that the religious belief of the

Egyptian people has an influence on the performance of your company?

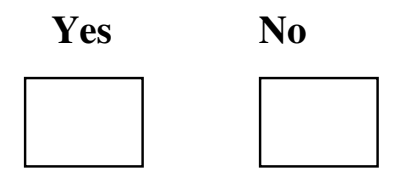

If yes, the kind and degree of the influence are:

\begin{tabular}{|l|l|l|l|}
\hline \multicolumn{4}{|c|}{ Positive } \\
\hline Very big & big & middle & little \\
\hline
\end{tabular}

\begin{tabular}{|l|l|l|l|}
\hline \multicolumn{4}{|c|}{ Negative } \\
\hline Very big & big & middle & little \\
\hline
\end{tabular}

Q.18: Do you think that the view of Egyptians people towards of the foreigners, especially the foreign companies and their products has an influence on

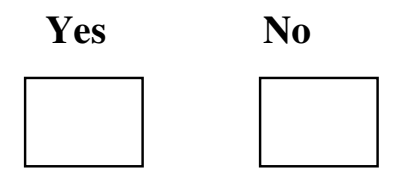
the performance of your company?

If yes, the kind and degree of the influence are:

\begin{tabular}{|l|l|l|l|}
\hline \multicolumn{4}{|c|}{ Positive } \\
\hline Very big & big & middle & little \\
\hline
\end{tabular}

\begin{tabular}{|l|l|l|l|}
\hline \multicolumn{4}{|c|}{ Negative } \\
\hline Very big & big & middle & little \\
\hline
\end{tabular}


Q.19: Is there influence of the similar competitive

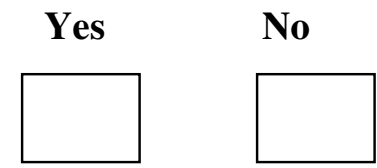

If yes, the kind and degree of the influence are:

\begin{tabular}{|l|l|l|l|}
\hline \multicolumn{4}{|c|}{ Positive } \\
\hline Very big & big & middle & little \\
\hline
\end{tabular}

\begin{tabular}{|l|l|l|l|}
\hline \multicolumn{4}{|c|}{ Negative } \\
\hline Very big & big & middle & little \\
\hline
\end{tabular}

Q.20: Is your company uses R O I as an indicator to performance evaluation?

Yes No

If yes, R I O calculated from last available accounts of your company $=\ldots . . . . \%$

\section{Note:}

The ratio of foreign contribution in the capital of your company equal .......

\section{The company name:}

\section{Address}

Tel.:

Fax:

\section{E-mail :}




\section{Appendix (2): The output of the Statistical Analysis}

Variables Entered/Removed

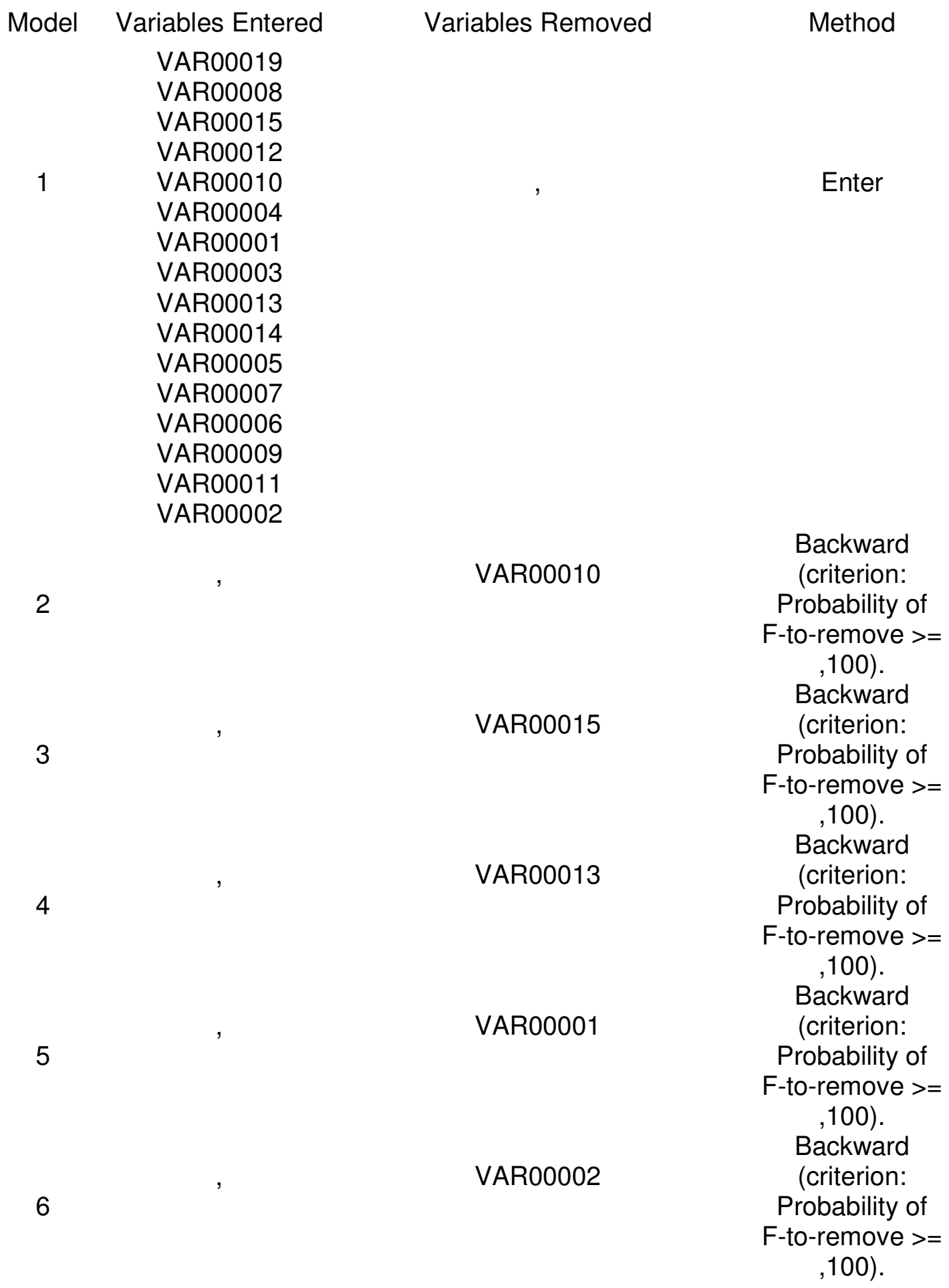

a All requested variables entered.

b Dependent Variable: VAR00020 
Model Summary

$\begin{array}{ccccc}\text { Model } & \text { R } & \text { R Square } & \text { Adjusted R Square } & \text { Std. Error of the Estimate } \\ 1 & , 925 & , 855 & , 677 & 2,6751 \\ 2 & , 925 & , 855 & , 700 & 2,5781 \\ 3 & , 924 & , 855 & , 719 & 2,4941 \\ 4 & , 923 & , 853 & , 733 & 2,4319 \\ 5 & , 922 & , 850 & , 745 & 2,3772 \\ 6 & , 915 & , 837 & , 737 & 2,4105\end{array}$

(1) The first model Predictors: (Constant), VAR00019, VAR00008, VAR00015, VAR00012, VAR00010, VAR00004, VAR00001, VAR00003, VAR00013, VAR00014, VAR00005, VAR00007, VAR00006, VAR00009, VAR00011, VAR00002

(2) The second model Predictors : (Constant), VAR00019, VAR00008, VAR00015, VAR00012, VAR00004, VAR00001, VAR00003, VAR00013, VAR00014, VAR00005, VAR00007, VAR00006, VAR00009, VAR00011, VAR00002

(3) The third model Predictors: (Constant), VAR00019, VAR00008, VAR00012, VAR00004, VAR00001, VAR00003, VAR00013, VAR00014, VAR00005, VAR00007, VAR00006, VAR00009, VAR00011, VAR00002

(4) The fourth model Predictors d Predictors: (Constant), VAR00019, VAR00008, VAR00012, VAR00004, VAR00001, VAR00003, VAR00014, VAR00005, VAR00007, VAR00006, VAR00009, VAR00011, VAR00002

(5) The fifth model Predictors : (Constant), VAR00019, VAR00008, VAR00012, VAR00004, VAR00003, VAR00014, VAR00005, VAR00007, VAR00006, VAR00009, VAR00011, VAR00002

(6) The sixth model Predictors: (Constant), VAR00019, VAR00008, VAR00012, VAR00004, VAR00003, VAR00014, VAR00005, VAR00007, VAR00006, VAR00009, VAR00011 


\begin{tabular}{|c|c|c|c|c|c|c|}
\hline & & $\mathrm{AN}$ & & & & \\
\hline Model & & Sum of Squares & $d f$ & Mean Square & $\mathrm{F}$ & Sig. \\
\hline 1 & Regression & 548,737 & 16 & 34,296 & 4,792 &, 003 \\
\hline & Residual & 93,033 & 13 & 7,156 & & \\
\hline & Total & 641,770 & 29 & & & \\
\hline 2 & Regression & 548,718 & 15 & 36,581 & 5,504 & ,001 \\
\hline & Residual & 93,051 & 14 & 6,647 & & \\
\hline & Total & 641,770 & 29 & & & \\
\hline 3 & Regression & 548,465 & 14 & 39,176 & 6,298 &, 001 \\
\hline & Residual & 93,304 & 15 & 6,220 & & \\
\hline & Total & 641,770 & 29 & & & \\
\hline 4 & Regression & 547,145 & 13 & 42,088 & 7,117 &, 000 \\
\hline & Residual & 94,625 & 16 & 5,914 & & \\
\hline & Total & 641,770 & 29 & & & \\
\hline 5 & Regression & 545,698 & 12 & 45,475 & 8,047 &, 000 \\
\hline & Residual & 96,072 & 17 & 5,651 & & \\
\hline & Total & 641,770 & 29 & & & \\
\hline 6 & Regression & 537,182 & 11 & 48,835 & 8,405 &, 000 \\
\hline & Residual & 104,588 & 18 & 5,810 & & \\
\hline & Total & 641,770 & 29 & & & \\
\hline
\end{tabular}

(1) The first model Predictors: (Constant), VAR00019, VAR00008, VAR00015, VAR00012, VAR00010, VAR00004, VAR00001, VAR00003, VAR00013, VAR00014, VAR00005, VAR00007, VAR00006, VAR00009, VAR00011, VAR00002

(2) The second model Predictors: (Constant), VAR00019, VAR00008, VAR00015, VAR00012, VAR00004, VAR00001, VAR00003, VAR00013, VAR00014, VAR00005, VAR00007, VAR00006, VAR00009, VAR00011, VAR00002

(3) The third model Predictors: (Constant), VAR00019, VAR00008, VAR00012, VAR00004, VAR00001, VAR00003, VAR00013, VAR00014, VAR00005, VAR00007, VAR00006, VAR00009, VAR00011, VAR00002 
(4) The fourth model Predictors: (Constant), VAR00019, VAR00008, VAR00012, VAR00004, VAR00001, VAR00003, VAR00014, VAR00005, VAR00007, VAR00006, VAR00009, VAR00011, VAR00002

(5) The fifth model Predictors: (Constant), VAR00019, VAR00008, VAR00012, VAR00004, VAR00003, VAR00014, VAR00005, VAR00007, VAR00006, VAR00009, VAR00011, VAR00002

(6) The sixth model Predictors: (Constant), VAR00019, VAR00008, VAR00012, VAR00004, VAR00003, VAR00014, VAR00005, VAR00007, VAR00006, VAR00009, VAR00011

(7) Dependent Variable: VAR00020 
Coefficients

$\begin{array}{llll} & \text { Standardized } & & \\ \text { Unstandardized Coefficients } & \text { Coefficients } & \text { t } & \text { Sig. }\end{array}$

Model

B Std. Error

Beta

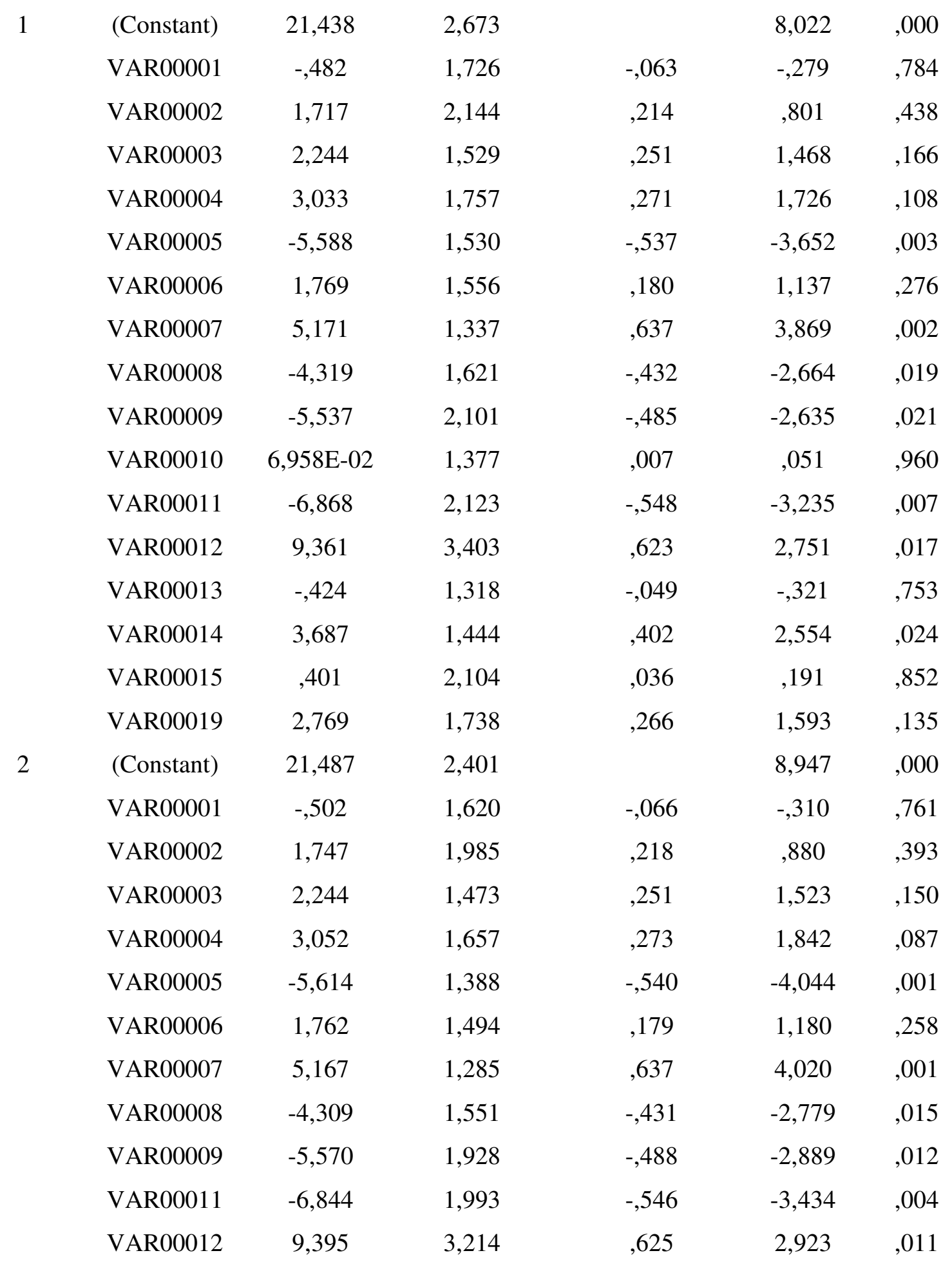




\begin{tabular}{|c|c|c|c|c|c|}
\hline VAR00013 &,- 420 & 1,268 &,- 048 &,- 331 & ,745 \\
\hline VAR00014 & 3,685 & 1,391 & ,401 & 2,650 & ,019 \\
\hline VAR00015 & ,395 & 2,024 &, 036 & ,195 &, 848 \\
\hline VAR00019 & 2,758 & 1,662 &, 265 & 1,659 &, 119 \\
\hline (Constant) & 21,752 & 1,917 & & 11,347 &, 000 \\
\hline VAR00001 &,- 661 & 1,353 &,- 087 &,- 489 & ,632 \\
\hline VAR00002 & 1,954 & 1,623 &, 243 & 1,204 & ,247 \\
\hline VAR00003 & 2,399 & 1,202 & ,268 & 1,996 & ,064 \\
\hline VAR00004 & 3,182 & 1,468 &, 285 & 2,167 &, 047 \\
\hline VAR00005 & $-5,518$ & 1,255 &,- 531 & $-4,397$ &, 001 \\
\hline VAR00006 & 1,786 & 1,440 &, 181 & 1,241 & ,234 \\
\hline VAR00007 & 5,222 & 1,214 & ,643 & 4,303 & ,001 \\
\hline VAR00008 & $-4,436$ & 1,360 &,- 444 & $-3,262$ &, 005 \\
\hline VAR00009 & $-5,715$ & 1,720 &,- 500 & $-3,322$ & ,005 \\
\hline VAR00011 & $-6,827$ & 1,926 &,- 545 & $-3,544$ &, 003 \\
\hline VAR00012 & 9,681 & 2,768 & ,644 & 3,497 & ,003 \\
\hline VAR00013 &,- 519 & 1,126 &,- 060 &,- 461 &, 652 \\
\hline VAR00014 & 3,787 & 1,247 & ,413 & 3,036 & ,008 \\
\hline VAR00019 & 2,620 & 1,454 &, 252 & 1,802 & ,092 \\
\hline (Constant) & 21,586 & 1,836 & & 11,758 &, 000 \\
\hline VAR00001 &,- 653 & 1,319 &,- 086 &,- 495 &, 628 \\
\hline VAR00002 & 1,840 & 1,564 &, 229 & 1,176 &, 257 \\
\hline VAR00003 & 2,481 & 1,159 &, 277 & 2,140 & ,048 \\
\hline VAR00004 & 3,115 & 1,424 &, 279 & 2,187 &, 044 \\
\hline VAR00005 & $-5,415$ & 1,204 &,- 521 & $-4,497$ &, 000 \\
\hline VAR00006 & 1,953 & 1,359 & ,198 & 1,438 &, 170 \\
\hline VAR00007 & 5,343 & 1,155 & ,658 & 4,625 & ,000 \\
\hline VAR00008 & $-4,443$ & 1,326 &,- 445 & $-3,351$ &, 004 \\
\hline VAR00009 & $-5,579$ & 1,652 &,- 488 & $-3,376$ &, 004 \\
\hline VAR00011 & $-7,192$ & 1,712 &,- 574 & $-4,202$ &, 001 \\
\hline VAR00012 & 9,588 & 2,692 & ,638 & 3,561 & ,003 \\
\hline VAR00014 & 3,837 & 1,212 & ,418 & 3,167 &, 006 \\
\hline VAR00019 & 2,874 & 1,312 &, 276 & 2,191 &, 044 \\
\hline (Constant) & 21,535 & 1,792 & & 12,018 &, 000 \\
\hline
\end{tabular}




$\begin{array}{cccccc}\text { VAR00002 } & 1,271 & 1,035 & , 158 & 1,228 & , 236 \\ \text { VAR00003 } & 2,345 & 1,101 & , 262 & 2,130 & , 048 \\ \text { VAR00004 } & 2,862 & 1,299 & , 256 & 2,203 & , 042 \\ \text { VAR00005 } & -5,162 & 1,066 & -, 496 & -4,844 & , 000 \\ \text { VAR00006 } & 2,090 & 1,301 & , 212 & 1,607 & , 126 \\ \text { VAR00007 } & 5,300 & 1,126 & , 653 & 4,706 & , 000 \\ \text { VAR00008 } & -4,308 & 1,269 & -, 431 & -3,396 & , 003 \\ \text { VAR00009 } & -5,453 & 1,596 & -, 477 & -3,417 & , 003 \\ \text { VAR00011 } & -7,091 & 1,661 & -, 566 & -4,269 & , 001 \\ \text { VAR00012 } & 9,445 & 2,617 & , 629 & 3,610 & , 002 \\ \text { VAR00014 } & 3,918 & 1,174 & , 427 & 3,338 & , 004 \\ \text { VAR00019 } & 3,064 & 1,226 & , 295 & 2,499 & , 023 \\ \text { (Constant) } & 21,691 & 1,812 & & 11,968 & , 000 \\ \text { VAR00003 } & 1,916 & 1,059 & , 214 & 1,810 & , 087 \\ \text { VAR00004 } & 2,811 & 1,316 & , 251 & 2,136 & , 047 \\ \text { VAR00005 } & -5,202 & 1,080 & -, 500 & -4,817 & , 000 \\ \text { VAR00006 } & 2,310 & 1,306 & , 235 & 1,769 & , 094 \\ \text { VAR00007 } & 5,270 & 1,142 & , 649 & 4,616 & , 000 \\ \text { VAR00008 } & -4,356 & 1,286 & -, 436 & -3,387 & , 003 \\ \text { VAR00009 } & -4,972 & 1,569 & -, 435 & -3,169 & , 005 \\ \text { VAR00011 } & -7,510 & 1,648 & -, 599 & -4,557 & , 000 \\ \text { VAR00012 } & 9,787 & 2,638 & , 651 & 3,710 & , 002 \\ \text { VAR00014 } & 4,244 & 1,159 & , 462 & 3,661 & , 002 \\ \text { VAR00019 } & 3,832 & 1,069 & , 369 & 3,586 & , 002\end{array}$

* Dependent Variable: VAR00020 


\section{Excluded Variables}

Beta In t Sig. Partial Correlation Collinearity Statistics

$\begin{array}{ccccccc}\text { Model } & & & & & & \text { Tolerance } \\ 3 & \text { VAR00010 } & , 007 & , 051 & , 960 & , 014 & , 610 \\ & \text { VAR00010 } & , 005 & , 040 & , 968 & , 011 & , 612 \\ 4 & \text { VAR00015 } & , 036 & , 195 & , 848 & , 052 & , 310 \\ & \text { VAR00010 } & , 001 & , 005 & , 996 & , 001 & , 616 \\ & \text { VAR00015 } & , 060 & , 367 & , 718 & , 094 & , 368 \\ & \text { VAR00013 } & -, 060 & -, 461 & , 652 & -, 118 & , 577 \\ & \text { VAR00010 } & , 014 & , 117 & , 908 & , 029 & , 650 \\ & \text { VAR00015 } & , 079 & , 567 & , 579 & , 140 & , 471 \\ & \text { VAR00013 } & -, 059 & -, 465 & , 648 & -, 116 & , 577 \\ & \text { VAR00001 } & -, 086 & -, 495 & , 628 & -, 123 & , 307 \\ 6 & \text { VAR00010 } & , 042 & , 358 & , 725 & , 086 & , 679 \\ & \text { VAR00015 } & , 105 & , 763 & , 456 & , 182 & , 486 \\ & \text { VAR00013 } & -, 025 & -, 202 & , 842 & -, 049 & , 603 \\ & \text { VAR00001 } & , 064 & , 542 & , 595 & , 130 & , 671 \\ & \text { VAR00002 } & , 158 & 1,228 & , 236 & , 285 & , 529\end{array}$

Predictors in the Model (2): (Constant), VAR00019, VAR00008, VAR00015, VAR00012, VAR00004, VAR00001, VAR00003, VAR00013, VAR00014, VAR00005, VAR00007, VAR00006, VAR00009, VAR00011, VAR00002

Predictors in the Model (3): (Constant), VAR00019, VAR00008, VAR00012, VAR00004, VAR00001, VAR00003, VAR00013, VAR00014, VAR00005, VAR00007, VAR00006, VAR00009, VAR00011, VAR00002

Predictors in the Model (4): (Constant), VAR00019, VAR00008, VAR00012, VAR00004, VAR00001, VAR00003, VAR00014, VAR00005, VAR00007, VAR00006, VAR00009, VAR00011, VAR00002

Predictors in the Model (5): (Constant), VAR00019, VAR00008, VAR00012, VAR00004, VAR00003, VAR00014, VAR00005, VAR00007, VAR00006, VAR00009, VAR00011, VAR00002 
Predictors in the Model (6): (Constant), VAR00019, VAR00008, VAR00012, VAR00004, VAR00003, VAR00014, VAR00005, VAR00007, VAR00006, VAR00009, VAR00011

* Dependent Variable: VAR00020 


\section{Acknowledgements}

First of all, I thank God for his gracious, merciful, and innumerable bounties to complete this research.

I would like to express my lot of thanks to my supervisor Prof. Dr. Dr. J. Bloech for his supervision on this research, skilful guidance, valuable comments and criticism, and his helping and supporting to me at both the scientific and social level during my residence in Germany.

I am indeed thankful to Prof. Dr. Wolfgang Bener for his accepting to be co-referee and his participating in the oral exam.

I thank Prof. Dr. Bizer for his participating in the oral exam.

I thank both Mr. Alaa Sobeih and Mr. Mohammad Abd-elshakour for their helping to me during the empirical study.

I thank all my family, specially my father for his supporting and praying to me all times, my wife and my daughters (Heba, Esraa, and Roaa) for their supporting, patient, and understanding in all times specially in the difficult times.

Finally, I want to express my thanks to the Egyptian Government for its financial support to me during the time of this research. 


\section{Curriculum Vitae}

Name: $\quad$ Hatem Abd-elfattah Elsharawy

Date of birth: $\quad 31.10 .1963$

Place of birth: Elmenoufia - Egypt

Nationality: Egyptian

Adresse: $\quad$ Christophorusweg 12 / 223

37075 Göttingen

E-Mail: sharawy1963@yahoo.com

\section{$\underline{\text { School Education }}$}

1969 -1975 Primary School (Shamma - Egypt)

1975 - 1978 Prep School (Shamma - Egypt)

1978 - 1981 Secondary School (Shamma - Egypt)

\section{University Education}

1981 - 1985 Faculty of Commerce (B. Com - Acc.), Elmenoufia University, Egypt

1988 - 1989 Faculty of Commerce (Pre-Master - Acc.), Assiut, University, Egypt

1989 - 1995 Faculty of Commerce (Master - Acc.), Elmenoufia University, Egypt

2001 - 2006 Scholarship to study Ph. D. in Faculty of Economy, Göttingen University

\section{$\underline{\text { Profession }}$}

1985 -1995 Demonstrator in Faculty of Commerce, Acc. Department, Elmenoufia University, Egypt.

1995 - 2001 Assistant lecturer in Faculty of Commerce, Acc. Department, Elmenoufia University, Egypt. 


\section{Eides Statt}

„Ich versichere an Eides Statt, dass ich die eingereichte Dissertation „, Developing Controlling and Performance Evaluation of Multinational Companies Operating in Egypt" selbstständig verfasst habe. Anderer als der von mir angegebenen Hilfsmittel und Schriften habe ich mich nicht bedient. Alle wörtlich oder sinngemäß den Schriften anderer Autorinnen und/oder Autoren entnommenen Stellen habe ich Kenntlich gemacht.“ 